\title{
Marcelo Malta Rodrigues Martins
}

\author{
Strong Lower Bounds for the \\ CVRP via Column and Cut \\ Generation
}

\section{DISSERTAÇÃO DE MESTRADO}

DEPARTAMENTO DE INFORMÁTICA Programa de Pós-Graduação em Informática 
Marcelo Malta Rodrigues Martins

\section{Strong Lower Bounds for the CVRP via Column and Cut Generation}

Dissertation presented to the Programa de Pós-Graduação em Informática of the Departamento de Informática - PUCRio as partial fulfillment of the requirements for the degree of Mestrado.

Advisor: Prof. Marcus Vinicius Soledade Poggi de Aragão Co-Advisor: Prof. Rafael Martinelli Pinto 


\title{
Marcelo Malta Rodrigues Martins
}

\section{Strong Lower Bounds for the CVRP via Column and Cut Generation}

\begin{abstract}
Dissertation presented to the Programa de Pós-Graduação em Informática of the Departamento de Informática of Centro Técnico Científico - PUC-Rio as partial fulfillment of the requirements for the degree of Mestrado.
\end{abstract}

Prof. Marcus Vinicius Soledade Poggi de Aragão Advisor Departamento de Informática - PUC-Rio

Prof. Rafael Martinelli Pinto

Co-Advisor Departamento de Engenharia Industrial - PUC-Rio

Prof. Marco Serpa Mollinaro Departamento de Informática - PUC-Rio

Prof. Eduardo Uchoa Barboza

Departamento de Engenharia de Produção - UFF

Prof. Marcio da Silveira Carvalho Coordinator of the Centro Técnico Científico - PUC-Rio 
All rights reserved.

\section{Marcelo Malta Rodrigues Martins}

Marcelo Malta Rodrigues Martins obtained a BSc in Computer Science from Universidade do Estado do Rio de Janeiro (UERJ). During this course he held a scholarship from Coordenação de Aperfeiçoamento de Pessoal de Nível Superior (CAPES), maintaining an excellent academic performance. He has experience as a software developer and worked in OLX/BomNegocio and IBM.

Bibliographic Data

Malta, Marcelo

Strong Lower Bounds for the CVRP via Column and Cut Generation / Marcelo Malta Rodrigues Martins; Advisor: Marcus Vinicius Soledade Poggi de Aragão; Co-advisor: Rafael Martinelli Pinto. - 2016.

67 f: il. (color.) ; $30 \mathrm{~cm}$

Dissertação de Mestrado - Pontifícia Universidade Católica do Rio de Janeiro, Departamento de Informática, 2016.

Inclui bibliografia

1. Informática - Dissertation. 2. Roteamento. 3. Geração de Colunas. 4. CVRP. 5. Pricing. 6. Cortes não robustos. I. Poggi, Marcus. II. Martinelli, Rafael. III. Pontifícia Universidade Católica do Rio de Janeiro. Departamento de Informática. IV. Título. 


\section{Acknowledgments}

I would like to thank my dear wife Marianna, for being such a good life partner, and for understanding all we had to sacrifice to achieve this.

To my family that always believed in me.

To my advisor Marcus Poggi, for the opportunity and guidance through the path.

To my co-advisor Rafael Martinelli, for his involvement since the beginning. Always available to explain things, over and over again, for encouraging me through the dark times and for his belief.

To Pontifícia Universidade Católica do Rio de Janeiro, which provided a great environment to develop my work.

To CAPES, for the financial support and to the Brazilians who pay taxes.

To Professors Eduardo Uchoa and Marco Molinaro for the insightful inputs, which contributed to the improvement of this thesis.

Finally, to all my friends who contributed to make it easier, especially Ricardo, who always encouraged me. 


\section{Abstract}

Malta, Marcelo; Poggi, Marcus; Martinelli, Rafael. Strong Lower Bounds for the CVRP via Column and Cut Generation. Rio de Janeiro, 2016. 67p. MSc Thesis - Departamento de Informática, Pontifícia Universidade Católica do Rio de Janeiro.

The Capacitated Vehicle Routing Problem (CVRP) is the seminal version of the vehicle routing problem, a classical problem in Operational Research. Introduced by Dantzig e Ramser, the CVRP generalizes the Traveling Salesman Problem (TSP) and the Bin Packing Problem (BPP). In addition, routing problems arise in several real world applications, often in the context of reducing costs, polluent emissions or energy within transportation activities. In fact, the cost with transportation can be roughly estimated to represent $5 \%$ to $20 \%$ of the overall cost of a delivered product. This means that any saving in routing can be much relevant. The CVRP is stated as follows: given a set of $n+1$ locations - a depot and $n$ customers the distances between every pair of locations, integer demands associated with each customer, and a vehicle capacity, we are interested in determining the set of routes that start at the depot, visits each customer exactly once and returns to the depot. The total distance traveled by the routes should be minimized and the sum of the demands of customers on each route should not exceed the vehicle capacity. This work considers that the number of available vehicles is given. State of the art algorithms for finding and proving optimal solutions for the CVRP compute their lower bounds through column generation and improving it by adding cutting planes. The columns generated may be elementary routes, where customers are visited only once, or relaxations such as q-routes and the more recent ng-routes, which differ on how they allow repeating customers along the routes. Cuts may be classified as robust, those that are defined over arc variables, and non-robust (or strong), those that are defined over the column generation master problem variables. The term robust used above refers to how adding the cut modifies the efficiency of solving the pricing problem. Besides the description above, the most efficient exact algorithms for the CVRP use too many elements turning its replication a hard long task. The objective of this work is to determine how good can be lower bounds computed by a column generation algorithm on ng-routes using only capacity cuts and a family of strong cuts, the limited memory subset row cuts. We assess the leverage achieved with the consideration of this kind of strong cuts and its combination with others techniques like Decremental Space State Relaxation (DSSR), Completion Bounds, ng-Routes and Capacity Cuts over a Set Partitioning formulation of the problem. Extensive computational experiments are presented along with an analysis of the results obtained.

\section{Keywords}

Routing; Column Generation; CVRP; Pricing; Non-robust cuts; 


\section{Resumo}

Malta, Marcelo; Poggi, Marcus; Martinelli, Rafael. Limites Inferiores Fortes para o CVRP via Geração de Colunas e Cortes. Rio de Janeiro, 2016. 67p. Dissertação de Mestrado - Departamento de Informática, Pontifícia Universidade Católica do Rio de Janeiro.

O Capacitated Vehicle Routing Problems (CVRP) é uma versão seminal do problema de roteamento de veículos, um clássico problema em Pesquisa Operacional. Introduzido por Dantzig e Ramser, o CVRP generaliza o Traveling Salesman Problem (TSP) e o Bin Packing Problem (BPP). Problemas de roteamento aparecem em diversas aplicações no mundo real, geralmente no contexto de diminuição de custos, emissão de poluentes ou energia dentro das atividades relacionadas ao transporte. De fato, estes custos podem ficar entre $5 \%$ e $20 \%$ do custo total do produto. Por isto, qualquer economia nos custos de roteamento pode ser relevante. O CVRP é definido da seguinte maneira: dado um conjunto de $n+1$ localidades um depósito e $n$ clientes - as distâncias entre cada par de localidades, as demandas inteiras associadas a cada cliente e a capacidade do veículo, quer se obter um conjunto de rotas que comecem no depósito, visitem cada cliente apenas uma vez e retornem ao depósito. A distâncias percorrida deve ser mínima e a soma das demandas dos clientes presentes em cada rota não pode exceder a capacidade do veículo. Este trabalho considera que o número de veículos disponíveis é conhecido. Algoritmos no estado da arte para encontrar e provar que uma solução é ótima, para o CVRP, calculam seus limites inferiores através de geração de colunas e depois os melhoram com a adição de planos de corte. As colunas geradas podem ser rotas elementares, onde obrigatoriamente cada cliente é visitado somente uma vez, ou uma relaxação desta obrigação com o uso de q-rotas ou ng-rotas, que diferem apenas em como é permitido que um cliente seja revisitado dentro de uma mesma rota. Já os cortes são classificados como robustos, aquele que são definidos sobre as variáveis dos arcos, e não robustos (ou fortes), que são os definidos sobre as variáveis do problema mestre da geração de colunas. O termo robusto, usado acima, se refere a como a adição do corte modifica a eficiência da resolução do problema de pricing. Além do descrito acima, o algoritmo exato mais eficiente para o CVRP usa muitos elementos, o que torna sua replicação uma tarefa difícil e longa. O objetivo deste trabalho é determinar o quão bom são os limites inferiores obtidos com geração de colunas de ng-rotas usando apenas cortes de capacidade e os recentes subset row cuts de memória limitada. Além disto, é avaliado o ganho conseguido com a consideração deste tipo de corte forte e as combinações com outras técnicas, como por exemplo, Decremental Space State Relaxation (DSSR), Completion Bounds, ng-rotas e cortes de capacidade sobre a formulação de Set Partitioning. Extensos experimentos computacionais são apresentados em conjunto com a análise dos resultados obtidos.

\section{Palavras-chave}

Roteamento; Geração de Colunas; CVRP; Pricing; Cortes não robustos; 


\section{Contents}

$\begin{array}{ll}\text { I Introduction } & \mathbf{1 0}\end{array}$

$\begin{array}{ll}\text { I.1 Literature Review } & 12\end{array}$

$\begin{array}{ll}\text { I.2 Motivation } & 13\end{array}$

$\begin{array}{lll}\text { I.3 Thesis Outline } & 13\end{array}$

II $\quad$ Mathematical Formulations $\quad 15$

$\begin{array}{ll}\text { II.1 Two Index Formulation } & 15\end{array}$

$\begin{array}{ll}\text { II.2 Set Partitioning } & 16\end{array}$

III Column Generation $\quad 18$

$\begin{array}{ll}\text { III.1 Pricing } & 19\end{array}$

III.2 Forbidding return to close customer neighbors: ng-Routes 22

Decremental State-Space Relaxation 25

Completion bounds $\quad 25$

Heuristic Pricing 26

IV Cuts $\quad 28$

IV.1 Capacity Cuts 28

IV.2 Subset Row Cuts $\quad 29$

IV.3 Limited Memory Subset Row Cut 30 Separation $\quad 31$

Pricing changes $\quad 32$

$\begin{array}{lll}\text { V Computational Experiments } & \mathbf{3 4}\end{array}$

$\begin{array}{lr}\text { VI Conclusion } & 64\end{array}$

$\begin{array}{lc}\text { Bibliography } & 65\end{array}$ 


\section{List of Figures}

III.1 Edge's reduced cost associated to customers' dual variables $\quad 19$

III.2 Examples of routes with $k$-cycles 21

III.3 Example of an allowed extension. $N G(1)=\{1,2\}, N G(2)=$ $\{2,3\}, N G(3)=\{1,3\}$

III.4 Example of a forbidden extension. $N G(1)=\{1,2\}, N G(2)=$ $\{2,3\}, N G(3)=\{1,3\}$ 


\section{List of Tables}

V.1 Comparison over a pure version 36

V.2 Comparison using DSSR 41

V.3 DSSR + CB $\quad 46$

V.4 Capacity Cuts $\quad 51$

V.5 DSSR + CB + CC 56

V.6 Comparison with Pecin et al. 61 


\section{I \\ Introduction}

Since the first appearance in the literature in the late 50's in the original work of Dantzig and Ramser [1], the Capacitated Vehicle Routing Problem (CVRP) has been widely studied by many researchers. Many contributions have been made in several directions since then. Some researchers focus on finding an exact algorithm, while others are concentrating efforts to find quasi-optimum solutions, meta-heuristics and hybrid methods. The objective of this text is to study the most recent proposed exact methods and understand the leverage gained in order to propose simple algorithms to find high quality lower bounds.

As shown in Toth and Vigo [2], it is estimated that the cost with the transportation can roughly be between $5 \%$ to $20 \%$ of the overall cost of a delivered product. This means that any saving in routing can be much relevant. Here is where the routing problem plays a significant role in real life scenario.

The CVRP can be defined as follows: a set of customers, each with a demand, needs to be serviced by a number of vehicles starting and ending at a central depot. Each customer needs to be visited exactly once while capacity of vehicle must not be exceeded. The objective is to service all customers traveling the minimum distance.

The CVRP is classified as being an $\mathcal{N} \mathcal{P}$-hard problem, therefore the use of exact optimization methods or simple enumerations of all feasible solutions may be difficult in acceptable CPU times, especially when the problem involves real-world data sets or when the instances are very large. Furthermore, it is easy to prove its $\mathcal{N P}$-completeness, since a CVRP with only one vehicle is the Traveling Salesman Problem (TSP) itself. As a result, there is no known polynomial time algorithm to find and prove its solution to be optimal. Exact methods to solve this problem rely on the use of lower bounds. The lower bounds proposed in the last thirty years are almost always based on mixed integer programming formulations.

Many formulations were suggested for this problem in the literature. Maybe the most basic one is the formulation based on a multi-commodity flow, introduced by Ford et al. [3]. Although this formulation has a polynomial number of constraints and variables, its linear relaxation is weak and, because of that, the efficiency of the method turned out to be quite limited. Another example of formulation is the one suggested by Laporte [4], the Two-Index Formulation (TIF), which has a stronger linear relaxation and successfully solved small instances using Branch-and-Cut (BC). Until nowadays this is usually the best formulation to solve instances where the 
routes in the solution must service many customers. It should be noted that this formulation has an exponential number of constraints, what is most often not an issue when computing the corresponding lower bound. A third formulation, which is central to this work is the Set Partitioning Formulation (SP) [5]. Usually, this formulation's linear relaxation produces a strong lower bound. The most successful recent exact algorithms use this formulation. The drawback of the SP formulation is that it has an exponential number of variables. Therefore it is necessary to use a Column Generation approach in order to deal with this large number of variables.

Column Generation is a technique used to solve formulations with an exponential number of variables. On each iteration, just a subset of variables is considered and, based on the current solution, one or more new variables with minimum reduced cost are generated through the resolution of a combinatorial optimization problem. Thus, the problem is solved iteratively, and the selection (pricing) of the new variables to be inserted in the formulation leads to improvements on the solution, i.e. they must have negative reduced cost. This auxiliary combinatorial optimization problem mentioned above is then called the pricing sub-problem.

CVRP formulations are limited to consider only routes that visit each customer exactly once. These routes are called elementary routes. When just such columns are considered, the column generation sub-problem correspond to solve the Elementary Shortest Path Problem with Resource Constraint (ESPPRC), which is known to be strongly $\mathcal{N} \mathcal{P}$-hard as shown by Dror [6]. The hardness of ESPPRC has motivated Christofides, Mingozzi and Toth [7] to also consider columns that are not elementary. They proposed the so-called q-routes, where customers can be visited as many times as desired as long as the demand of each customer is counted every time it is visited. The column generation sub-problem now corresponds to solve the Shortest Path Problem with Resource Constraints (SPPRC), which is weakly $\mathcal{N} \mathcal{P}$-hard, i.e., there are pseudo-polynomial algorithms available for solving it.

Naturally, relaxing the routes implies having weaker lower bounds. Tighter lower bounds can be obtained by enforcing partial elementarity on the set of qroutes. A first effort is to forbid the q-routes to have cycles of small sizes. The larger is the size of the smallest cycle in the q-routes the better is the lower bounds obtained. Unfortunately, the complexity of eliminating cycles grows with the factorial of the size of the largest eliminated cycle, shown by Irnich and Villeneuve [8]. This motivated the proposition of another route relaxation: ng-routes, introduced by Baldacci et al. [9]. It intends to prevent cycles among customers in a given neighborhood.

The CVRP lower bounds obtained with the SP formulation can be strengthened by adding polyhedral cuts. This work considers only two classes of cuts: (i) The Rounded Capacity Cuts, which are defined over the variables of the TIF formulation and can be directly translated to the variables of the SP formulation. (ii) The Limited Memory Subset Row Cuts, which are a generalization of the Subset Row Cuts and are defined over the variables of the SP formulation. This 
dissertation aims at developing pricing and separation algorithms for finding lower bounds for the CVRP using the SP formulation with ng-routes and these two classes.

\section{I.1 Literature Review}

As briefly mentioned before, the first algorithm to solve the SPPRC was proposed by Christofides et al. citechristofides-qroute. It introduced the idea of qroutes without 2 -cycles, which allows multiple visits to a customer in a same route, on the condition that at least two other customers are visited between successive visits. The elimination of 2-cycles does not change the overall complexity of the pricing algorithm, but it improves significantly the lower bounds obtained. Later, Irnich and Villeneuve [8] generalized q-routes to eliminate k-cycles, but this included a factor of $k$ ! to the time complexity of the pricing. Fukasawa et al. [10] showed that is not worthy to use $k>4$. Besides, they were able to solve to optimality all instances in the literature with up 135 customers using a Branch-Cut-and-Price algorithm using only cuts on the Two-Index Formulation.

Later in 2008, Baldacci et al. [11] solved almost all instances in Fukasawa et al. [10] work within considerably less computational time. They were able to obtain good estimates for the optimal dual variables values, leading the algorithm to converge in fewer iterations. Moreover, the cuts on the Two-Index Formulation and other cuts for the Set Partitioning formulation as Strengthened Capacity Cuts and Clique Cuts were also used. In the same year, Pessoa et al. [12] improved upon Fukasawa et al.[10] using cuts from an extended formulation with capacity index. Differently from the cuts on the Set Partitioning Formulation, these cuts do not change the complexity of the dynamic programming algorithm used to price the q-routes.

Three years after their previous paper, Baldacci et al. [9] introduced a new route relaxation named ng-routes. Those routes prevent cycles within the neighborhood of each customer. This new relaxation improves a lot the bounds obtained with q-routes. Using this new relaxation along with Subset Row Cuts and Weak Subset Row Cuts, the results presented in Baldacci et al. [11] were improved, but no new optimal solution was proved.

In 2011, Martinelli et al. [13] were able to increase the size of the neighborhoods of customers which are forbidden. The performance of the exact pricing was enhanced by using Decremental State Space Relaxation (DSSR), proposed by Righini and Salani [14], and completion bounds. This technique iteratively grows the size of the neighborhoods on which cycles are forbidden. This idea was later extended by Martinelli et al. [15] leading to a speed up of the solution of the ESPPRC.

In 2012, Contardo [16] successfully solved for the very first time the hard instance M-n151-k12. To obtain this result, he combined cuts from the Two-Index Formulation with the Strong Strengthened Capacity Cuts and the Subset Row Cuts. The columns were q-routes without 2-cycles. Although this leads to a poor 
relaxation, the partial elementarity of the routes was enforced by the Strong Degree Cuts. These cuts are an alternative way to prevent a customer to be revisited and consequently guaranteeing partial elementarity. In the sequence, Røpke [17] also solved successfully the instance M-n151-k12 after a long run of a Branch-Cut-andPrice algorithm with specialized branching rules and strong branching - it took almost 6 days.

In 2014, Contardo and Martinelli [18] combined their previous works ([13], [16]). Using ng-route relaxation, DSSR and completion bounds, the pricing was improved. Strengthened Capacity Cuts, Subset Row Cuts and Strong Degree Cuts were also considered. With these changes, they were able to solve for the very first time the hard instance F-n135-k7 using only a column generation approach.

And finally, also in 2014, Pecin et al. [19] introducted the Limited Memory Subset Row Cuts. They are a weakening of the traditional Subset Row Cuts, introduced in Jepsen et al. [20], which are Chvátal-Gomory rank-1 cuts. This weakening allows the pricing to be dynamically adjusted, making it much less costly and yet without compromising its effectiveness. Combining this relaxation with elements from all previous work the algorithm was able to solve all the classical instances from the literature with up to 200 vertices in reasonable times, including the hard instances M-n200-k17 and M-n200-k16.

\section{I.2 Motivation}

The algorithm proposed by Pecin et al. [21] was the first one to solve all the classical instances from the literature with up to 200 vertices. However, this algorithm was a combination of several methods and it is not clear what was the improvement made by each one. It is believed that $\mathrm{lm}$-SRC was the main contribution for this improvement.

Therefore, the objective of this work is to devise a pure implementation of the algorithm proposed in Pecin et al. [21], using only the lm-SRC combined with Rounded Capacity Cuts on the SP formulation considering ng-routes. This has not been done yet and will enlighten the improvement that can be obtained on the lower bounds. To evaluate this approach, we run the algorithm for the same instances that Pecin et al. [21] and we also present the lower bounds for different sizes of ng-sets.

\section{I.3 Thesis Outline}

This thesis is structured as follows.

- Chapter II presents the two most used formulations to solve the CVRP.

- Chapter III explains how to use a Column Generation approach to solve the Set Partitioning Formulation. It also shows techniques to improve the performance of pricing new columns. 
- Chapter IV introduces examples of cuts that can be separated in attempt of improving the bounds obtained.

- Chapter V presents computational results.

- Chapter VI draws some insights from what is reported and suggest some future work. 


\section{II \\ Mathematical Formulations}

This section presents two formulations to solve the CVRP. We start with the Two Index Formulation (TIF), which was proposed by Laporte and Nobert [4]. Then, we present the Set Partitioning Formulation proposed by Balinski and Quandt [5], which is the widely adopted formulation to solve the CVRP.

\section{II.1 Two Index Formulation}

The CVRP considers a complete and undirected graph $G=(V, E)$ where $V=$

$\{0, \ldots, n\}$ represents the vertex set and $E$ the edges set. Vertices in $N=\{1, \ldots, n\}$ correspond to the customers, whereas the depot is represented by 0. Each edge $(i, j) \in E$ can be represented by a single index $e=(i, j)$ and it has a nonnegative cost $c_{i j}$ to be traversed and $x_{e}$ denotes the number of times the edge is traversed by a vehicle. Each customer $i$ has a nonnegative demand $q_{i}$ and $Q$ represents the capacity of each vehicle $k$ available in the fleet $K$. Given a set of customers $S \subseteq V$, let $\delta(S)$ denote the set of edges $e \in E$ which have only one endpoint in $S$. Let $q(S)=\sum_{i \in S} q_{i}$ and let $r(S)$ be a lower bound on the number of vehicles needed to service the customers on set $S$. The overall objective is to minimize the total cost of the edges traversed. The Two Index Formulation is then defined as follows:

$$
\min \sum_{e \in E} c_{e} x_{e}
$$

subject to

$$
\begin{array}{lr}
\sum_{e \in \delta(\{i\})} x_{e}=2 & \forall i \in N \\
\sum_{e \in \delta(\{0\})} x_{e}=2|K| & \\
\sum_{e \in \delta(S)} x_{e} \geq 2 r(S) & \forall S \subseteq N \\
x_{e} \in\{0,1\}, & \forall e \in E \backslash \delta(0) \\
x_{e} \in\{0,1,2\} & \forall e \in \delta(0)
\end{array}
$$

Constraints (II.2) guarantee that each customer is serviced by just one vehicle (it must arrive and leave the customer). In addition, the constraint (II.3) imposes 
that if we take the set of edges with an endpoint at the depot, considering that we have $|K|$ vehicles leaving and returning to it, then there are $2|K|$ edges from this set being traversed. These two constraints are also known as the degree constraints and they are part of the polynomial-sized constraints of the formulation. The constraints (II.4) are the capacity constraints which, for any subset $S$ of customers, state that at least $r(S)$ vehicles must enter and leave $S$. Note that these constraints, besides assuring that no vehicle will have its capacity violated, they also eliminate subtours. The exact way to obtain $r(S)$ is by solving a Bin Packing problem, which is known to be an $\mathcal{N} \mathcal{P}$-Hard problem [22]. However, the formulation remains valid if $r(S)$ is replaced by a lower bound on its value, such as $k(S)=\lceil q(S) / Q\rceil$. Constraints (II.5) impose that $x_{e}$ can be 1 or 0 , representing whether the edge was traversed or not. And finally, the constraints (II.6) allow some $x_{e}$ to be also 2 if the edge has an endpoint at the depot, allowing routes with only one customer to be build. Those last two constraints are the integrality constraints.

Until today this is the best formulation to solve instances in which there are routes with too many customers to be service on the solutions found. It should be noted that this formulation has an exponential number of constraints, what is often not an issue when computing its corresponding lower bounds.

\section{II.2 Set Partitioning}

The Two Index Formulation can be rewritten using a variable for each feasible route. A route is a path which starts at the depot, traverses a sequence of customers and finishes back to depot without violating the vehicle's capacity $Q$. Let $\Omega$ represent the set of all feasible routes. We define a binary variable $\lambda_{r}$ which represents whether the route $r \in \Omega$ is used or not. Let $b_{r}^{e}$ be a constant value indicating how many times route $r$ traverses edge $e$. The reformulation is as follows.

$$
\min \sum_{e \in E} c_{e} x_{e}
$$

subject to

$$
\begin{array}{lr}
\sum_{r \in \Omega} b_{r}^{e} \lambda_{r}=x_{e} & \forall e \in E \\
\sum_{e \in \delta(\{i\})} x_{e}=2 & \forall i \in N \\
\sum_{e \in \delta(\{0\})} x_{e}=2|K| & \\
\lambda_{r} \in\{0,1\} & \forall r \in \Omega \\
x_{e} \in\{0,1\} & \forall e \in E \backslash \delta(0) \\
x_{e} \in\{0,1,2\} & \forall e \in \delta(0)
\end{array}
$$

Constraints (II.8) bind varaibles $x_{e}$ and $\lambda_{r} . x_{e}$ is given by the number of times 
an edge is traversed by all routes in the set $\Omega$. Now we can replace variables $x_{e}$ using this relation with $\lambda_{r}$ to obtain a new formulation.

$$
\min \sum_{e \in E} c_{e} \sum_{r \in \Omega} b_{r}^{e} \lambda_{r}
$$

subject to

$$
\begin{array}{ll}
\sum_{e \in \delta(\{i\})} \sum_{r \in \Omega} b_{r}^{e} \lambda_{r}=2, & \forall i \in N \\
\sum_{e \in \delta(\{0\})} \sum_{r \in \Omega} b_{r}^{e} \lambda_{r}=2|K| & \\
\lambda_{r} \in\{0,1\} & \forall r \in \Omega
\end{array}
$$

Let $a_{r}^{i} \in\{0,1\}$ denote if a customer $i$ is visited by a route $r$. Knowing that a route traverses two adjacent edges when servicing a customer and when leaving and returning to the depot, we can write $\sum_{e \in \delta(\{i\})} b_{r}^{e}=2 a_{r}^{i}, \forall i \in V$ and $\forall r \in \Omega$. Analogously, we can also write the cost of a route $c_{r}=\sum_{e \in E} c_{e} b_{r}^{e}, \forall r \in \Omega$. Finally, we can write the Set Partitioning Formulation as follows.$$
\min \sum_{r \in \Omega} c_{r} \lambda_{r}
$$

subject to

$$
\begin{array}{ll}
\sum_{r \in \Omega} a_{i r} \lambda_{r}=1, & \forall i \in N \\
\sum_{r \in \Omega} \lambda_{r}=|K|, & \\
\lambda_{r} \in\{0,1\} & \forall r \in \Omega
\end{array}
$$

Constraints (II.19) impose that a customer $i$ is serviced by only one route $r \in \Omega$. Constraint (II.20) assures that $|K|$ vehicles are used. And finally, constraints (II.21) force the variables $\lambda_{r}$ to be binary.

Despite the fact that at first the formulation seems quite simple, the set $\Omega$ can contain an exponential number of routes which results in an exponential number of variables. So, to handle that it is necessary the use of a Column Generation approach, as presented in Chapter III.

It is important to notice that it is not necessary that set $\Omega$ contain only elementary routes because the formulation will discard any route with coefficient $a_{i r}>1$ through the constraint (II.19), since the $\lambda_{r}$ variables are binary. This behavior makes the task to solve the Column Generation easier, but the quality of the lower bounds obtained may drop significantly, as we will discuss in Chapter III. 


\section{III \\ Column Generation}

Column generation is a technique that allows dealing with linear programs with a large number of variables, usually the ones on which the number of variables grows exponentially with the size of the problem. This can be exploited when the search for a variable with smallest reduced cost can be done by solving a combinatorial optimization problem. The overall idea is to split the linear programming problem in two problems: the restricted master problem and the pricing sub-problem. Analogous to the revised simplex method, the restricted master considers only a small subset of the variables. In order to obtain new columns/variables to improve the restricted master solution, an auxiliary problem called pricing sub-problem is solved. The input for the pricing problem are the values of the dual variables at the current restricted master optimal solution. Determining whether there are new columns with potential to improve the master solution reduces to check whether the optimum solution value for the pricing sub-problem is strictly negative. Columns with negative reduced cost are added to the restricted master which is then solved again. This iterative process continues until no suitable column is priced from the sub-problem.

The Set Partitioning Formulation, presented in Section II.2, requires enumerating all possible routes which a vehicle can perform. The number of routes grows exponentially with the number of customers. When only routes that visit exactly once each customer are considered, the pricing sub-problem corresponds to the Elementary Shortest Path Problem with Resource Constraints (ESPPRC), where the resource constraints refer to the use of the capacity of the vehicle regarding the demand of each customer visited along the route. To avoid the task of solving the strongly $\mathcal{N} \mathcal{P}$-hard ESPPRC problem at each iteration, a relaxation of the route definition may be considered, including in the SP formulation columns which correspond to routes that visit customers more than once. The pricing problem is then the Shortest Path Problem with Resource Constraints (SPPRC). Allowing these multiple visits to customers may weaken significantly the lower bounds obtained on the linear relaxation of the SP formulation. A way of strengthening the lower bounds would be to propose forms of controlling the number of additional visits to each customer in a route. There are two main approaches in the literature to achieve this objective. The first one aims at eliminating cycles of a given size along the relaxed routes. The second comes from observing that cycles are more likely to occur among customers that are close to each other. As a consequence it explores 
this idea by forbidding the relaxed route to return to a customer that belongs to a neighborhood set of other customers that are close to it. Next section provides more details of the pricing problem and how the relaxation works, allowing multiple visits along a route. The following sections are dedicated to the approach that exploits the idea of avoiding many visits to customers. It reduces to find minimum reduced cost $n g$-routes, as these routes are called.

\section{III.1 Pricing}

The reduced cost of a column is given by Equation (III.1) where $\pi_{i}$ denote the dual variables associated to constraints (II.19) and $\pi_{0}$ is the dual variable associated to constraint (II.20). Thus, the reduced cost of a route is its original cost $c_{r}$ minus the dual variable $\pi_{0}$ and the dual variable $\pi_{i}$ for each customer $i$ visited by this route.

$$
\bar{c}_{r}=c_{r}-\pi_{0}-\sum_{i \in N} a_{i r} \pi_{i}
$$

The dual variables associated with each customer can be split equally between the edge entering and the one leaving the customer. Figure III.1 illustrates this idea. Therefore, the reduced cost can be rewritten as a function of edges as shown in Equation (III.2).

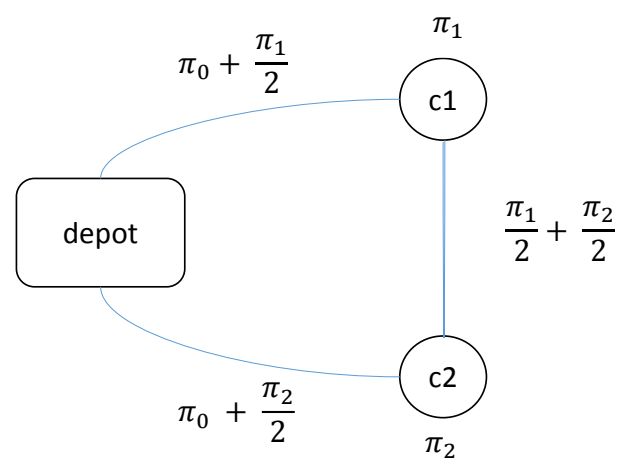

Figure III.1: Edge's reduced cost associated to customers' dual variables

$$
\bar{c}_{e}=c_{e}-\left(\pi_{u}+\pi_{v}\right) / 2
$$

At start the column generation procedure needs to construct an initial feasible subset of variables, so that the restricted master can be first solved. The initial set $\Omega$ can be constructed taking one route at time and greedily visiting customer which has not been visited yet, without exceeding the vehicle capacity. This heuristic can yield more than $|K|$ routes, however in our experiments it did not occur when using the classical instances for the problem. The pseudo code to the procedure is shown in Algorithm III.1.

The general pricing algorithm builds a dynamic programming matrix $\mathcal{M}$ of size $(Q+1) \times|N|$, where each entry $\mathcal{M}(q, i)$ contains the list of all paths which 


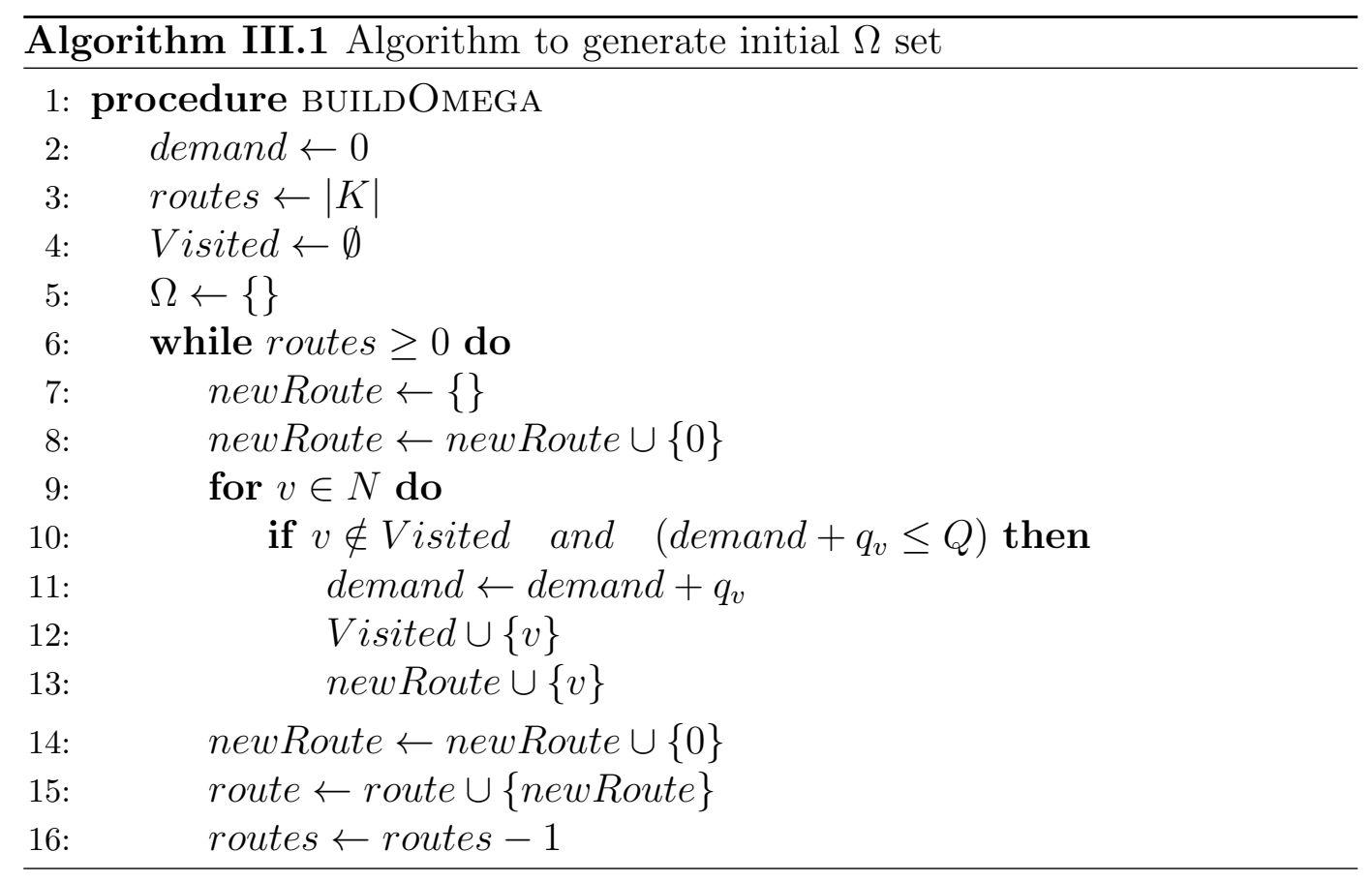

starts at the depot vertex, visits a set of customers and ends at customer $i$ with cumulative demand $q$. At the beginning of the algorithm, the matrix is empty except for entry $\mathcal{M}(0,0)$ which contains one single element representing the path which has not yet left the depot. The algorithm then fills the matrix iteratively for each customer from cumulative demand 1 up to $Q$. On each step, when analyzing entry $\mathcal{M}(q, i)$, all possible extensions to customer $i$ and cumulative demand $q$ are considered and stored in the matrix. The process terminates when the whole matrix is filled and the algorithm returns any route with negative reduced cost found on entries $\mathcal{M}(q, 0), q \in\{1, \ldots, Q\}$.

Associated to each path in the matrix, the algorithm stores a label containing a set of required information. For the general pricing algorithm, the label associated to a path $P$ is defined as $\mathcal{L}(P)=(v(P), q(P), N(P), \bar{c}(P))$, where $v(P)$ is the last customer of the path, $q(P)$ is the total demand, $N(P)$ is the set of visited customers, and $\bar{c}(P)$ is the total reduced cost.

Note that the dynamic programming algorithm stores all possible paths from the depot to each customer without violating the available capacity. Clearly, this approach is exponential and may be prohibitive for all but some small instances. The first effort to reduce the number of labels generated by the algorithm is to use a dominance rule, which discards a dominated label known to provide a reduced cost no better than a dominant one. Given two labels $\mathcal{L}\left(P_{1}\right)$ and $\mathcal{L}\left(P_{2}\right), \mathcal{L}\left(P_{1}\right)$ dominates $\mathcal{L}\left(P_{2}\right)$ if the following conditions hold.

(i) $v\left(P_{1}\right)=v\left(P_{2}\right)$

(ii) $q\left(P_{1}\right) \leq q\left(P_{2}\right)$

(iii) $N\left(P_{1}\right) \subseteq N\left(P_{2}\right)$ 
(iv) $\bar{c}\left(P_{1}\right) \leq \bar{c}\left(P_{2}\right)$

The first three conditions guarantee that path $P_{1}$ is allowed to perform at least the same possible paths back to the depot as $P_{2}$ and the last one guarantees that any of these completions back to the depot results in a better reduced cost when taken from $P_{1}$ than from $P_{2}$. This concludes that $\mathcal{L}\left(P_{2}\right)$ is dominated by $\mathcal{L}\left(P_{1}\right)$.

The goal of the pricing problem presented is to find one or more elementary routes which do not exceed the vehicle capacity and have negative reduced cost. As mentioned before, this is an $\mathcal{N} \mathcal{P}$-hard problem and for this reason we chose to solve the SPPRC, for which the time complexity to fill the matrix is $\mathcal{O}\left(|N|^{2} Q\right)$. The idea is to keep just the best path on each entry $\mathcal{M}(q, i)$. This can be done by using the recurrence presented in Equation (III.3).

$$
\left\{\begin{array}{l}
T\left(q_{i}, i\right)=\bar{c}_{0 i} \\
T(D, i)=\min _{j \in N} T\left(D-q_{i}, j\right)+\bar{c}_{j i},
\end{array}\right.
$$

A first approach to generated relaxed routes was introduced by Christofides, Mingozzi and Toth [7]. They proposed the so called $q$-routes. In their work, They showed that restricting $q$-routes to forbid 2-cycles does not change the pricing complexity and it improves the bounds for the SP formulation. Figure III.2 illustrates the generalization of $q$-routes without $k$-cycles, where $k$ stands for the length of a cycle.

1-cycle

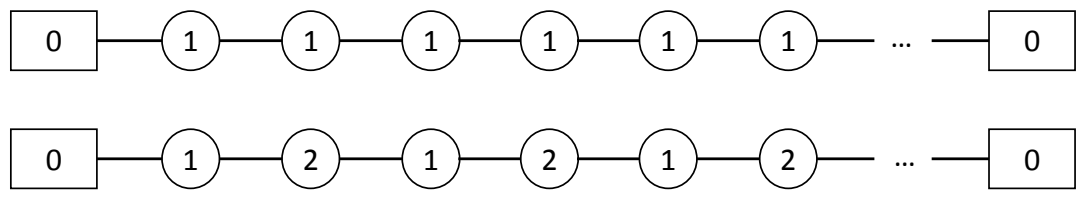

2-cycle

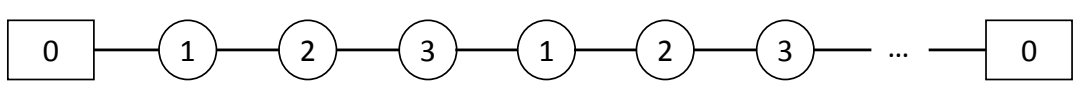

3-cycle
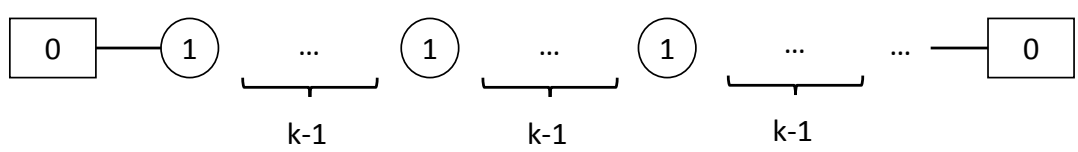

Figure III.2: Examples of routes with $k$-cycles

It is clear that larger values for $k$ improve the lower bounds for the SP formulation. However, Fukasawa et al. [10] showed that it is not worthy to consider $k>4$, due to its impact over pricing complexity. In fact, $k$-cycle elimination impacts the pricing complexity by a factor of $k$ !. Unfortunately, 4-cycle elimination is still not enough to obtain lower bounds near the ones obtained only considering elementary routes. 


\section{III.2 Forbidding return to close customer neigh- bors: ng-Routes}

Recently, Baldacci et al. [9] introduced a new approach, called the ng-route relaxation. The $n g$-route relaxation also allows a customer to be visited more than once but instead avoiding cycles of fixed length, it avoids cycles based on memory sets $N G_{v} \subseteq N$, associated with each customer $v$. Knowing that cycles are more likely to appear in the neighborhood of a given customer $v$, the memory sets are usually built using the closest neighbors of each customer. The size of the $n g$-sets is represented by $\Delta(N G)$ and it is defined a priori. Although larger values for $\Delta(N G)$ yield routes closer to elementarity, they also will impact in the overall complexity of the pricing.

Let $\Pi(P)$ be the customer set replacing the set $N(P)$ of visited customers in the labels used by the dynamic programming algorithm. Its meaning is changed to be the set of visited customers path $P$ remembers so far. Thus, a label can now be defined as $\mathcal{L}(P)=(v(P), q(P), \Pi(P), \bar{c}(P))$. An extension from label $\mathcal{L}(P)$ to a customer $v_{p+1}$ can only occurs, if and only if $v_{p+1} \notin \Pi(P)$ and $q(P)+q_{v_{p+1}} \leq Q$. After a successful extension, a new label $L\left(P^{\prime}\right)$ is created for path $P^{\prime}=\left(0, \ldots, v_{p}, v_{p+1}\right)$ by the operation presented in Equation (III.4).

$$
\mathcal{L}\left(P^{\prime}\right)=\left(v_{p+1}, q(P)+q_{v_{p+1}}, \Pi(P) \cap N_{v_{p+1}} \cup\left\{v_{p+1}\right\}, \bar{c}(P)+\bar{c}_{v_{p} v_{p+1}}\right)
$$

Clearly with the introduction of $\Pi(P)$, the dominance rule changes. Condition (iii) presented in Section III.1 now turns into $\Pi\left(P_{1}\right) \subseteq \Pi\left(P_{2}\right)$, meaning that label $\mathcal{L}\left(P_{1}\right)$ dominates label $\mathcal{L}\left(P_{2}\right)$ only when its memory is a subset of $\mathcal{L}\left(P_{2}\right)$ memory, i.e. any allowed extension from path $P_{2}$ can also be made from path $P_{1}$. This clearly reinforces the dominance rule based on the fact that, for any path $P, \Pi(P) \subseteq N(P)$, leading to a reduction on the number of labels.

As showed in Equation (III.4), the memory set $\Pi(P)$ is updated at each extension with the intersection of all $n g$-sets of all customers previously visited, united by the current customer. The overall contruction of the memory set is presented in Equation (III.5). Notice that it is easy to see $|\Pi(P)| \leq|C(P)|$, but even with this reduction, the size of $\Pi(P)$ still has an impact in the pricing complexity.

$$
\Pi(P)=\left\{i_{k} \in C(P): i_{k} \in \bigcap_{s=k+1}^{P} N G_{s}, k=1, \ldots, p-1\right\} \cup i_{p}
$$

To make the extension process clearer, we present two figures. In Figure III.3, by the time the extension from customer 1 to 2,1 is forgotten (since $1 \notin N G_{2}$ ) and it is available to be revisited immediately or in the next extensions. Figure III.4 presents the opposite situation. Since $3 \in N G_{2}, 3$ is not allowed to be revisited, which forbids the extension. 


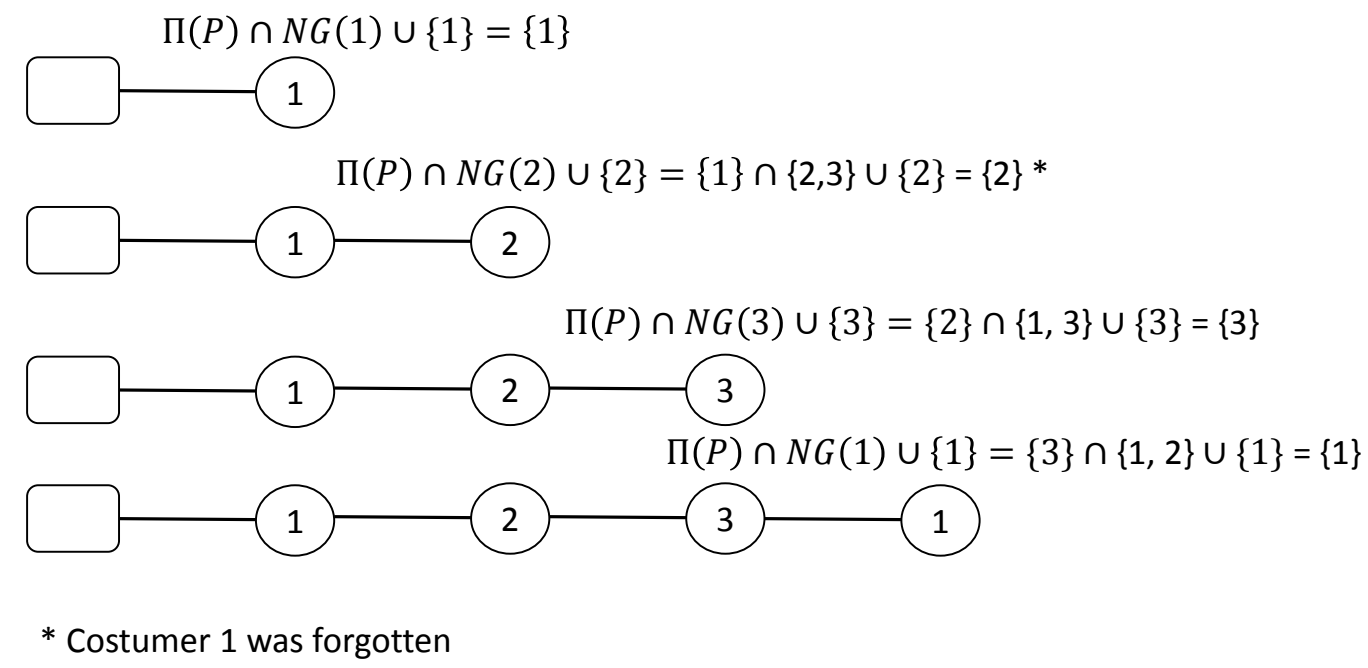

Figure III.3: Example of an allowed extension. $N G(1)=\{1,2\}, N G(2)=$ $\{2,3\}, N G(3)=\{1,3\}$

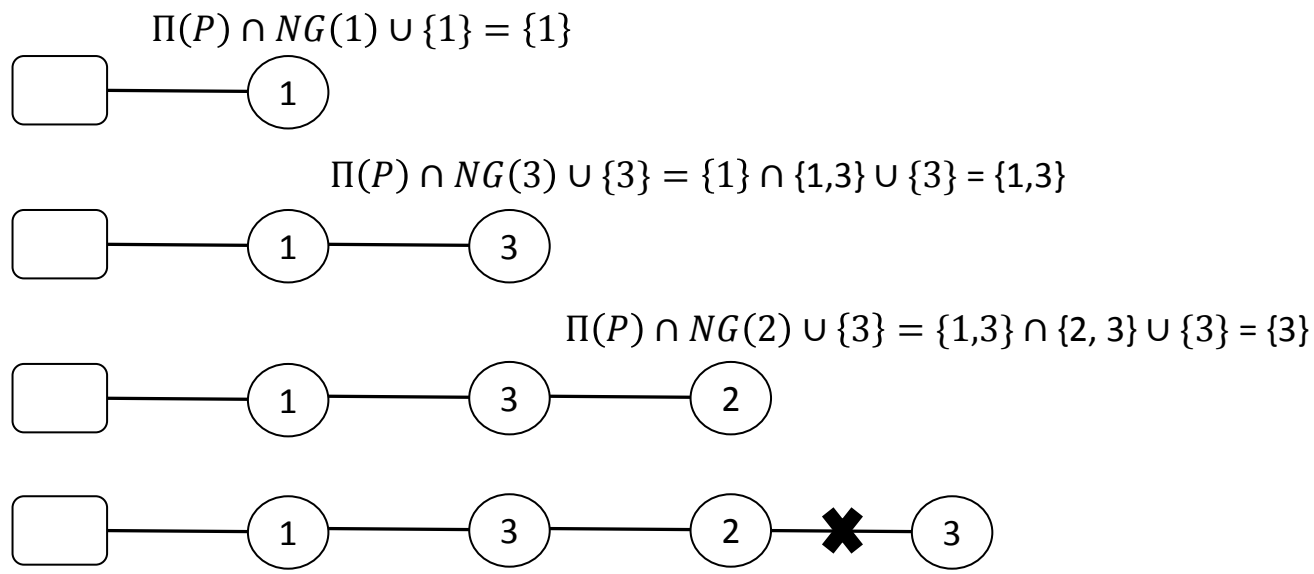

Figure III.4: Example of a forbidden extension. $N G(1)=\{1,2\}, N G(2)=$ $\{2,3\}, N G(3)=\{1,3\}$

If a given extension is to the depot, then we successfully build an $n g$-route. And from this point, there is no other extensions available. One problem arises with solving the SPPRC with this route relaxation, the exponential number of labels that can be generated and stored. The mitigation of this "curse of dimensionality" is the main concern when build an algorithm to solve the problem. The control mechanism and the algorithm to solve the problem will be formally introduced in the next section.

As mentioned previously, the $n g$-route relaxation improves the pricing problem by reducing the number of labels stored because of the changes done in the dominance rule. A label $\mathcal{L}\left(P_{1}\right)$ dominates another label $\mathcal{L}\left(P_{2}\right)$ if and only if, every feasible extensions from $P_{2}$ can be done with better or equal reduced cost when taken from $P_{1}$. Therefore $P_{2}$ can be removed from the list of labels. It is interesting 
to check whether a label dominates or is dominated, whenever this label is created and the label list should be ordered by reduced cost for simplicity. Thus, the new sufficient conditions are:

(i) $v\left(P_{1}\right)=v\left(P_{2}\right)$

(ii) $q\left(P_{1}\right) \leq q\left(P_{2}\right)$

(iii) $\Pi\left(P_{1}\right) \subseteq \Pi\left(P_{2}\right)$

(iv) $\bar{c}\left(P_{1}\right) \leq \bar{c}\left(P_{2}\right)$

The dominance rule limits the number of non-dominated label by $2^{\Delta(N G)-1}$ in each bucket. Considering the whole matrix, there are at most $2^{\Delta(N G)-1}|N| Q$ nondominated labels in it. This may be reasonable fast depending how large is $\Delta(N G)$.

The complete algorithm for the exact version of the pricing problem with $n g$-route relaxation is shown in Algorithm III.2.

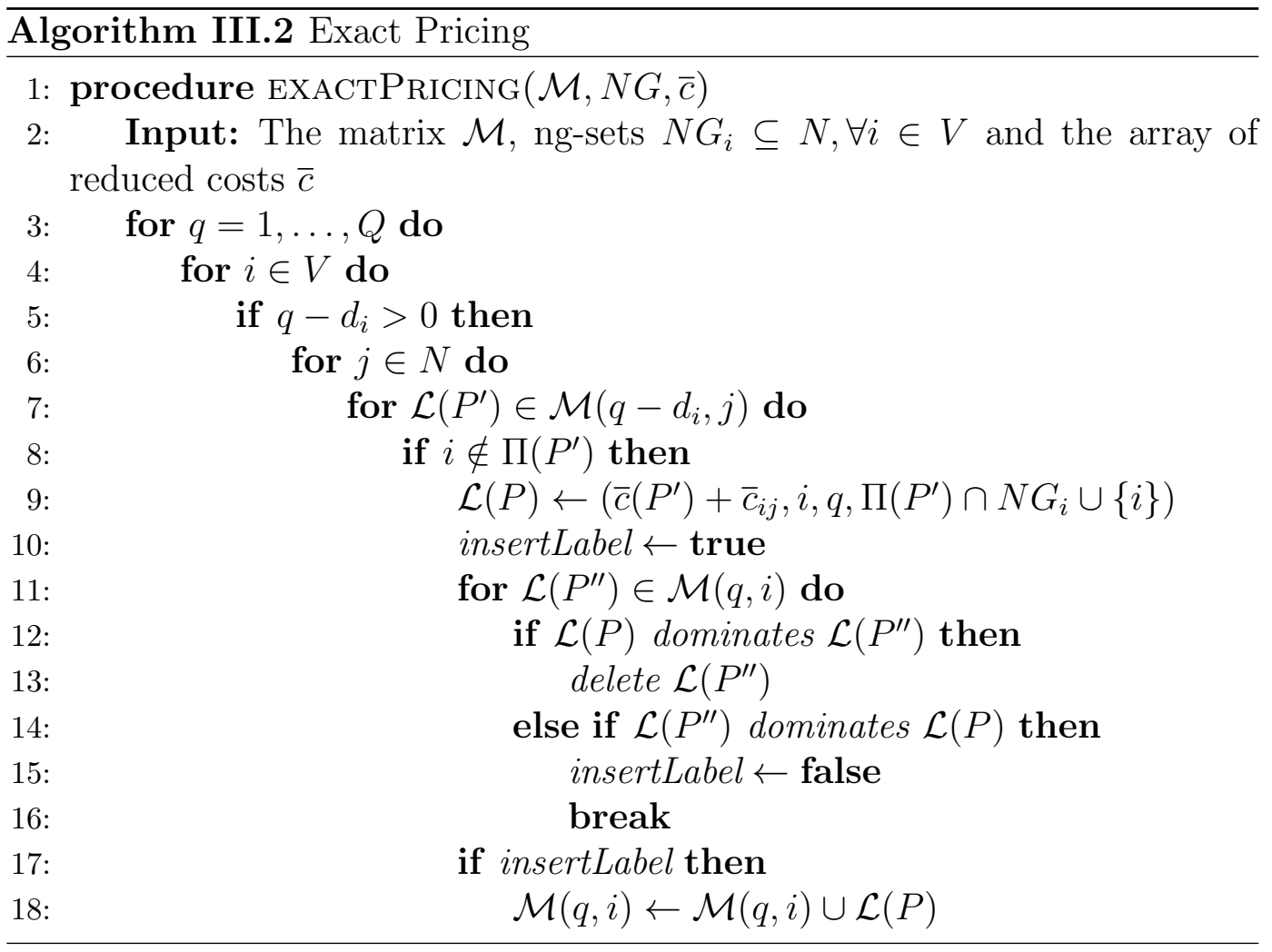

Next, we present three techniques to speed up the exact pricing. The first one is the Decremental State Space Relaxation (DSSR), introduced by Righini and Salani in [23] for the pricing with elementary routes and further adapted to the $n g$-route relaxation by Martinelli et al. [15]. The second one is called the completion bounds and finally the last one is a heuristic pricing. 


\section{(a) Decremental State-Space Relaxation}

The Decremental State-Space Relaxation consists in relaxing totally or partially the $n g$-route restrictions, allowing the occurrence of some cycles which would not appear in a regular run of the algorithm (depending on the level of relaxation, it may allow any cycle to appear). The algorithm then iteratively removes some relaxations until a feasible $n g$-route is found. This way, each iteration of the DSSR pricing sub-problem provides a lower bound on the solution of the original pricing with the complete $n g$-sets.

The relaxation is done by using sets $\Gamma_{v}^{k} \subseteq N G_{v}$, where $k$ is the index of current iteration of the DSSR algorithm. At first, each $\Gamma_{v}^{0}$ may be empty (meaning that any cycle may happen in the solution) and at each iteration, it checks the best route found by the pricing algorithm w.r.t. the regular $n g$-sets $N G_{v}$. If the best route found is $n g$-feasible (or if there is no route with negative reduced cost), the algorithm stops and return this route (resp. none) and any other $n g$-feasible route with negative reduced cost. On the other hand, if the best route violates any $n g$-set, it reduces the relaxation by updating $\Gamma_{u}^{k+1}=\Gamma_{u}^{k} \cup\{w\}$, for all customers $u \in N$ present in the forbidden cycle, where $w \in N$ is the customer on which the cycle happens.

The Algorithm III.3 presents a pseudo code to this framework. The exactPricing is the same algorithm showed in III.2 and selectRoutes selects routes with negative reduced costs.

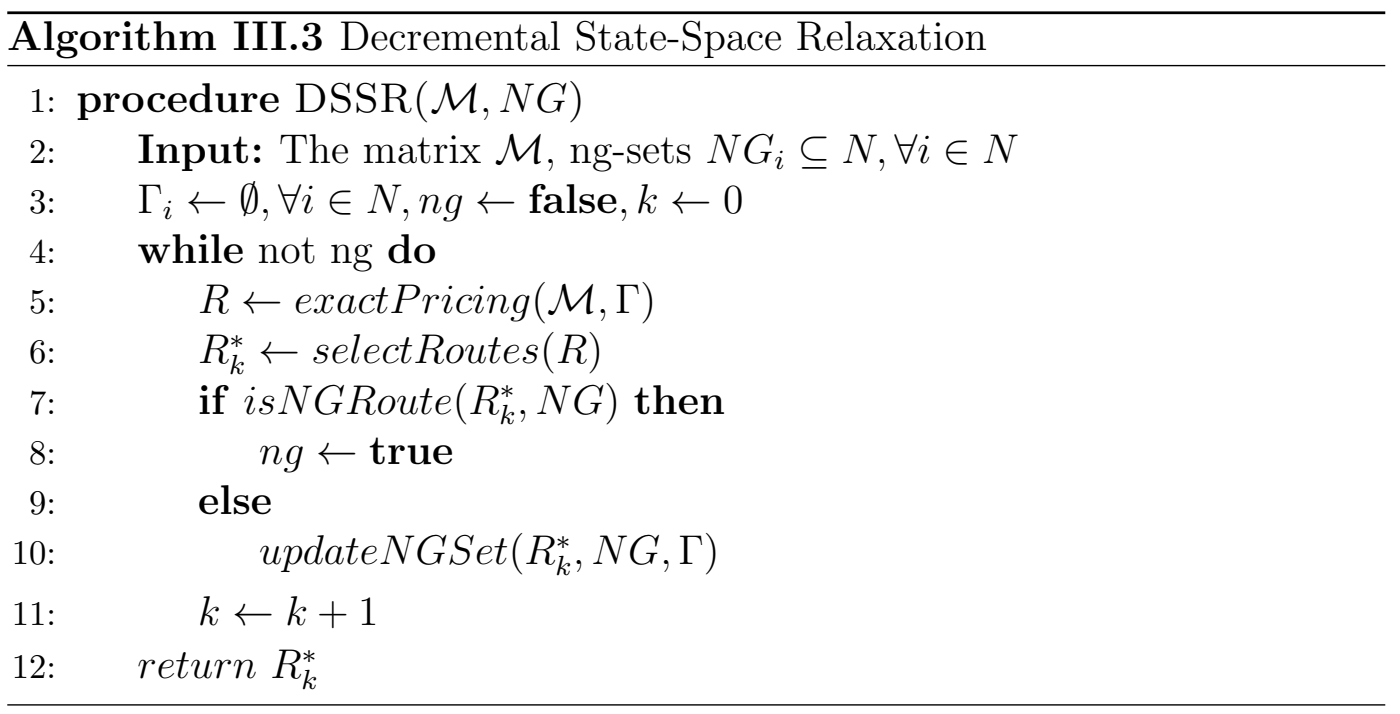

\section{(b) Completion bounds}

The Completion Bounds is another technique devised to speed up the pricing sub-problem running time. It works within the DSSR and it is similar to the dominance rule in the sense that it also eliminates labels. Given the fact that at an iteration of the DSSR algorithm any previous iteration is a relaxation of the 
current one, the dynamic programming matrix of a previous iteration provides valid lower bounds on the reduced cost values for all the paths. This information may be used to avoid an extension of a path by checking if its current reduces cost value plus the lower bound for the remaining path would lead to a non-negative value. Thus, at the end of each DSSR iteration $k$, the best lower bound for each customer $v \in N$ with every capacity $q \leq Q$ is calculated, in order to be used during iteration $k+1$. These lower bounds are then stored in an auxiliary matrix $\widehat{T}$, which is filled with the value of the best path that starts at a customer $i$ and ends at the depot with total capacity at most $q$. This process is shown in Equation III.6

$$
\widehat{T}_{k}(q, i)=\min _{q^{\prime} \leq q}\left(T_{k}^{*}(q, i)\right)
$$

After the matrix $\widehat{T}$ is filled, its values may be used in the next iteration to avoid the extension to a new labels $\mathcal{L}(P)=(v(P), q(P), \Pi(P), \bar{c}(P))$. A label is discarded if the following condition hold:

$$
\bar{c}(P)+\bar{c}_{i j}+\widehat{T}(Q-q(P), v(P)) \geq 0
$$

It is clear that when the left-hand side of Equation III.7 is greater or equal than zero, the label $\mathcal{L}(P)$ cannot generate any routes with negative reduced cost, and then it may be eliminated. This will make the exact pricing converges faster, especially because the lower bounds found become stronger on each new iteration of the DSSR algorithm.

\section{(c) Heuristic Pricing}

As a further improvement to speed up the whole column generation procedure, any heuristic pricing approach may be used before running the exact dynamic programming algorithm. The idea is to find as many routes with negative reduced cost as possible using a faster algorithm, thus reducing the number of calls to the exact algorithm. In this dissertation, we use a simplification of the exact algorithm described in Section III.1. Instead of maintaining a list of paths in each dynamic programming matrix $\mathcal{M}(q, v)$ entry, we keep only the path with best reduced cost so far, discarding any other labels which may appear. This modification may seem quite simple at first, but one may notice that when used, this approach may find up to $90 \%$ of the total columns generated during the column generation, obtaining a drastic improvement on the overall running time of the solution procedure.

To exemplify how the algorithm works, when we are filling the bucket $\mathcal{M}(q, i)$, if $q-d_{i}>0$ we have to look at all buckets in row $\mathcal{M}\left(q-d_{i}, i\right)$, looking for those which may improve the reduced cost and perform a proper extension, with respect to $n g$-routes. In other words, we want the best bucket where $i \notin \Pi(P)$. The Algorithm III.4 shows a pseudo-code for this procedure.

Analogously to the exact pricing algorithm, after running the pricing, a procedure must be executed to build the best $n g$-routes found. This procedure will 


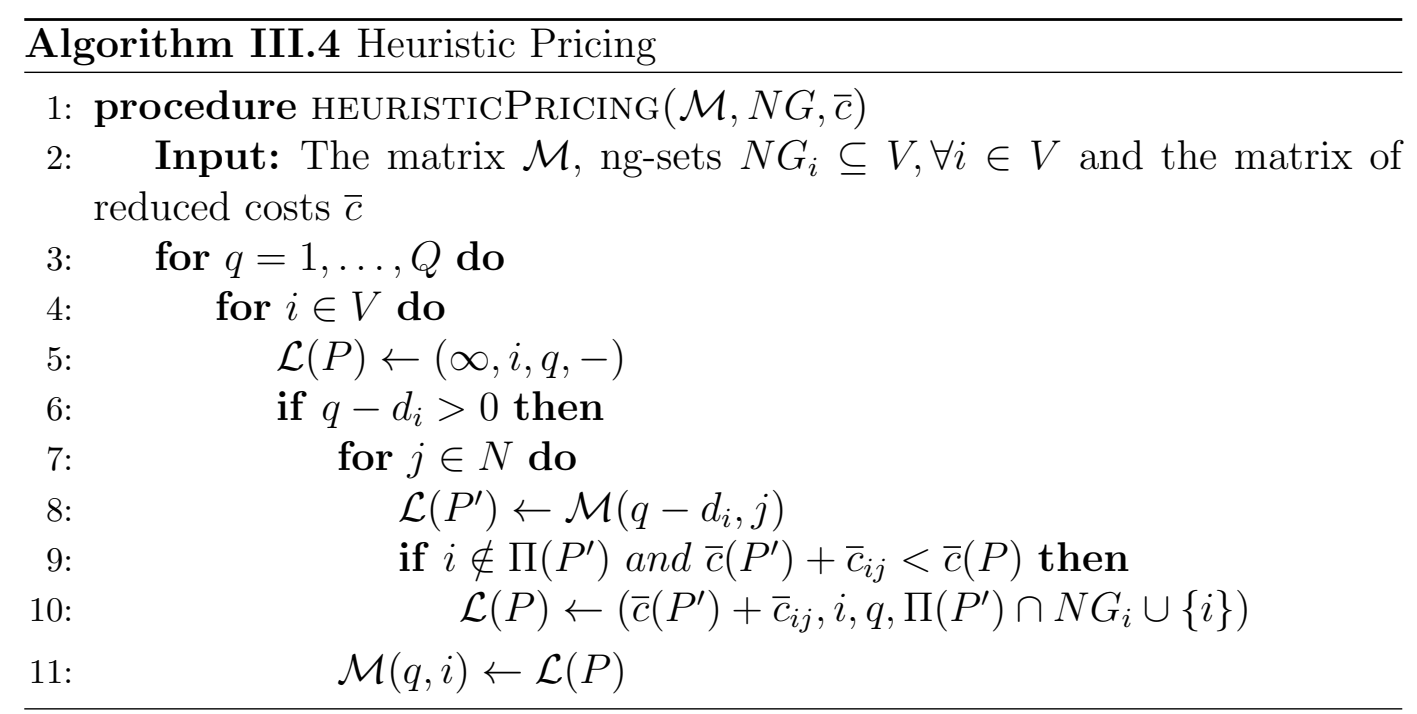

iterate over all buckets of the matrix $\mathcal{M}$, sorting them by its reduced cost and checking if the reduced cost remains negative when taking the path back to the depot.

Finally, in order to prove the optimality on the last iteration, a run of the complete exact pricing still must be performed. This happens because it not all paths are taken into consideration by the heuristic and there is a chance that feasible routes with negative reduced cost are not built. Moreover, it is noteworthy to mention that the complexity of the heuristic pricing compares to the one of the $q$-route relaxation, i.e., it is weakly $\mathcal{N} \mathcal{P}$-hard, being performed in the pseudo-polynomial time of $\mathcal{O}\left(Q|N|^{2}\right)$. 


\section{IV \\ Cuts}

In this chapter we present some cuts to the CVRP. Cuts are used to improve the lower bounds quality. They can be described as valid inequalities which are added to the mathematical formulation when violated by the current solution. The procedure of identification of such violated cuts is called the cut separation algorithm. When dealing with column generation, we classify the cuts in two types: robust cuts and strong cuts. Regardless the name, they differ basically in how the dual variables associated to them can be translated into reduced cost to the pricing. Robust cuts have the particularity that the contribution of their dual variables to the computation of the reduced costs of paths can be decomposed along the edges, and therefore they may be considered in the pricing algorithm without compromising its performance, regardless of the number of robust cuts added. On the other hand, strong cuts requires additional resources in the labels, typically one resource per active cut, which is represented by one additional dimension. Those dimensions are used to control whether an extension should be reward/penalized with the value of the dual variable associated to the cut. Therefore, it is straightforward to notice that with the increase on the number of strong cuts, the pricing loses performance.

During the last 15 years, many different families of both robust and strong cuts were presented for the CVRP. In this work, we consider one family of robust cuts, the Capacity Cuts [24], and one family of strong cuts, the Subset-Row Cuts $[20]$.

\section{IV.1 Capacity Cuts}

The Capacity Cuts are a family of robust cuts originated by the generalization of the famous Sub-tour Elimination Cuts for the TSP. They are similar to the capacity constraint showed in Equation (II.4). It is know that to calculate $r(s)$ exactly one needs to solve the Bin Packing Problem which is a strongly $\mathcal{N} \mathcal{P}$-hard problem [22]. However, the inequality remains valid if one replaces $r(S)$ on the right-hand side with the lower bound $k(S)=\lceil q(S) / Q\rceil$. Using the relation shown in Section II.2, when we presented the decomposition of the Two Index Formulation into the Set Partitioning Formulation, we can state the Rounded Capacity Cuts as in Equation (IV.1). 


$$
\sum_{r \in \Omega} \sum_{e \in \delta(S)} b_{r}^{e} \lambda_{r} \geq 2 k(S), S \subseteq N
$$

To separate these cuts, we use the CVRPSEP package, presented in [25]. Moreover, as mentioned earlier, being robust these cuts do not change the pricing sub-problem complexity. This is due to the possibility of mapping the dual variables associate to them directly into the edges of the original graph. Thus, using this mapping, the dual variables may be directly introduced in Equation (III.2).

\section{IV.2 Subset Row Cuts}

The Subset-Row Cuts (SRCs) are a family of strong cuts introduced in 2008 by [20] and since then some works have shown they lead to good improvements on lower bounds values $[9,18]$. Their general form is a Chvátal-Gomory Rank-1 Cut, obtained from the Constraints (II.19) of the SP formulation. Given a subset of customers $C \subseteq N$ and a multiplier $p \in \mathbb{R}, 0<p<1$, they are shown in Equation (IV.2).

$$
\sum_{r \in \Omega}\left\lfloor p \sum_{i \in C} a_{i}^{r}\right\rfloor \lambda_{r} \leq\lfloor p|C|\rfloor
$$

Some results for different choices of $(|C|, p)$-SRCs are published in the literature and the $(3,1 / 2)$-SRCs are shown to be the most promising ones. Their definition is presented in Equation (IV.3).

$$
\begin{aligned}
& \sum_{r \in \Omega}\left\lfloor\frac{1}{2} \sum_{i \in C} a_{i}^{r}\right\rfloor \lambda_{r} \leq\left\lfloor\frac{3}{2}\right\rfloor \\
& \sum_{r \in \Omega}\left\lfloor\frac{1}{2} \sum_{i \in C} a_{i}^{r}\right\rfloor \lambda_{r} \leq 1
\end{aligned}
$$

Despite their success, the SRCs are still hard to separate (the only known separation is to enumerate all sets $C$ ) and they are also hard to be considered in the pricing sub-problem. Each new SRC added to the SP formulation introduces a new resource for the pricing sub-problem. In the case of $(3,1 / 2)$-SRCs, for each cut $c \in \mathcal{C}$ (where $\mathcal{C}$ is the set of all separated SRCs) there must exist an integer counter $s r_{c}$ on each label which is incremented every time the path reaches a customer $v \in C$. When this counter reaches 2 , the dual variable $\sigma_{c}$ associated to the cut must be subtracted to the path's current reduced cost value and the counter returns to 0 .

In addition to the above modification, the dominance rule described in Section III.2 must also be changed to consider the reduced cost adjustment. When testing if a given label $\mathcal{L}\left(P_{1}\right)$ dominates $\mathcal{L}\left(P_{2}\right)$, the impact of future contributions of dual variables $\sigma_{c}$ must be taken into account. Since $\sigma_{c} \leq 0$, its introduction represents a penalization for an extension and this weaken the dominance rule. This means that when $s r_{c}\left(P_{1}\right)>s r_{c}\left(P_{2}\right)$, in the worst-case the contribution of $\sigma_{c}$ for this SRC may 
occur only for path $P_{1}$ and the dominance rule must consider this case. Therefore, the new dominance rule turns into the following:

(i) $v\left(P_{1}\right)=v\left(P_{2}\right)$

(ii) $q\left(P_{1}\right) \leq q\left(P_{2}\right)$

(iii) $\Pi\left(P_{1}\right) \subseteq \Pi\left(P_{2}\right)$

(iv) $\bar{c}\left(P_{1}\right) \leq \bar{c}\left(P_{2}\right)+\sum_{c \in \mathcal{C}: s r_{c}\left(P_{1}\right)>s r_{c}\left(P_{2}\right)} \sigma_{c}$

\section{IV.3 Limited Memory Subset Row Cut}

Recently, a relaxation to the SRCs was introduced by [19] called the Limited Memory Subset-Row Cuts (lm-SRCs). The intuition is analogous to the $n g$-route relaxation. Each customer now has a memory set $M_{v}$ containing the SRCs it "remembers". Thus, every time a path $P$ with $s r_{c}(P)>0$ reaches a customer with $c \notin M_{v}$, the path "forgets" the lm-SRC $c$ by setting $s r_{c}(P)=0$. If we were to consider an SRC in its original form, it would be the same as adding this cut to the memory set of all customers.

When creating a new $\mathrm{lm}$-SRC, it may be added to the memory set of any customer. Nevertheless, there is a subset of customers required to remember the new $\mathrm{lm}$-SRC for it to be violated by the current solution. These are the ones appearing from an odd visit to set $C$ until the following visit, on every route considered during the separation routine and besides the ones already in set $C$. For example, suppose $C=\{1,2,3\}, r_{1}=(0,1,4,5,3,7,4,0), r_{2}=(0,8,2,8,6,2,8,0)$. Let $\lambda_{r_{1}}>0$ and $\lambda_{r_{2}}>0$ in a way this solution violates a $(3,1 / 2)$-SRC. Considering route $r_{1}$, at the moment the customer 1 is visited, the counter of the cut will be incremented. When visiting customer 3 , the counter will be incremented again and the cut will be added to the memory set of all vertices between 1 and 3 . Repeating this process for the second route, the cut will be added to the memory set $M_{v}$ of customers $v \in\{1,2,3\} \cup\{4,5\} \cup\{8,6\}$.

The consequence of the relaxation is that now some routes which were considered in the original SRC are not considered in the relaxed lm-SRC anymore. If we define $\alpha_{r}(C, p, M)$ as being the coefficient of a route $r$ on the new lm-SRC, Equation (IV.4) shows its new definition.

$$
\sum_{r \in \Omega} \alpha_{r}(C, p, M) \lambda_{r} \leq\lfloor p|C|\rfloor
$$

When $M=N$ the lm-SRC will be exactly as in the SRC and the function $\alpha_{r}$ will return $\left\lfloor p \sum_{i \in C} a_{i}^{r}\right\rfloor$. On the other hand, if $|M|<|N|$ the function $\alpha_{r}$ will return a smaller coefficient for some routes in the inequality. This happens because every time a route $r$ leaves $M$, the variable state is reset to zero. So, only vertices in the memory set will keep the state of the cut. For those which are not in $M$, the state 
of the cut is zero by definition. It means that the duals variables $\sigma_{s}$ associated to the cuts will only play a role along extensions among vertices in $M$.

The main difference between the SRCs and the lm-SRCs is that the new version only tracks the state of the cuts among a subset of the customers sets and because of that fewer extensions will be penalized. This makes fewer buckets to be affected and the dominance will be improved. This can be noticed in practice by a speed up on the labeling algorithm by a factor $\Theta\left(n / M_{\text {avg }}\right)$, where $M_{\text {avg }}$ is the average size of the memory sets. Consequently, more lm-SRCs may be added to the formulation before the pricing loses performance.

\section{(a) Separation}

The first step of the lm-SRCs separation is to identify every subset of customers $C$ which violate the Equation IV.4. This step can be done enumerating all subsets of customers of size three. To do that, we consider all $\lambda_{r}$ variables with positive value from the solution of the restricted master problem and the routes associated with those variables. Then, we check for each route which triplets had at least two customer visited. Then, we verify if the left hand side of the Equation (IV.4) would be larger than one, which consists of a violation. Algorithm IV.1 illustrates how the separation is done. Let $a_{i}^{r}$ keep the same notation as seen before - it represents the number of times a customer $i$ was visited by route $r$.

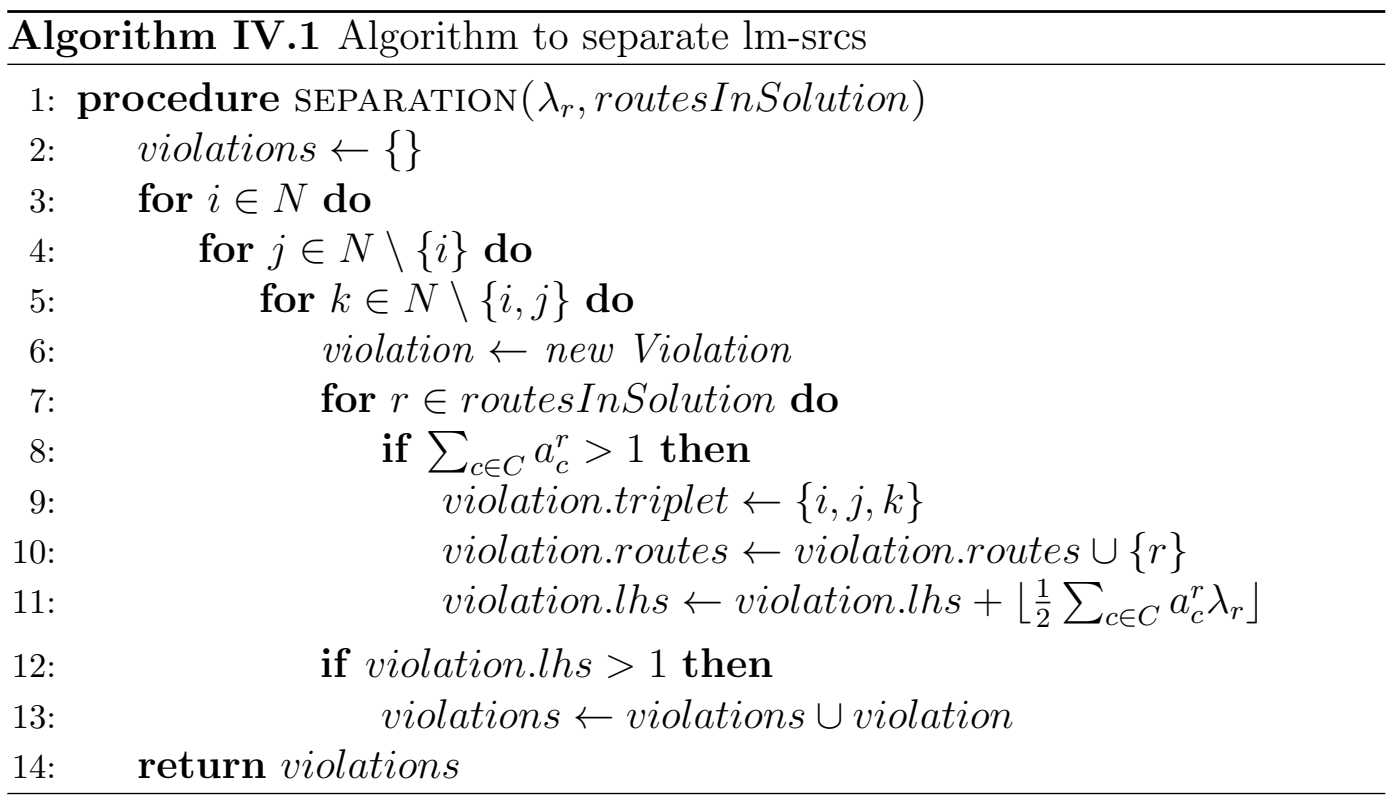

Algorithm IV.1 tests if a violation occurs for each possible triplet. Note that are, in this case, $\left(\begin{array}{c}N \\ 3\end{array}\right)$ triplets. So it is necessary to keep in mind to not return all cuts found to the master problem in order to minimize the impact on the pricing. In this work, we setup the limit of 500 cuts at each time the separation is called.

Knowing which triplets were violated, we now calculate the cut memory $M$. This minimal set represents which customers will remember a certain cut during 
the pricing execution. Initially, $M=C$ and the memory set is updated with every customer between two visits to a vertices in $C$, as described earlier. This process is describe in Algorithm IV.2, where we associate a state variable to control the parity of visits to vertices in the triplet.

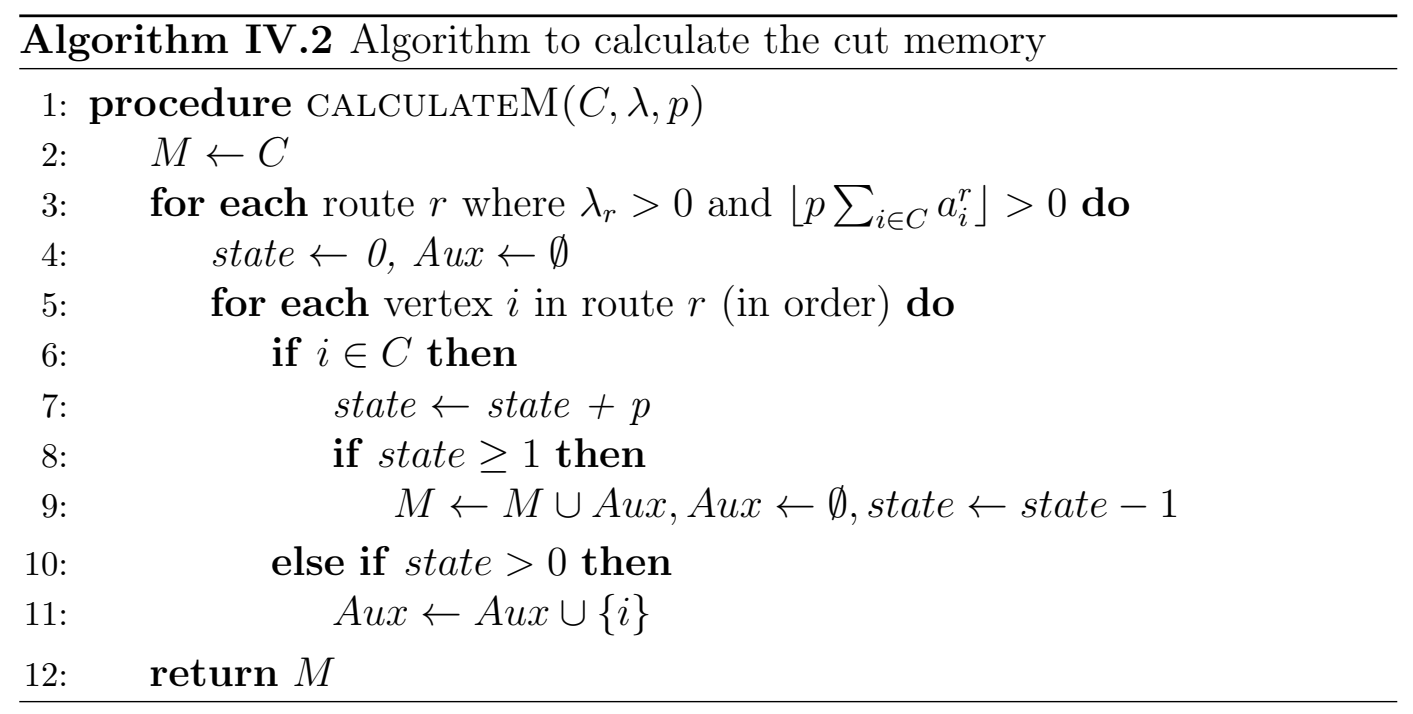

Finally, we just have to calculate the route coefficients to properly add the cut into the formulation. This process is done to every route in set $\Omega$, regardless its solution value, even if it is zero. As mentioned previously, the route coefficient in the $\mathrm{lm}$-SRC will be smaller or equal to one in SRC. Algorithm IV.3 shows how to calculate these coefficients.

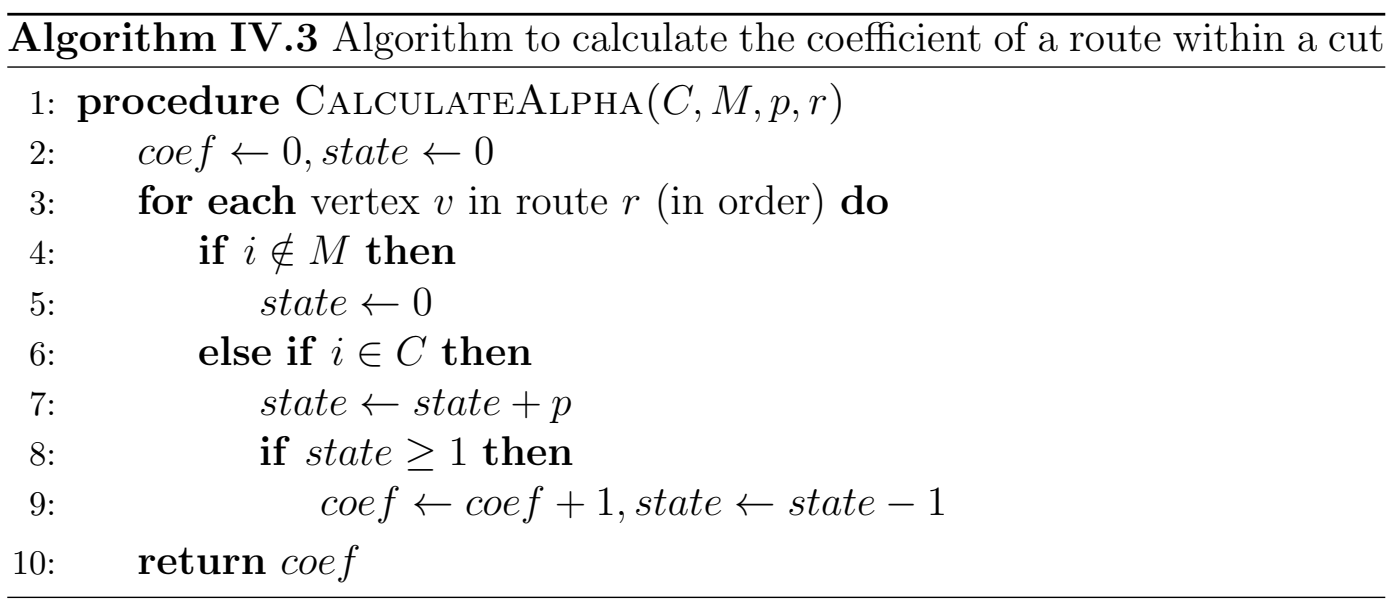

\section{(b) Pricing changes}

Here is where the $\mathrm{lm}$-SRC shows its effectiveness when comparing with regular SRC. Both families of cuts add a new resource to the label to track the state of each active cut. Therefore, the labels becomes $\mathcal{L}(P)=\left(\bar{c}(P), v(P), q(P), \Pi(P), s r_{c}(P)\right)$ where $s r_{c}(P)$ is the vector of states corresponding to $n_{S}$ lm-SRCs with non-zero duals variables in the current master LP solution. 
Since $\sigma_{c}<0$, the consideration of a SRC represents a penalization for one extension and this weakens the dominance rule. In fact, the dominance rule presented in Section IV.2 remains the same, but now, as the pricing "forgets" some lm-SRCs, condition (iv) of the dominance rule will be strengthened.

Another change in the pricing is when performing an extension $j \rightarrow i$, we have to check each $\operatorname{lm}$-SRC $c$ that $j$ remembers, if $i \in M(c)$. If that is not the case, $c$ will be forgotten, which means that the state variable of the cut will be set as zero. On the other hand if $i \in M(c), i \in C(c)$ and state $\geq 1$ then the dual variable $\sigma_{c}$ should penalize this extension. To illustrate the idea, we present Algorithm IV.4

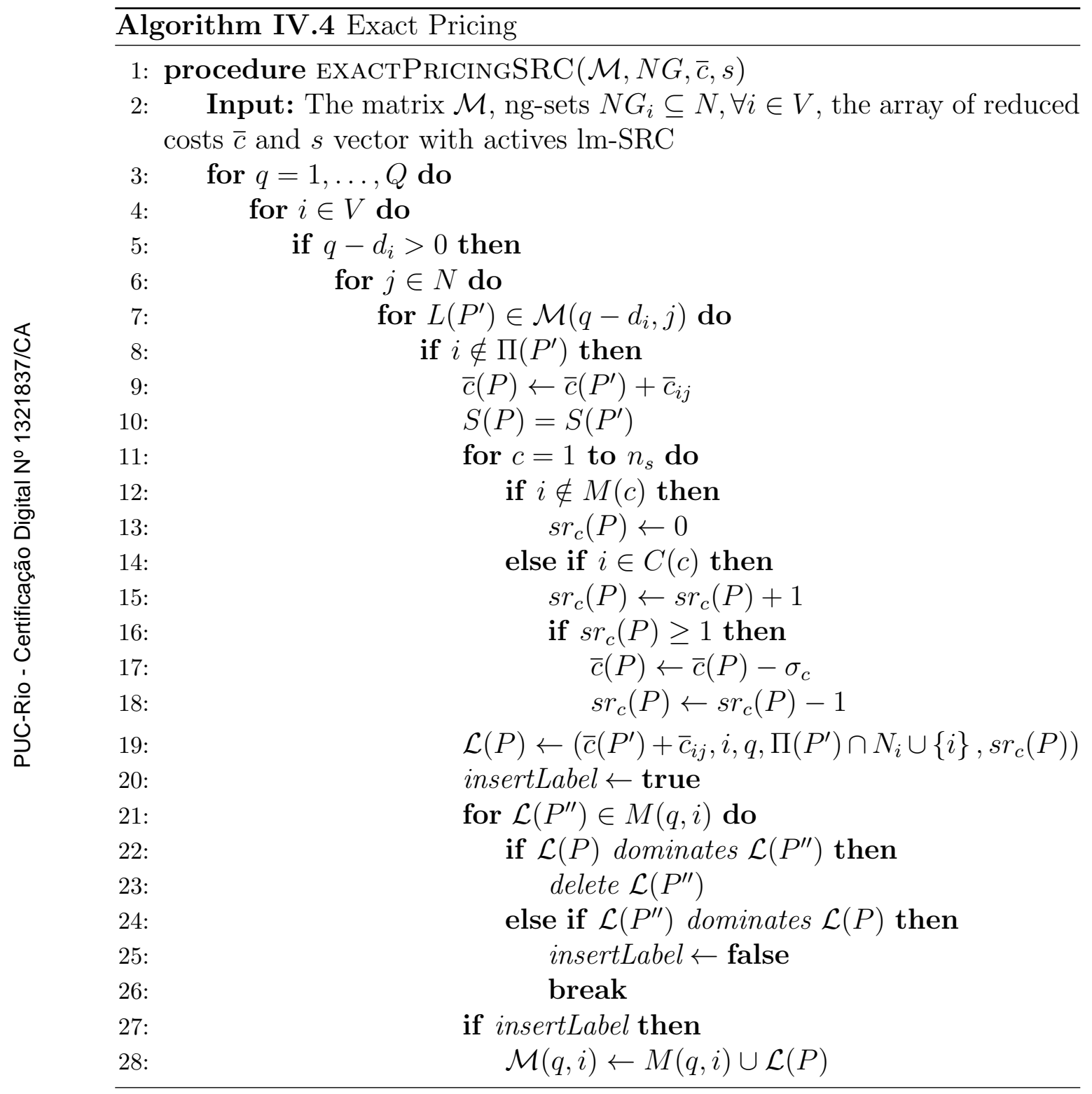




\section{V \\ Computational Experiments}

In this chapter we report a detailed computational experiment for a large set of CVRP instances, comparing the leverage obtained with the lm-SRC combined with the techniques presented in this thesis. Furthermore, we present a comparison between the bounds found by our approaches and those found by Pecin et al. [19]. For our computational experiments, we use the standard classes of instances (A, B, E, M, and P) available at CVRPLib (http://vrp.galgos.inf.puc-rio.br).

The algorithms were implemented in $\mathrm{C}++$, using Microsoft Visual Studio 2013 and Gurobi 6.5 [26]. The experiments were conducted on a Intel Core i7-3960X 3.30GHz with 64GB RAM running Linux Ubuntu Server 14.04.

We start presenting the comparison between a simple version using only the Set Partitioning Formulation, $n g$-routes and the additional lm-src. We setup the size of the $n g$-sets to be 8 for all tests. The results are presented in Table V.1. Columns Routes represent the number of routes that were generated during the process, columns Heu and Exa show the amount of time spent by the heuristic pricing and the exact pricing, respectively. Column Sep shows the total number of separated $\mathrm{lm}$-SRCs and column Act shows the number of lm-SRCs which were active in the last resolution of the formulation. In order to keep the formulation more compact, after running the heuristic pricing, if any lm-SRC was not active, we remove it from the formulation. Lines with dash instead of values reached the time limit that we setup as 2 hours. At the end of each table, we calculate the average of each column for those instances that had finished in both configuration, with and without the consideration of the $\mathrm{lm}$-SRC.

Other strategies were used in the attempt to improve the running time. We limited the number of routes that can be returned by the pricing in 20 . As said before, we also limited the number of strong cuts that are added into the formulation at each iteration to be at most 500. Finally, we tried to minimize the number of runs of the exact pricing. To do that, first we run the heuristic pricing until no routes are found, then we separate the cuts and if no cuts were found we run the exact pricing.

Looking closer to Table V.1, we can immediately see the power of the lm-SRC. The number of instances which was equal to the known lower bound increased from 2 to 25 , however the number of instances which do not finished within the two hour time limit was 21 out of 93 instances tested and the elapsed time of the remaining instances increased significantly. 
In Table V.2 we show the results of the comparison of a version using $n g$ routes with DSSR to the one with the addition of the lm-SRCs. The number of instances which reached the known lower bound was the same, however the number of instances that were timed out decreased from 25 to 21 . In this test we used the DSSR technique as presented in Section III.2(a).

The following test combined $n g$-routes, DSSR and Completion Bounds and compares the results with and without lm-SRCs. They are presented in Table V.3. In this test, we did not notice any relevant changes from the one only considering DSSR.

In Table V.4 we combine $n g$-routes with the Capacity Cuts, presented in Section IV.1. Capacity cuts had a great role, increasing the number of instances that reached the known lower bound to 18. Combining them with the $1 \mathrm{~m}-\mathrm{SRCs}$ also showed a great improvement and the instances that reached the known lower bound were increased to 53 and the number of instances timed out decrease to 7 .

Finally, we tested the combination of all techniques presented in this thesis with the addition of lm-SRCs. In Table V.5 we show the results that we found. In this test, we saw the number of instances that reached the knwon lower bound to remain the same as those tested with only the Capacity Cuts, with and without the lm-SRCs. We also show the comparison with the lower bound found by Pecin et al. [19]. These results are presented in Table V.6. 
PUC-Rio - Certificação Digital № 1321837/CA

Table V.1: Comparison over a pure version

\begin{tabular}{|c|c|c|c|c|c|c|c|c|c|c|c|c|c|}
\hline \multirow{2}{*}{ Ins } & \multirow{2}{*}{$\mathrm{OPT}$} & \multicolumn{5}{|c|}{ without $1 \mathrm{~m}-\mathrm{SRC}$} & \multicolumn{7}{|c|}{ with $1 \mathrm{~m}-\mathrm{SRC}$} \\
\hline & & Value & Time & Routes & Heu & Exa & Value & Time & Routes & Heu & Exa & Sep & Act \\
\hline$A-n 32-k 5$ & 784 & 770.286 & 0.872 & 999 & 60 & 3 & 784 & 17.764 & 1713 & 117 & 7 & 458 & 33 \\
\hline$A-n 33-k 5$ & 661 & 653.727 & 0.42 & 771 & 46 & 2 & 661 & 1.584 & 933 & 64 & 3 & 478 & 29 \\
\hline$A-n 33-k 6$ & 742 & 732.1 & 0.383 & 791 & 46 & 2 & 738.333 & 2.012 & 1047 & 100 & 4 & 863 & 27 \\
\hline $\mathrm{A}-\mathrm{n} 34-\mathrm{k} 5$ & 778 & 746.012 & 0.475 & 885 & 48 & 1 & 767.117 & 12.109 & 1756 & 173 & 6 & 1392 & 83 \\
\hline$A-n 36-k 5$ & 799 & 776.276 & 0.797 & 1230 & 71 & 2 & 796.5 & 1999.12 & 2537 & 200 & 11 & 2644 & 84 \\
\hline $\mathrm{A}-\mathrm{n} 37-\mathrm{k} 5$ & 669 & 657.811 & 1.139 & 1504 & 82 & 3 & 669 & 15.381 & 2340 & 159 & 4 & 1224 & 30 \\
\hline $\mathrm{A}-\mathrm{n} 37-\mathrm{k} 6$ & 949 & 925.407 & 0.473 & 900 & 50 & 2 & 939.488 & 8.057 & 1462 & 169 & 6 & 1528 & 60 \\
\hline $\mathrm{A}-\mathrm{n} 38-\mathrm{k} 5$ & 730 & 695.417 & 0.696 & 1027 & 57 & 3 & 726.273 & 14.34 & 1798 & 139 & 5 & 2050 & 59 \\
\hline$A-n 39-k 5$ & 822 & 799.842 & 1.066 & 1328 & 78 & 4 & 817.102 & 82.229 & 2199 & 198 & 8 & 2219 & 117 \\
\hline$A-n 39-k 6$ & 831 & 806.672 & 0.866 & 1209 & 68 & 3 & 827.473 & 216.208 & 2402 & 292 & 10 & 2694 & 128 \\
\hline $\mathrm{A}-\mathrm{n} 44-\mathrm{k} 6$ & 937 & 926.641 & 0.711 & 1082 & 59 & 2 & 933.914 & 8.797 & 1516 & 165 & 5 & 1978 & 79 \\
\hline$A-n 45-k 6$ & 944 & 927.25 & 0.941 & 1276 & 71 & 2 & 944 & 7.607 & 1743 & 114 & 5 & 1000 & 46 \\
\hline $\mathrm{A}-\mathrm{n} 45-\mathrm{k} 7$ & 1146 & 1124.67 & 0.739 & 1228 & 66 & 1 & 1133.05 & 4.277 & 1556 & 141 & 3 & 1452 & 58 \\
\hline $\mathrm{A}-\mathrm{n} 46-\mathrm{k} 7$ & 914 & 904.626 & 1.107 & 1484 & 79 & 2 & 914 & 4.777 & 1814 & 106 & 5 & 495 & 39 \\
\hline $\mathrm{A}-\mathrm{n} 48-\mathrm{k} 7$ & 1073 & 1053.08 & 1.209 & 1308 & 73 & 3 & 1073 & 7.925 & 1669 & 111 & 6 & 1000 & 48 \\
\hline $\mathrm{A}-\mathrm{n} 53-\mathrm{k} 7$ & 1010 & 992.378 & 2.395 & 2151 & 119 & 3 & - & - & - & - & - & - & - \\
\hline $\mathrm{A}-\mathrm{n} 54-\mathrm{k} 7$ & 1167 & 1137.06 & 1.489 & 1522 & 82 & 3 & 1159.6 & 59.922 & 2695 & 253 & 9 & 3199 & 127 \\
\hline$A-n 55-k 9$ & 1073 & 1059.03 & 1.151 & 1366 & 72 & 3 & 1070.67 & 11.189 & 2069 & 178 & 6 & 3816 & 81 \\
\hline$A-n 60-k 9$ & 1354 & 1323.32 & 1.726 & 1816 & 94 & 2 & 1339.03 & 31.824 & 2824 & 243 & 7 & 4288 & 139 \\
\hline $\mathrm{A}-\mathrm{n} 61-\mathrm{k} 9$ & 1034 & 1010.24 & 1.418 & 1537 & 84 & 2 & 1031.33 & 33.25 & 2439 & 244 & 8 & 3273 & 136 \\
\hline $\mathrm{A}-\mathrm{n} 62-\mathrm{k} 8$ & 1288 & 1250.24 & 3.093 & 2184 & 118 & 5 & 1274.37 & 53.241 & 3322 & 307 & 9 & 6054 & 129 \\
\hline$A-n 63-k 10$ & 1314 & 1286.58 & 1.944 & 1798 & 94 & 3 & 1299.6 & 18.276 & 2676 & 201 & 6 & 3067 & 84 \\
\hline
\end{tabular}


PUC-Rio - Certificação Digital № 1321837/CA

Table V.1: Continued from previous page

\begin{tabular}{|c|c|c|c|c|c|c|c|c|c|c|c|c|c|}
\hline \multirow{2}{*}{ Ins } & \multirow{2}{*}{ OPT } & \multicolumn{5}{|c|}{ without $1 \mathrm{~m}-\mathrm{SRC}$} & \multicolumn{7}{|c|}{ with $1 \mathrm{~m}$-SRC } \\
\hline & & Value & Time & Routes & Heu & Exa & Value & Time & Routes & $\mathrm{Heu}$ & Exa & Sep & Act \\
\hline A-n63-k9 & 1616 & 1579.13 & 1.463 & 1547 & 81 & 2 & 1602.61 & 46.092 & 2731 & 265 & 7 & 3903 & 140 \\
\hline A-n64-k9 & 1401 & 1368.24 & 2.212 & 1924 & 105 & 3 & 1391.02 & 2753.64 & 3247 & 275 & 9 & 4228 & 128 \\
\hline A-n65-k9 & 1174 & 1147.33 & 1.76 & 1784 & 94 & 2 & 1169.43 & 47.386 & 3163 & 307 & 7 & 4399 & 146 \\
\hline$A-n 69-k 9$ & 1159 & 1129.97 & 2.85 & 2190 & 118 & 3 & 1150.53 & 68.922 & 3324 & 258 & 8 & 3129 & 147 \\
\hline $\mathrm{A}-\mathrm{n} 80-\mathrm{k} 10$ & 1763 & 1729.81 & 4.969 & 2977 & 155 & 3 & 1748.09 & 715.984 & 4633 & 412 & 9 & 5872 & 176 \\
\hline $\mathrm{B}-\mathrm{n} 45-\mathrm{k} 5$ & 751 & 688.901 & 2.407 & 1846 & 103 & 4 & - & - & - & - & - & - & - \\
\hline $\mathrm{B}-\mathrm{n} 41-\mathrm{k} 6$ & 829 & 797.722 & 0.638 & 889 & 50 & 2 & 814.604 & 13.529 & 1439 & 160 & 7 & 2574 & 102 \\
\hline B-n39-k5 & 549 & 521.071 & 1.988 & 1407 & 86 & 6 & - & - & - & - & - & - & - \\
\hline $\mathrm{B}-\mathrm{n} 38-\mathrm{k} 6$ & 805 & 741.634 & 0.947 & 1075 & 64 & 2 & - & - & - & - & - & - & - \\
\hline $\mathrm{B}-\mathrm{n} 35-\mathrm{k} 5$ & 955 & 868.083 & 0.963 & 1176 & 70 & 3 & 926.018 & 345.894 & 3414 & 382 & 14 & 2353 & 136 \\
\hline $\mathrm{B}-\mathrm{n} 34-\mathrm{k} 5$ & 788 & 755.231 & 0.996 & 1209 & 72 & 5 & 773.636 & 50.469 & 2179 & 220 & 11 & 2991 & 98 \\
\hline $\mathrm{B}-\mathrm{n} 31-\mathrm{k} 5$ & 672 & 661.207 & 0.411 & 774 & 44 & 2 & 666.191 & 5.649 & 1207 & 121 & 6 & 1309 & 56 \\
\hline $\mathrm{B}-\mathrm{n} 57-\mathrm{k} 7$ & 1153 & 1126.77 & 2.604 & 1881 & 99 & 4 & - & - & - & - & - & - & - \\
\hline $\mathrm{B}-\mathrm{n} 56-\mathrm{k} 7$ & 707 & 635.601 & 3.727 & 1830 & 111 & 7 & - & - & - & - & - & - & - \\
\hline $\mathrm{B}-\mathrm{n} 52-\mathrm{k} 7$ & 747 & 687.348 & 2.168 & 1601 & 95 & 5 & - & - & - & - & - & - & - \\
\hline $\mathrm{B}-\mathrm{n} 51-\mathrm{k} 7$ & 1032 & 964.287 & 1.682 & 1351 & 74 & 4 & - & - & - & - & - & - & - \\
\hline $\mathrm{B}-\mathrm{n} 50-\mathrm{k} 8$ & 1312 & 1266.45 & 1.905 & 1188 & 70 & 4 & 1282.79 & 38.627 & 1753 & 207 & 9 & 3178 & 111 \\
\hline $\mathrm{B}-\mathrm{n} 50-\mathrm{k} 7$ & 741 & 690.528 & 1.83 & 1570 & 89 & 2 & - & - & - & - & - & - & - \\
\hline $\mathrm{B}-\mathrm{n} 45-\mathrm{k} 6$ & 678 & 652.65 & 1.413 & 1043 & 65 & 4 & 666.834 & 50.152 & 1912 & 254 & 7 & 4386 & 130 \\
\hline $\mathrm{B}-\mathrm{n} 44-\mathrm{k} 7$ & 909 & 865.181 & 0.738 & 991 & 55 & 2 & 880.067 & 568.848 & 2098 & 255 & 10 & 2892 & 131 \\
\hline$B-n 43-k 6$ & 742 & 703.674 & 1.048 & 1142 & 63 & 3 & 723.319 & 515.204 & 3149 & 353 & 15 & 3748 & 152 \\
\hline $\mathrm{B}-\mathrm{n} 78-\mathrm{k} 10$ & 1221 & 1166.73 & 4.913 & 2689 & 141 & 3 & - & - & - & - & - & - & - \\
\hline B-n68-k9 & 1272 & 1198.2 & 3.135 & 2249 & 120 & 2 & - & - & - & - & - & - & - \\
\hline
\end{tabular}


PUC-Rio - Certificação Digital № 1321837/CA

Table V.1: Continued from previous page

\begin{tabular}{|c|c|c|c|c|c|c|c|c|c|c|c|c|c|}
\hline \multirow{2}{*}{ Ins } & \multirow{2}{*}{$\mathrm{OPT}$} & \multicolumn{5}{|c|}{ without $1 \mathrm{~m}-\mathrm{SRC}$} & \multicolumn{7}{|c|}{ with $1 \mathrm{~m}-\mathrm{SRC}$} \\
\hline & & Value & Time & Routes & Heu & Exa & Value & Time & Routes & $\mathrm{Heu}$ & Exa & Sep & Act \\
\hline $\mathrm{B}-\mathrm{n} 67-\mathrm{k} 10$ & 1032 & 999.204 & 2.455 & 2113 & 111 & 2 & 1028.42 & 146.339 & 3684 & 310 & 11 & 4632 & 132 \\
\hline$B-n 66-k 9$ & 1316 & 1257.22 & 2.862 & 2077 & 111 & 4 & - & - & - & - & - & - & - \\
\hline $\mathrm{B}-\mathrm{n} 64-\mathrm{k} 9$ & 861 & 808.253 & 2.777 & 1959 & 105 & 3 & - & - & - & - & - & - & - \\
\hline B-n57-k9 & 1598 & 1571.99 & 1.681 & 1550 & 85 & 3 & 1592.7 & 52.658 & 2707 & 219 & 7 & 2768 & 123 \\
\hline $\mathrm{B}-\mathrm{n} 63-\mathrm{k} 10$ & 1496 & 1456.86 & 1.608 & 1634 & 88 & 2 & 1496 & 330.42 & 3381 & 294 & 11 & 3615 & 121 \\
\hline $\mathrm{E}-\mathrm{n} 76-\mathrm{k} 8$ & 735 & 717.819 & 4.774 & 2680 & 140 & 2 & 732.929 & 297.045 & 4775 & 408 & 9 & 4048 & 195 \\
\hline $\mathrm{E}-\mathrm{n} 76-\mathrm{k} 7$ & 682 & 664.202 & 8.047 & 3176 & 171 & 3 & - & - & - & - & - & - & - \\
\hline E-n76-k14 & 1021 & 1001.85 & 1.18 & 1288 & 67 & 2 & 1014.75 & 7.432 & 1627 & 145 & 4 & 1363 & 106 \\
\hline E-n76-k10 & 830 & 811.767 & 2.258 & 1903 & 98 & 1 & 825.787 & 28.103 & 2774 & 211 & 4 & 2535 & 160 \\
\hline $\mathrm{E}-\mathrm{n} 51-\mathrm{k} 5$ & 521 & 517.135 & 1.991 & 1703 & 92 & 2 & 521 & 9.098 & 2008 & 128 & 5 & 500 & 32 \\
\hline E-n33-k4 & 835 & 820.918 & 3.153 & 1351 & 76 & 3 & 831.484 & 74.362 & 2611 & 212 & 5 & 1597 & 84 \\
\hline$E-n 30-k 3$ & 534 & 478.709 & 1.448 & 1339 & 89 & 3 & - & - & - & - & - & - & - \\
\hline$E-n 23-k 3$ & 569 & 564.413 & 5.989 & 944 & 68 & 2 & 569 & 12.535 & 977 & 87 & 2 & 706 & 8 \\
\hline$E-n 22-k 4$ & 375 & 373.875 & 0.095 & 357 & 23 & 1 & 375 & 0.112 & 361 & 25 & 1 & 86 & 3 \\
\hline E-n101-k8 & 815 & 789.372 & 16.688 & 4694 & 243 & 3 & - & - & - & - & - & - & - \\
\hline E-n101-k14 & 1067 & 1047.2 & 5.102 & 2889 & 147 & 2 & 1061.12 & 62.95 & 4028 & 291 & 6 & 3909 & 211 \\
\hline E-n31-k7 & 379 & 378 & 0.486 & 1015 & 59 & 1 & 379 & 0.613 & 1037 & 65 & 1 & 126 & 8 \\
\hline E-n13-k4 & 247 & 247 & 0.014 & 73 & 10 & 1 & 247 & 0.014 & 73 & 10 & 1 & 0 & 0 \\
\hline P-n55-k10 & 694 & 680.06 & 0.656 & 1023 & 55 & 1 & 689.193 & 5.335 & 1367 & 147 & 3 & 1224 & 100 \\
\hline$P-n 23-k 8$ & 529 & 529 & 0.016 & 563 & 4 & 1 & 529 & 0.016 & 563 & 4 & 1 & 0 & 0 \\
\hline P-n50-k10 & 696 & 687.347 & 0.461 & 812 & 45 & 2 & 694.223 & 1.435 & 969 & 84 & 2 & 433 & 53 \\
\hline $\mathrm{P}-\mathrm{n} 45-\mathrm{k} 5$ & 510 & 502.349 & 1.253 & 1506 & 82 & 1 & 510 & 12.715 & 2234 & 145 & 4 & 1175 & 50 \\
\hline $\mathrm{P}-\mathrm{n} 40-\mathrm{k} 5$ & 458 & 452.5 & 0.864 & 1294 & 68 & 1 & 458 & 4.648 & 1633 & 105 & 4 & 583 & 28 \\
\hline
\end{tabular}


PUC-Rio - Certificação Digital № 1321837/CA

Table V.1: Continued from previous page

\begin{tabular}{|c|c|c|c|c|c|c|c|c|c|c|c|c|c|}
\hline \multirow{2}{*}{ Ins } & \multirow{2}{*}{$\mathrm{OPT}$} & \multicolumn{5}{|c|}{ without $1 \mathrm{~m}-\mathrm{SRC}$} & \multicolumn{7}{|c|}{ with $1 \mathrm{~m}-\mathrm{SRC}$} \\
\hline & & Value & Time & Routes & Heu & Exa & Value & Time & Routes & Heu & Exa & Sep & Act \\
\hline $\mathrm{P}-\mathrm{n} 22-\mathrm{k} 8$ & 603 & 601.25 & 0.021 & 146 & 11 & 1 & 603 & 0.036 & 155 & 16 & 2 & 16 & 3 \\
\hline$P-n 22-k 2$ & 216 & 214.5 & 0.592 & 883 & 64 & 2 & 216 & 1.356 & 1015 & 83 & 3 & 130 & 5 \\
\hline$P-n 21-k 2$ & 211 & 210.556 & 0.366 & 670 & 52 & 1 & 211 & 0.522 & 674 & 54 & 1 & 235 & 8 \\
\hline$P-n 20-k 2$ & 216 & 210 & 0.295 & 592 & 47 & 1 & 216 & 1.874 & 784 & 77 & 4 & 240 & 13 \\
\hline $\mathrm{P}-\mathrm{n} 19-\mathrm{k} 2$ & 212 & 209.714 & 0.275 & 405 & 39 & 3 & 212 & 1.416 & 527 & 57 & 5 & 131 & 13 \\
\hline $\mathrm{P}-\mathrm{n} 16-\mathrm{k} 8$ & 450 & 443.667 & 0.01 & 59 & 8 & 1 & 450 & 0.012 & 61 & 10 & 1 & 5 & 4 \\
\hline $\mathrm{P}-\mathrm{n} 101-\mathrm{k} 4$ & 681 & 669.044 & 111.742 & 9909 & 577 & 9 & - & - & - & - & - & - & - \\
\hline $\mathrm{P}-\mathrm{n} 76-\mathrm{k} 5$ & 627 & 614.86 & 16.051 & 4303 & 230 & 5 & - & - & - & - & - & - & - \\
\hline $\mathrm{P}-\mathrm{n} 76-\mathrm{k} 4$ & 593 & 586.502 & 27.43 & 4929 & 286 & 7 & 593 & 963.096 & 7437 & 536 & 14 & 3500 & 73 \\
\hline $\mathrm{P}-\mathrm{n} 70-\mathrm{k} 10$ & 827 & 809.29 & 1.522 & 1581 & 82 & 1 & 823.067 & 20.438 & 2358 & 196 & 4 & 2300 & 155 \\
\hline P-n65-k10 & 792 & 783.126 & 1.294 & 1334 & 70 & 2 & 792 & 5.995 & 1741 & 112 & 3 & 1338 & 89 \\
\hline $\mathrm{P}-\mathrm{n} 60-\mathrm{k} 15$ & 968 & 959.606 & 0.34 & 784 & 40 & 1 & 967.465 & 1.098 & 898 & 75 & 2 & 504 & 55 \\
\hline $\mathrm{P}-\mathrm{n} 60-\mathrm{k} 10$ & 744 & 736.528 & 1.052 & 1123 & 61 & 3 & 743.094 & 5.236 & 1577 & 119 & 3 & 1278 & 70 \\
\hline $\mathrm{P}-\mathrm{n} 55-\mathrm{k} 7$ & 568 & 555.362 & 1.456 & 1518 & 80 & 1 & 564.192 & 45.85 & 2559 & 198 & 6 & 1929 & 118 \\
\hline P-n55-k15 & 989 & 968.361 & 7.423 & 162367 & 6 & 1 & 984.457 & 39.94 & 162450 & 38 & 2 & 378 & 53 \\
\hline P-n51-k10 & 741 & 732.955 & 0.383 & 830 & 43 & 1 & 740.778 & 1.973 & 1121 & 101 & 3 & 853 & 52 \\
\hline$P-n 50-k 8$ & 631 & 614.641 & 0.456 & 796 & 39 & 1 & 625.061 & 7.783 & 1249 & 125 & 4 & 1146 & 126 \\
\hline P-n50-k7 & 554 & 545.399 & 0.881 & 1222 & 63 & 1 & 554 & 7.805 & 1638 & 110 & 4 & 1063 & 63 \\
\hline $\mathrm{M}-\mathrm{n} 151-\mathrm{k} 12$ & 1015 & 995.728 & 46.443 & 7398 & 381 & 4 & 1009.65 & 5099.56 & 11653 & 927 & 18 & 13943 & 349 \\
\hline $\mathrm{M}-\mathrm{n} 121-\mathrm{k} 7$ & 1034 & 1026.37 & 62.187 & 6878 & 364 & 9 & - & - & - & - & - & - & - \\
\hline $\mathrm{M}-\mathrm{n} 101-\mathrm{k} 10$ & 820 & 818.367 & 13.344 & 4644 & 251 & 12 & 820 & 77.95 & 6196 & 427 & 19 & 7434 & 15 \\
\hline $\mathrm{M}-\mathrm{n} 200-\mathrm{k} 16$ & 1274 & 1250.23 & 135.503 & 9450 & 481 & 5 & - & - & - & - & - & - & - \\
\hline
\end{tabular}


PUC-Rio - Certificação Digital № 1321837/CA

Table V.1: Continued from previous page

\begin{tabular}{|c|c|c|c|c|c|c|c|c|c|c|c|c|c|}
\hline \multirow{2}{*}{ Ins } & \multirow{2}{*}{$\mathrm{OPT}$} & \multicolumn{5}{|c|}{ without $1 \mathrm{~m}$-SRC } & \multicolumn{7}{|c|}{ with $1 \mathrm{~m}-\mathrm{SRC}$} \\
\hline & & Value & Time & Routes & Heu & Exa & Value & Time & Routes & Heu & Exa & Sep & Act \\
\hline $\mathrm{M}-\mathrm{n} 200-\mathrm{k} 17$ & 1275 & 1252.52 & 135.413 & 9590 & 489 & 5 & - & - & - & - & - & - & - \\
\hline Average & 839.271 & 820.654 & 2.596 & 3743.686 & 78.3 & 2.357 & 833.905 & 216.544 & 4538.014 & 189.914 & 6.157 & 2226.529 & 84.957 \\
\hline
\end{tabular}


PUC-Rio - Certificação Digital № 1321837/CA

Table V.2: Comparison using DSSR

\begin{tabular}{|c|c|c|c|c|c|c|c|c|c|c|c|c|c|}
\hline \multirow{2}{*}{ Ins } & \multirow{2}{*}{ OPT } & \multicolumn{5}{|c|}{ without $1 \mathrm{~m}-\mathrm{SRC}$} & \multicolumn{7}{|c|}{ with $1 \mathrm{~m}-\mathrm{SRC}$} \\
\hline & & Value & Time & Routes & Heu & Exa & Value & Time & Routes & $\mathrm{Heu}$ & Exa & Sep & Act \\
\hline$A-n 32-k 5$ & 784 & 770.286 & 0.818 & 999 & 60 & 3 & 784 & 17.836 & 1713 & 117 & 7 & 458 & 33 \\
\hline $\mathrm{A}-\mathrm{n} 33-\mathrm{k} 5$ & 661 & 653.727 & 0.394 & 771 & 46 & 2 & 661 & 1.638 & 933 & 64 & 3 & 478 & 29 \\
\hline$A-n 33-k 6$ & 742 & 732.1 & 0.378 & 791 & 46 & 2 & 738.333 & 2.038 & 1047 & 100 & 4 & 863 & 27 \\
\hline$A-n 34-k 5$ & 778 & 746.012 & 0.477 & 885 & 48 & 1 & 767.117 & 12.45 & 1756 & 173 & 6 & 1392 & 83 \\
\hline $\mathrm{A}-\mathrm{n} 36-\mathrm{k} 5$ & 799 & 776.276 & 0.842 & 1230 & 71 & 2 & 796.5 & 1999.4 & 2537 & 200 & 11 & 2644 & 84 \\
\hline $\mathrm{A}-\mathrm{n} 37-\mathrm{k} 5$ & 669 & 657.811 & 1.131 & 1504 & 82 & 3 & 669 & 15.443 & 2340 & 159 & 4 & 1224 & 30 \\
\hline $\mathrm{A}-\mathrm{n} 37-\mathrm{k} 6$ & 949 & 925.407 & 0.509 & 900 & 50 & 2 & 939.488 & 8.064 & 1462 & 169 & 6 & 1528 & 60 \\
\hline$A-n 38-k 5$ & 730 & 695.417 & 0.687 & 1027 & 57 & 3 & 726.273 & 14.387 & 1798 & 139 & 5 & 2050 & 59 \\
\hline $\mathrm{A}-\mathrm{n} 39-\mathrm{k} 5$ & 822 & 799.842 & 1.074 & 1328 & 78 & 4 & 817.102 & 82.032 & 2199 & 198 & 8 & 2219 & 117 \\
\hline$A-n 39-k 6$ & 831 & 806.672 & 0.904 & 1209 & 68 & 3 & 827.473 & 215.688 & 2402 & 292 & 10 & 2694 & 128 \\
\hline $\mathrm{A}-\mathrm{n} 44-\mathrm{k} 6$ & 937 & 926.641 & 0.712 & 1082 & 59 & 2 & 933.914 & 8.853 & 1516 & 165 & 5 & 1978 & 79 \\
\hline $\mathrm{A}-\mathrm{n} 45-\mathrm{k} 6$ & 944 & 927.25 & 0.937 & 1276 & 71 & 2 & 944 & 7.578 & 1743 & 114 & 5 & 1000 & 46 \\
\hline $\mathrm{A}-\mathrm{n} 45-\mathrm{k} 7$ & 1146 & 1124.67 & 0.793 & 1228 & 66 & 1 & 1133.05 & 4.278 & 1556 & 141 & 3 & 1452 & 58 \\
\hline $\mathrm{A}-\mathrm{n} 46-\mathrm{k} 7$ & 914 & 904.626 & 1.112 & 1484 & 79 & 2 & 914 & 4.848 & 1814 & 106 & 5 & 495 & 39 \\
\hline $\mathrm{A}-\mathrm{n} 48-\mathrm{k} 7$ & 1073 & 1053.08 & 1.156 & 1308 & 73 & 3 & 1073 & 8.018 & 1669 & 111 & 6 & 1000 & 48 \\
\hline $\mathrm{A}-\mathrm{n} 53-\mathrm{k} 7$ & 1010 & 992.378 & 2.359 & 2151 & 119 & 3 & - & - & - & - & - & - & - \\
\hline $\mathrm{A}-\mathrm{n} 54-\mathrm{k} 7$ & 1167 & 1137.06 & 1.481 & 1522 & 82 & 3 & 1159.6 & 58.701 & 2695 & 253 & 9 & 3199 & 127 \\
\hline $\mathrm{A}-\mathrm{n} 55-\mathrm{k} 9$ & 1073 & 1059.03 & 1.157 & 1366 & 72 & 3 & 1070.67 & 11.024 & 2069 & 178 & 6 & 3816 & 81 \\
\hline $\mathrm{A}-\mathrm{n} 60-\mathrm{k} 9$ & 1354 & 1323.32 & 1.768 & 1816 & 94 & 2 & 1339.03 & 31.858 & 2824 & 243 & 7 & 4288 & 139 \\
\hline $\mathrm{A}-\mathrm{n} 61-\mathrm{k} 9$ & 1034 & 1010.24 & 1.432 & 1537 & 84 & 2 & 1031.33 & 32.755 & 2439 & 244 & 8 & 3273 & 136 \\
\hline $\mathrm{A}-\mathrm{n} 62-\mathrm{k} 8$ & 1288 & 1250.24 & 3.108 & 2184 & 118 & 5 & 1274.37 & 53.001 & 3322 & 307 & 9 & 6054 & 129 \\
\hline$A-n 63-k 10$ & 1314 & 1286.58 & 1.929 & 1798 & 94 & 3 & 1299.6 & 18.121 & 2676 & 201 & 6 & 3067 & 84 \\
\hline
\end{tabular}


PUC-Rio - Certificação Digital № 1321837/CA

Table V.2: Continued from previous page

\begin{tabular}{|c|c|c|c|c|c|c|c|c|c|c|c|c|c|}
\hline \multirow{2}{*}{ Ins } & \multirow{2}{*}{$\mathrm{OPT}$} & \multicolumn{5}{|c|}{ without $1 \mathrm{~m}-\mathrm{SRC}$} & \multicolumn{7}{|c|}{ with $1 \mathrm{~m}-\mathrm{SRC}$} \\
\hline & & Value & Time & Routes & Heu & Exa & Value & Time & Routes & Heu & Exa & Sep & Act \\
\hline$A-n 63-k 9$ & 1616 & 1579.13 & 1.466 & 1547 & 81 & 2 & 1602.61 & 46.184 & 2731 & 265 & 7 & 3903 & 140 \\
\hline $\mathrm{A}-\mathrm{n} 64-\mathrm{k} 9$ & 1401 & 1368.24 & 2.215 & 1924 & 105 & 3 & 1391.02 & 2754.31 & 3247 & 275 & 9 & 4228 & 128 \\
\hline$A-n 65-k 9$ & 1174 & 1147.33 & 1.763 & 1784 & 94 & 2 & 1169.43 & 48.613 & 3163 & 307 & 7 & 4399 & 146 \\
\hline A-n69-k9 & 1159 & 1129.97 & 2.867 & 2190 & 118 & 3 & 1150.53 & 69.044 & 3324 & 258 & 8 & 3129 & 147 \\
\hline $\mathrm{A}-\mathrm{n} 80-\mathrm{k} 10$ & 1763 & 1729.81 & 4.966 & 2977 & 155 & 3 & 1748.09 & 716.846 & 4633 & 412 & 9 & 5872 & 176 \\
\hline$B-n 45-k 5$ & 751 & 688.901 & 2.305 & 1846 & 103 & 4 & - & - & - & - & - & - & - \\
\hline $\mathrm{B}-\mathrm{n} 41-\mathrm{k} 6$ & 829 & 797.722 & 0.577 & 889 & 50 & 2 & 814.604 & 13.524 & 1439 & 160 & 7 & 2574 & 102 \\
\hline B-n39-k5 & 549 & 521.071 & 1.993 & 1407 & 86 & 6 & - & - & - & - & - & - & - \\
\hline B-n38-k6 & 805 & 741.634 & 0.981 & 1075 & 64 & 2 & - & - & - & - & - & - & - \\
\hline B-n35-k5 & 955 & 868.083 & 0.943 & 1176 & 70 & 3 & 926.018 & 345.301 & 3414 & 382 & 14 & 2353 & 136 \\
\hline B-n34-k5 & 788 & 755.231 & 0.981 & 1209 & 72 & 5 & 773.636 & 50.205 & 2179 & 220 & 11 & 2991 & 98 \\
\hline B-n31-k5 & 672 & 661.207 & 0.393 & 774 & 44 & 2 & 666.191 & 5.652 & 1207 & 121 & 6 & 1309 & 56 \\
\hline $\mathrm{B}-\mathrm{n} 57-\mathrm{k} 7$ & 1153 & 1126.77 & 2.619 & 1881 & 99 & 4 & - & - & - & - & - & - & - \\
\hline B-n56-k7 & 707 & 635.601 & 3.687 & 1830 & 111 & 7 & - & - & - & - & - & - & - \\
\hline B-n52-k7 & 747 & 687.348 & 2.427 & 1601 & 95 & 5 & - & - & - & - & - & - & - \\
\hline $\mathrm{B}-\mathrm{n} 51-\mathrm{k} 7$ & 1032 & 964.287 & 1.581 & 1351 & 74 & 4 & - & - & - & - & - & - & - \\
\hline B-n50-k8 & 1312 & 1266.45 & 1.592 & 1188 & 70 & 4 & 1282.79 & 38.502 & 1753 & 207 & 9 & 3178 & 111 \\
\hline B-n50-k7 & 741 & 690.528 & 1.977 & 1570 & 89 & 2 & - & - & - & - & - & - & - \\
\hline $\mathrm{B}-\mathrm{n} 45-\mathrm{k} 6$ & 678 & 652.65 & 1.584 & 1043 & 65 & 4 & 666.834 & 49.616 & 1912 & 254 & 7 & 4386 & 130 \\
\hline $\mathrm{B}-\mathrm{n} 44-\mathrm{k} 7$ & 909 & 865.181 & 0.783 & 991 & 55 & 2 & 880.067 & 567.824 & 2098 & 255 & 10 & 2892 & 131 \\
\hline $\mathrm{B}-\mathrm{n} 43-\mathrm{k} 6$ & 742 & 703.674 & 1.116 & 1142 & 63 & 3 & 723.319 & 514.972 & 3149 & 353 & 15 & 3748 & 152 \\
\hline $\mathrm{B}-\mathrm{n} 78-\mathrm{k} 10$ & 1221 & 1166.73 & 5.038 & 2689 & 141 & 3 & - & - & - & - & - & - & - \\
\hline B-n68-k9 & 1272 & 1198.2 & 3.129 & 2249 & 120 & 2 & - & - & - & - & - & - & - \\
\hline
\end{tabular}


PUC-Rio - Certificação Digital № 1321837/CA

Table V.2: Continued from previous page

\begin{tabular}{|c|c|c|c|c|c|c|c|c|c|c|c|c|c|}
\hline \multirow{2}{*}{ Ins } & \multirow{2}{*}{$\mathrm{OPT}$} & \multicolumn{5}{|c|}{ without $1 \mathrm{~m}$-SRC } & \multicolumn{7}{|c|}{ with $1 \mathrm{~m}-\mathrm{SRC}$} \\
\hline & & Value & Time & Routes & Heu & Exa & Value & Time & Routes & Heu & Exa & Sep & Act \\
\hline $\mathrm{B}-\mathrm{n} 67-\mathrm{k} 10$ & 1032 & 999.204 & 2.453 & 2113 & 111 & 2 & 1028.42 & 147.802 & 3684 & 310 & 11 & 4632 & 132 \\
\hline $\mathrm{B}-\mathrm{n} 66-\mathrm{k} 9$ & 1316 & 1257.22 & 2.845 & 2077 & 111 & 4 & - & - & - & - & - & - & - \\
\hline $\mathrm{B}-\mathrm{n} 64-\mathrm{k} 9$ & 861 & 808.253 & 2.621 & 1959 & 105 & 3 & - & - & - & - & - & - & - \\
\hline B-n57-k9 & 1598 & 1571.99 & 1.676 & 1550 & 85 & 3 & 1592.7 & 51.958 & 2707 & 219 & 7 & 2768 & 123 \\
\hline $\mathrm{B}-\mathrm{n} 63-\mathrm{k} 10$ & 1496 & 1456.86 & 1.581 & 1634 & 88 & 2 & 1496 & 330.134 & 3381 & 294 & 11 & 3615 & 121 \\
\hline $\mathrm{E}-\mathrm{n} 76-\mathrm{k} 8$ & 735 & 717.819 & 4.764 & 2680 & 140 & 2 & 732.929 & 299.893 & 4775 & 408 & 9 & 4048 & 195 \\
\hline $\mathrm{E}-\mathrm{n} 76-\mathrm{k} 7$ & 682 & 664.202 & 8.066 & 3176 & 171 & 3 & - & - & - & - & - & - & - \\
\hline E-n76-k14 & 1021 & 1001.85 & 1.176 & 1288 & 67 & 2 & 1014.75 & 7.488 & 1627 & 145 & 4 & 1363 & 106 \\
\hline E-n76-k10 & 830 & 811.767 & 2.248 & 1903 & 98 & 1 & 825.787 & 27.888 & 2774 & 211 & 4 & 2535 & 160 \\
\hline E-n51-k5 & 521 & 517.135 & 1.966 & 1703 & 92 & 2 & 521 & 9.046 & 2008 & 128 & 5 & 500 & 32 \\
\hline E-n33-k4 & 835 & 820.918 & 3.147 & 1351 & 76 & 3 & 831.484 & 75.211 & 2611 & 212 & 5 & 1597 & 84 \\
\hline$E-n 30-k 3$ & 534 & 478.709 & 1.457 & 1339 & 89 & 3 & - & - & - & - & - & - & - \\
\hline$E-n 23-k 3$ & 569 & 564.413 & 5.968 & 944 & 68 & 2 & 569 & 12.716 & 977 & 87 & 2 & 706 & 8 \\
\hline$E-n 22-k 4$ & 375 & 373.875 & 0.093 & 357 & 23 & 1 & 375 & 0.112 & 361 & 25 & 1 & 86 & 3 \\
\hline E-n101-k8 & 815 & 789.372 & 16.878 & 4694 & 243 & 3 & - & - & - & - & - & - & - \\
\hline E-n101-k14 & 1067 & 1047.2 & 5.086 & 2889 & 147 & 2 & 1061.12 & 62.59 & 4028 & 291 & 6 & 3909 & 211 \\
\hline $\mathrm{E}-\mathrm{n} 31-\mathrm{k} 7$ & 379 & 378 & 0.491 & 1015 & 59 & 1 & 379 & 0.616 & 1037 & 65 & 1 & 126 & 8 \\
\hline E-n13-k4 & 247 & 247 & 0.014 & 73 & 10 & 1 & 247 & 0.014 & 73 & 10 & 1 & 0 & 0 \\
\hline $\mathrm{P}-\mathrm{n} 55-\mathrm{k} 10$ & 694 & 680.06 & 0.646 & 1023 & 55 & 1 & 689.193 & 5.283 & 1367 & 147 & 3 & 1224 & 100 \\
\hline$P-n 23-k 8$ & 529 & 529 & 0.017 & 563 & 4 & 1 & 529 & 0.016 & 563 & 4 & 1 & 0 & 0 \\
\hline $\mathrm{P}-\mathrm{n} 50-\mathrm{k} 10$ & 696 & 687.347 & 0.46 & 812 & 45 & 2 & 694.223 & 1.427 & 969 & 84 & 2 & 433 & 53 \\
\hline$P-n 45-k 5$ & 510 & 502.349 & 1.256 & 1506 & 82 & 1 & 510 & 12.781 & 2234 & 145 & 4 & 1175 & 50 \\
\hline $\mathrm{P}-\mathrm{n} 40-\mathrm{k} 5$ & 458 & 452.5 & 0.858 & 1294 & 68 & 1 & 458 & 4.629 & 1633 & 105 & 4 & 583 & 28 \\
\hline
\end{tabular}


PUC-Rio - Certificação Digital № 1321837/CA

Table V.2: Continued from previous page

\begin{tabular}{|c|c|c|c|c|c|c|c|c|c|c|c|c|c|}
\hline \multirow{2}{*}{ Ins } & \multirow{2}{*}{$\mathrm{OPT}$} & \multicolumn{5}{|c|}{ without $1 \mathrm{~m}-\mathrm{SRC}$} & \multicolumn{7}{|c|}{ with $1 \mathrm{~m}-\mathrm{SRC}$} \\
\hline & & Value & Time & Routes & Heu & Exa & Value & Time & Routes & Heu & Exa & Sep & Act \\
\hline $\mathrm{P}-\mathrm{n} 22-\mathrm{k} 8$ & 603 & 601.25 & 0.02 & 146 & 11 & 1 & 603 & 0.033 & 155 & 16 & 2 & 16 & 3 \\
\hline $\mathrm{P}-\mathrm{n} 22-\mathrm{k} 2$ & 216 & 214.5 & 0.582 & 883 & 64 & 2 & 216 & 1.367 & 1015 & 83 & 3 & 130 & 5 \\
\hline $\mathrm{P}-\mathrm{n} 21-\mathrm{k} 2$ & 211 & 210.556 & 0.367 & 670 & 52 & 1 & 211 & 0.524 & 674 & 54 & 1 & 235 & 8 \\
\hline $\mathrm{P}-\mathrm{n} 20-\mathrm{k} 2$ & 216 & 210 & 0.297 & 592 & 47 & 1 & 216 & 1.829 & 784 & 77 & 4 & 240 & 13 \\
\hline $\mathrm{P}-\mathrm{n} 19-\mathrm{k} 2$ & 212 & 209.714 & 0.275 & 405 & 39 & 3 & 212 & 1.416 & 527 & 57 & 5 & 131 & 13 \\
\hline $\mathrm{P}-\mathrm{n} 16-\mathrm{k} 8$ & 450 & 443.667 & 0.016 & 59 & 8 & 1 & 450 & 0.012 & 61 & 10 & 1 & 5 & 4 \\
\hline $\mathrm{P}-\mathrm{n} 101-\mathrm{k} 4$ & 681 & 669.044 & 112.183 & 9909 & 577 & 9 & - & - & - & - & - & - & - \\
\hline $\mathrm{P}-\mathrm{n} 76-\mathrm{k} 5$ & 627 & 614.86 & 16.071 & 4303 & 230 & 5 & - & - & - & - & - & - & - \\
\hline $\mathrm{P}-\mathrm{n} 76-\mathrm{k} 4$ & 593 & 586.502 & 27.423 & 4929 & 286 & 7 & 593 & 946.706 & 7437 & 536 & 14 & 3500 & 73 \\
\hline $\mathrm{P}-\mathrm{n} 70-\mathrm{k} 10$ & 827 & 809.29 & 1.576 & 1581 & 82 & 1 & 823.067 & 20.964 & 2358 & 196 & 4 & 2300 & 155 \\
\hline $\mathrm{P}-\mathrm{n} 65-\mathrm{k} 10$ & 792 & 783.126 & 1.291 & 1334 & 70 & 2 & 792 & 6.037 & 1741 & 112 & 3 & 1338 & 89 \\
\hline $\mathrm{P}-\mathrm{n} 60-\mathrm{k} 15$ & 968 & 959.606 & 0.34 & 784 & 40 & 1 & 967.465 & 1.099 & 898 & 75 & 2 & 504 & 55 \\
\hline $\mathrm{P}-\mathrm{n} 60-\mathrm{k} 10$ & 744 & 736.528 & 1.05 & 1123 & 61 & 3 & 743.094 & 5.182 & 1577 & 119 & 3 & 1278 & 70 \\
\hline $\mathrm{P}-\mathrm{n} 55-\mathrm{k} 7$ & 568 & 555.362 & 1.458 & 1518 & 80 & 1 & 564.192 & 45.917 & 2559 & 198 & 6 & 1929 & 118 \\
\hline $\mathrm{P}-\mathrm{n} 55-\mathrm{k} 15$ & 989 & 968.361 & 7.578 & 162367 & 6 & 1 & 984.457 & 39.951 & 162450 & 38 & 2 & 378 & 53 \\
\hline $\mathrm{P}-\mathrm{n} 51-\mathrm{k} 10$ & 741 & 732.955 & 0.385 & 830 & 43 & 1 & 740.778 & 2.039 & 1121 & 101 & 3 & 853 & 52 \\
\hline$P-n 50-k 8$ & 631 & 614.641 & 0.458 & 796 & 39 & 1 & 625.061 & 7.728 & 1249 & 125 & 4 & 1146 & 126 \\
\hline $\mathrm{P}-\mathrm{n} 50-\mathrm{k} 7$ & 554 & 545.399 & 0.882 & 1222 & 63 & 1 & 554 & 7.806 & 1638 & 110 & 4 & 1063 & 63 \\
\hline M-n151-k12 & 1015 & 995.728 & 46.326 & 7398 & 381 & 4 & 1009.65 & 5098.44 & 11653 & 927 & 18 & 13943 & 349 \\
\hline $\mathrm{M}-\mathrm{n} 121-\mathrm{k} 7$ & 1034 & 1026.37 & 62.104 & 6878 & 364 & 9 & - & - & - & - & - & - & - \\
\hline $\mathrm{M}-\mathrm{n} 101-\mathrm{k} 10$ & 820 & 818.367 & 12.802 & 4644 & 251 & 12 & 820 & 75.618 & 6196 & 427 & 19 & 7434 & 15 \\
\hline $\mathrm{M}-\mathrm{n} 200-\mathrm{k} 16$ & 1274 & 1250.23 & 134.12 & 9450 & 481 & 5 & - & - & - & - & - & - & - \\
\hline
\end{tabular}


PUC-Rio - Certificação Digital № 1321837/CA

Table V.2: Continued from previous page

\begin{tabular}{|c|c|c|c|c|c|c|c|c|c|c|c|c|c|}
\hline \multirow{2}{*}{ Ins } & \multirow{2}{*}{$\mathrm{OPT}$} & \multicolumn{5}{|c|}{ without $1 \mathrm{~m}$-SRC } & \multicolumn{7}{|c|}{ with $1 \mathrm{~m}-\mathrm{SRC}$} \\
\hline & & Value & Time & Routes & Heu & Exa & Value & Time & Routes & Heu & Exa & Sep & Act \\
\hline $\mathrm{M}-\mathrm{n} 200-\mathrm{k} 17$ & 1275 & 1252.52 & 136.099 & 9590 & 489 & 5 & - & - & - & - & - & - & - \\
\hline Average & 839.271 & 820.654 & 2.587 & 3743.686 & 78.3 & 2.357 & 833.905 & 216.298 & 4538.014 & 189.914 & 6.157 & 2226.529 & 84.957 \\
\hline
\end{tabular}


PUC-Rio - Certificação Digital № 1321837/CA

Table V.3: DSSR + CB

\begin{tabular}{|c|c|c|c|c|c|c|c|c|c|c|c|c|c|}
\hline \multirow{2}{*}{ Ins } & \multirow{2}{*}{$\mathrm{OPT}$} & \multicolumn{5}{|c|}{ without $1 \mathrm{~m}$-SRC } & \multicolumn{7}{|c|}{ with $1 \mathrm{~m}-\mathrm{SRC}$} \\
\hline & & Value & Time & Routes & $\mathrm{Heu}$ & Exa & Value & Time & Routes & $\mathrm{Heu}$ & Exa & Sep & Act \\
\hline$A-n 32-k 5$ & 784 & 770.286 & 0.848 & 999 & 60 & 3 & 784 & 16.215 & 1713 & 117 & 7 & 458 & 33 \\
\hline$A-n 33-k 5$ & 661 & 653.727 & 0.418 & 771 & 46 & 2 & 661 & 1.684 & 933 & 64 & 3 & 478 & 29 \\
\hline$A-n 33-k 6$ & 742 & 732.1 & 0.37 & 791 & 46 & 2 & 738.333 & 1.922 & 1047 & 100 & 4 & 863 & 27 \\
\hline$A-n 34-k 5$ & 778 & 746.012 & 0.484 & 885 & 48 & 1 & 767.117 & 12.114 & 1756 & 173 & 6 & 1392 & 83 \\
\hline$A-n 36-k 5$ & 799 & 776.276 & 0.844 & 1230 & 71 & 2 & 796.5 & 1999.7 & 2537 & 200 & 11 & 2644 & 84 \\
\hline$A-n 37-k 5$ & 669 & 657.811 & 1.143 & 1504 & 82 & 3 & 669 & 15.357 & 2340 & 159 & 4 & 1224 & 30 \\
\hline $\mathrm{A}-\mathrm{n} 37-\mathrm{k} 6$ & 949 & 925.407 & 0.473 & 900 & 50 & 2 & 939.488 & 8.104 & 1462 & 169 & 6 & 1528 & 60 \\
\hline $\mathrm{A}-\mathrm{n} 38-\mathrm{k} 5$ & 730 & 695.417 & 0.687 & 1027 & 57 & 3 & 726.273 & 14.442 & 1798 & 139 & 5 & 2050 & 59 \\
\hline$A-n 39-k 5$ & 822 & 799.842 & 1.071 & 1328 & 78 & 4 & 817.102 & 81.826 & 2199 & 198 & 8 & 2219 & 117 \\
\hline$A-n 39-k 6$ & 831 & 806.672 & 0.864 & 1209 & 68 & 3 & 827.473 & 216.221 & 2402 & 292 & 10 & 2694 & 128 \\
\hline$A-n 44-k 6$ & 937 & 926.641 & 0.712 & 1082 & 59 & 2 & 933.914 & 8.862 & 1516 & 165 & 5 & 1978 & 79 \\
\hline$A-n 45-k 6$ & 944 & 927.25 & 0.992 & 1276 & 71 & 2 & 944 & 7.597 & 1743 & 114 & 5 & 1000 & 46 \\
\hline $\mathrm{A}-\mathrm{n} 45-\mathrm{k} 7$ & 1146 & 1124.67 & 0.738 & 1228 & 66 & 1 & 1133.05 & 4.276 & 1556 & 141 & 3 & 1452 & 58 \\
\hline $\mathrm{A}-\mathrm{n} 46-\mathrm{k} 7$ & 914 & 904.626 & 1.105 & 1484 & 79 & 2 & 914 & 4.797 & 1814 & 106 & 5 & 495 & 39 \\
\hline $\mathrm{A}-\mathrm{n} 48-\mathrm{k} 7$ & 1073 & 1053.08 & 1.145 & 1308 & 73 & 3 & 1073 & 7.932 & 1669 & 111 & 6 & 1000 & 48 \\
\hline $\mathrm{A}-\mathrm{n} 53-\mathrm{k} 7$ & 1010 & 992.378 & 2.365 & 2151 & 119 & 3 & - & - & - & - & - & - & - \\
\hline $\mathrm{A}-\mathrm{n} 54-\mathrm{k} 7$ & 1167 & 1137.06 & 1.518 & 1522 & 82 & 3 & 1159.6 & 59.182 & 2695 & 253 & 9 & 3199 & 127 \\
\hline$A-n 55-k 9$ & 1073 & 1059.03 & 1.202 & 1366 & 72 & 3 & 1070.67 & 11.157 & 2069 & 178 & 6 & 3816 & 81 \\
\hline $\mathrm{A}-\mathrm{n} 60-\mathrm{k} 9$ & 1354 & 1323.32 & 1.738 & 1816 & 94 & 2 & 1339.03 & 31.832 & 2824 & 243 & 7 & 4288 & 139 \\
\hline $\mathrm{A}-\mathrm{n} 61-\mathrm{k} 9$ & 1034 & 1010.24 & 1.432 & 1537 & 84 & 2 & 1031.33 & 33.241 & 2439 & 244 & 8 & 3273 & 136 \\
\hline$A-n 62-k 8$ & 1288 & 1250.24 & 3.113 & 2184 & 118 & 5 & 1274.37 & 53.084 & 3322 & 307 & 9 & 6054 & 129 \\
\hline$A-n 63-k 10$ & 1314 & 1286.58 & 2.257 & 1798 & 94 & 3 & 1299.6 & 18.253 & 2676 & 201 & 6 & 3067 & 84 \\
\hline
\end{tabular}


PUC-Rio - Certificação Digital № 1321837/CA

Table V.3: Continued from previous page

\begin{tabular}{|c|c|c|c|c|c|c|c|c|c|c|c|c|c|}
\hline \multirow{2}{*}{ Ins } & \multirow{2}{*}{$\mathrm{OPT}$} & \multicolumn{5}{|c|}{ without $1 \mathrm{~m}-\mathrm{SRC}$} & \multicolumn{7}{|c|}{ with $1 \mathrm{~m}-\mathrm{SRC}$} \\
\hline & & Value & Time & Routes & Heu & Exa & Value & Time & Routes & Heu & Exa & Sep & Act \\
\hline A-n63-k9 & 1616 & 1579.13 & 1.473 & 1547 & 81 & 2 & 1602.61 & 46.1 & 2731 & 265 & 7 & 3903 & 140 \\
\hline A-n64-k9 & 1401 & 1368.24 & 2.216 & 1924 & 105 & 3 & 1391.02 & 2753.11 & 3247 & 275 & 9 & 4228 & 128 \\
\hline$A-n 65-k 9$ & 1174 & 1147.33 & 1.757 & 1784 & 94 & 2 & 1169.43 & 48.122 & 3163 & 307 & 7 & 4399 & 146 \\
\hline$A-n 69-k 9$ & 1159 & 1129.97 & 2.882 & 2190 & 118 & 3 & 1150.53 & 70.723 & 3324 & 258 & 8 & 3129 & 147 \\
\hline $\mathrm{A}-\mathrm{n} 80-\mathrm{k} 10$ & 1763 & 1729.81 & 4.944 & 2977 & 155 & 3 & 1748.09 & 714.275 & 4633 & 412 & 9 & 5872 & 176 \\
\hline$B-n 45-k 5$ & 751 & 688.901 & 2.394 & 1846 & 103 & 4 & - & - & - & - & - & - & - \\
\hline B-n41-k6 & 829 & 797.722 & 0.585 & 889 & 50 & 2 & 814.604 & 13.646 & 1439 & 160 & 7 & 2574 & 102 \\
\hline B-n39-k5 & 549 & 521.071 & 2.027 & 1407 & 86 & 6 & - & - & - & - & - & - & - \\
\hline B-n38-k6 & 805 & 741.634 & 0.924 & 1075 & 64 & 2 & - & - & - & - & - & - & - \\
\hline B-n35-k5 & 955 & 868.083 & 0.943 & 1176 & 70 & 3 & 926.018 & 345.966 & 3414 & 382 & 14 & 2353 & 136 \\
\hline B-n34-k5 & 788 & 755.231 & 0.988 & 1209 & 72 & 5 & 773.636 & 50.094 & 2179 & 220 & 11 & 2991 & 98 \\
\hline B-n31-k5 & 672 & 661.207 & 0.395 & 774 & 44 & 2 & 666.191 & 5.694 & 1207 & 121 & 6 & 1309 & 56 \\
\hline $\mathrm{B}-\mathrm{n} 57-\mathrm{k} 7$ & 1153 & 1126.77 & 2.641 & 1881 & 99 & 4 & - & - & - & - & - & - & - \\
\hline B-n56-k7 & 707 & 635.601 & 3.472 & 1830 & 111 & 7 & - & - & - & - & - & - & - \\
\hline B-n52-k7 & 747 & 687.348 & 2.379 & 1601 & 95 & 5 & - & - & - & - & - & - & - \\
\hline $\mathrm{B}-\mathrm{n} 51-\mathrm{k} 7$ & 1032 & 964.287 & 1.574 & 1351 & 74 & 4 & - & - & - & - & - & - & - \\
\hline B-n50-k8 & 1312 & 1266.45 & 1.629 & 1188 & 70 & 4 & 1282.79 & 39.079 & 1753 & 207 & 9 & 3178 & 111 \\
\hline B-n50-k7 & 741 & 690.528 & 2.067 & 1570 & 89 & 2 & - & - & - & - & - & - & - \\
\hline $\mathrm{B}-\mathrm{n} 45-\mathrm{k} 6$ & 678 & 652.65 & 1.499 & 1043 & 65 & 4 & 666.834 & 50.453 & 1912 & 254 & 7 & 4386 & 130 \\
\hline B-n44-k7 & 909 & 865.181 & 0.712 & 991 & 55 & 2 & 880.067 & 568.004 & 2098 & 255 & 10 & 2892 & 131 \\
\hline$B-n 43-k 6$ & 742 & 703.674 & 1.029 & 1142 & 63 & 3 & 723.319 & 515.07 & 3149 & 353 & 15 & 3748 & 152 \\
\hline $\mathrm{B}-\mathrm{n} 78-\mathrm{k} 10$ & 1221 & 1166.73 & 4.469 & 2689 & 141 & 3 & - & - & - & - & - & - & - \\
\hline $\mathrm{B}-\mathrm{n} 68-\mathrm{k} 9$ & 1272 & 1198.2 & 3.112 & 2249 & 120 & 2 & - & - & - & - & - & - & - \\
\hline
\end{tabular}


PUC-Rio - Certificação Digital № 1321837/CA

Table V.3: Continued from previous page

\begin{tabular}{|c|c|c|c|c|c|c|c|c|c|c|c|c|c|}
\hline \multirow{2}{*}{ Ins } & \multirow{2}{*}{$\mathrm{OPT}$} & \multicolumn{5}{|c|}{ without $1 \mathrm{~m}-\mathrm{SRC}$} & \multicolumn{7}{|c|}{ with $1 \mathrm{~m}-\mathrm{SRC}$} \\
\hline & & Value & Time & Routes & Heu & Exa & Value & Time & Routes & $\mathrm{Heu}$ & Exa & Sep & Act \\
\hline $\mathrm{B}-\mathrm{n} 67-\mathrm{k} 10$ & 1032 & 999.204 & 2.462 & 2113 & 111 & 2 & 1028.42 & 148.288 & 3526 & 319 & 12 & 6814 & 135 \\
\hline $\mathrm{B}-\mathrm{n} 66-\mathrm{k} 9$ & 1316 & 1257.22 & 3.108 & 2077 & 111 & 4 & - & - & - & - & - & - & - \\
\hline $\mathrm{B}-\mathrm{n} 64-\mathrm{k} 9$ & 861 & 808.253 & 2.762 & 1959 & 105 & 3 & - & - & - & - & - & - & - \\
\hline $\mathrm{B}-\mathrm{n} 57-\mathrm{k} 9$ & 1598 & 1571.99 & 1.688 & 1550 & 85 & 3 & 1592.7 & 51.932 & 2707 & 219 & 7 & 2768 & 123 \\
\hline $\mathrm{B}-\mathrm{n} 63-\mathrm{k} 10$ & 1496 & 1456.86 & 1.616 & 1634 & 88 & 2 & 1496 & 331.582 & 3381 & 294 & 11 & 3615 & 121 \\
\hline $\mathrm{E}-\mathrm{n} 76-\mathrm{k} 8$ & 735 & 717.819 & 4.774 & 2680 & 140 & 2 & 732.929 & 297.473 & 4775 & 408 & 9 & 4048 & 195 \\
\hline $\mathrm{E}-\mathrm{n} 76-\mathrm{k} 7$ & 682 & 664.202 & 8.118 & 3176 & 171 & 3 & - & - & - & - & - & - & - \\
\hline E-n76-k14 & 1021 & 1001.85 & 1.181 & 1288 & 67 & 2 & 1014.75 & 7.496 & 1627 & 145 & 4 & 1363 & 106 \\
\hline E-n76-k10 & 830 & 811.767 & 2.25 & 1903 & 98 & 1 & 825.787 & 28.129 & 2774 & 211 & 4 & 2535 & 160 \\
\hline $\mathrm{E}-\mathrm{n} 51-\mathrm{k} 5$ & 521 & 517.135 & 1.971 & 1703 & 92 & 2 & 521 & 9.013 & 2008 & 128 & 5 & 500 & 32 \\
\hline E-n33-k4 & 835 & 820.918 & 3.131 & 1351 & 76 & 3 & 831.484 & 74.101 & 2611 & 212 & 5 & 1597 & 84 \\
\hline$E-n 30-k 3$ & 534 & 478.709 & 1.442 & 1339 & 89 & 3 & - & - & - & - & - & - & - \\
\hline$E-n 23-k 3$ & 569 & 564.413 & 5.998 & 944 & 68 & 2 & 569 & 12.521 & 977 & 87 & 2 & 706 & 8 \\
\hline $\mathrm{E}-\mathrm{n} 22-\mathrm{k} 4$ & 375 & 373.875 & 0.093 & 357 & 23 & 1 & 375 & 0.112 & 361 & 25 & 1 & 86 & 3 \\
\hline E-n101-k8 & 815 & 789.372 & 16.902 & 4694 & 243 & 3 & - & - & - & - & - & - & - \\
\hline E-n101-k14 & 1067 & 1047.2 & 5.055 & 2889 & 147 & 2 & 1061.12 & 62.618 & 4028 & 291 & 6 & 3909 & 211 \\
\hline $\mathrm{E}-\mathrm{n} 31-\mathrm{k} 7$ & 379 & 378 & 0.488 & 1015 & 59 & 1 & 379 & 0.613 & 1037 & 65 & 1 & 126 & 8 \\
\hline $\mathrm{E}-\mathrm{n} 13-\mathrm{k} 4$ & 247 & 247 & 0.014 & 73 & 10 & 1 & 247 & 0.014 & 73 & 10 & 1 & 0 & 0 \\
\hline $\mathrm{P}-\mathrm{n} 55-\mathrm{k} 10$ & 694 & 680.06 & 0.642 & 1023 & 55 & 1 & 689.193 & 5.284 & 1367 & 147 & 3 & 1224 & 100 \\
\hline $\mathrm{P}-\mathrm{n} 23-\mathrm{k} 8$ & 529 & 529 & 0.016 & 563 & 4 & 1 & 529 & 0.018 & 563 & 4 & 1 & 0 & 0 \\
\hline $\mathrm{P}-\mathrm{n} 50-\mathrm{k} 10$ & 696 & 687.347 & 0.49 & 812 & 45 & 2 & 694.223 & 1.42 & 969 & 84 & 2 & 433 & 53 \\
\hline $\mathrm{P}-\mathrm{n} 45-\mathrm{k} 5$ & 510 & 502.349 & 1.257 & 1506 & 82 & 1 & 510 & 12.716 & 2234 & 145 & 4 & 1175 & 50 \\
\hline $\mathrm{P}-\mathrm{n} 40-\mathrm{k} 5$ & 458 & 452.5 & 0.865 & 1294 & 68 & 1 & 458 & 4.621 & 1633 & 105 & 4 & 583 & 28 \\
\hline
\end{tabular}


PUC-Rio - Certificação Digital № 1321837/CA

Table V.3: Continued from previous page

\begin{tabular}{|c|c|c|c|c|c|c|c|c|c|c|c|c|c|}
\hline \multirow{2}{*}{ Ins } & \multirow{2}{*}{$\mathrm{OPT}$} & \multicolumn{5}{|c|}{ without $1 \mathrm{~m}-\mathrm{SRC}$} & \multicolumn{7}{|c|}{ with $1 \mathrm{~m}-\mathrm{SRC}$} \\
\hline & & Value & Time & Routes & $\mathrm{Heu}$ & Exa & Value & Time & Routes & $\mathrm{Heu}$ & Exa & Sep & Act \\
\hline $\mathrm{P}-\mathrm{n} 22-\mathrm{k} 8$ & 603 & 601.25 & 0.078 & 146 & 11 & 1 & 603 & 0.033 & 155 & 16 & 2 & 16 & 3 \\
\hline $\mathrm{P}-\mathrm{n} 22-\mathrm{k} 2$ & 216 & 214.5 & 0.585 & 883 & 64 & 2 & 216 & 1.415 & 1015 & 83 & 3 & 130 & 5 \\
\hline $\mathrm{P}-\mathrm{n} 21-\mathrm{k} 2$ & 211 & 210.556 & 0.366 & 670 & 52 & 1 & 211 & 0.52 & 674 & 54 & 1 & 235 & 8 \\
\hline $\mathrm{P}-\mathrm{n} 20-\mathrm{k} 2$ & 216 & 210 & 0.295 & 592 & 47 & 1 & 216 & 1.841 & 784 & 77 & 4 & 240 & 13 \\
\hline $\mathrm{P}-\mathrm{n} 19-\mathrm{k} 2$ & 212 & 209.714 & 0.276 & 405 & 39 & 3 & 212 & 1.413 & 527 & 57 & 5 & 131 & 13 \\
\hline $\mathrm{P}-\mathrm{n} 16-\mathrm{k} 8$ & 450 & 443.667 & 0.009 & 59 & 8 & 1 & 450 & 0.012 & 61 & 10 & 1 & 5 & 4 \\
\hline $\mathrm{P}-\mathrm{n} 101-\mathrm{k} 4$ & 681 & 669.044 & 112.751 & 9909 & 577 & 9 & - & - & - & - & - & - & - \\
\hline $\mathrm{P}-\mathrm{n} 76-\mathrm{k} 5$ & 627 & 614.86 & 16.081 & 4303 & 230 & 5 & - & - & - & - & - & - & - \\
\hline $\mathrm{P}-\mathrm{n} 76-\mathrm{k} 4$ & 593 & 586.502 & 27.378 & 4929 & 286 & 7 & 593 & 948.867 & 7437 & 536 & 14 & 3500 & 73 \\
\hline $\mathrm{P}-\mathrm{n} 70-\mathrm{k} 10$ & 827 & 809.29 & 1.531 & 1581 & 82 & 1 & 823.067 & 20.875 & 2358 & 196 & 4 & 2300 & 155 \\
\hline $\mathrm{P}-\mathrm{n} 65-\mathrm{k} 10$ & 792 & 783.126 & 1.315 & 1334 & 70 & 2 & 792 & 5.993 & 1741 & 112 & 3 & 1338 & 89 \\
\hline $\mathrm{P}-\mathrm{n} 60-\mathrm{k} 15$ & 968 & 959.606 & 0.34 & 784 & 40 & 1 & 967.465 & 1.169 & 898 & 75 & 2 & 504 & 55 \\
\hline $\mathrm{P}-\mathrm{n} 60-\mathrm{k} 10$ & 744 & 736.528 & 1.051 & 1123 & 61 & 3 & 743.094 & 5.274 & 1577 & 119 & 3 & 1278 & 70 \\
\hline $\mathrm{P}-\mathrm{n} 55-\mathrm{k} 7$ & 568 & 555.362 & 1.513 & 1518 & 80 & 1 & 564.192 & 45.879 & 2559 & 198 & 6 & 1929 & 118 \\
\hline $\mathrm{P}-\mathrm{n} 55-\mathrm{k} 15$ & 989 & 968.361 & 7.48 & 162367 & 6 & 1 & 984.457 & 40.139 & 162450 & 38 & 2 & 378 & 53 \\
\hline $\mathrm{P}-\mathrm{n} 51-\mathrm{k} 10$ & 741 & 732.955 & 0.382 & 830 & 43 & 1 & 740.778 & 1.989 & 1121 & 101 & 3 & 853 & 52 \\
\hline $\mathrm{P}-\mathrm{n} 50-\mathrm{k} 8$ & 631 & 614.641 & 0.457 & 796 & 39 & 1 & 625.061 & 7.711 & 1249 & 125 & 4 & 1146 & 126 \\
\hline $\mathrm{P}-\mathrm{n} 50-\mathrm{k} 7$ & 554 & 545.399 & 0.881 & 1222 & 63 & 1 & 554 & 7.828 & 1638 & 110 & 4 & 1063 & 63 \\
\hline $\mathrm{M}-\mathrm{n} 151-\mathrm{k} 12$ & 1015 & 995.728 & 46.381 & 7398 & 381 & 4 & 1009.65 & 5094.99 & 11653 & 927 & 18 & 13943 & 349 \\
\hline $\mathrm{M}-\mathrm{n} 121-\mathrm{k} 7$ & 1034 & 1026.37 & 61.983 & 6878 & 364 & 9 & - & - & - & - & - & - & - \\
\hline $\mathrm{M}-\mathrm{n} 101-\mathrm{k} 10$ & 820 & 818.367 & 12.905 & 4644 & 251 & 12 & 820 & 75.75 & 6196 & 427 & 19 & 7434 & 15 \\
\hline $\mathrm{M}-\mathrm{n} 200-\mathrm{k} 16$ & 1274 & 1250.23 & 133.6 & 9450 & 481 & 5 & - & - & - & - & - & - & - \\
\hline
\end{tabular}


PUC-Rio - Certificação Digital № 1321837/CA

Table V.3: Continued from previous page

\begin{tabular}{|c|c|c|c|c|c|c|c|c|c|c|c|c|c|}
\hline \multirow{2}{*}{ Ins } & \multirow{2}{*}{$\mathrm{OPT}$} & \multicolumn{5}{|c|}{ without $1 \mathrm{~m}-\mathrm{SRC}$} & \multicolumn{7}{|c|}{ with $1 \mathrm{~m}$-SRC } \\
\hline & & Value & Time & Routes & Heu & Exa & Value & Time & Routes & Heu & Exa & Sep & Act \\
\hline M-n200-k17 & 1275 & 1252.52 & 134.934 & 9590 & 489 & 5 & - & - & - & - & - & - & - \\
\hline Average & 839.271 & 820.654 & 2.592 & 3743.686 & 78.3 & 2.357 & 833.905 & 216.254 & 4535.757 & 190.043 & 6.171 & 2257.7 & 85 \\
\hline
\end{tabular}


PUC-Rio - Certificação Digital № 1321837/CA

Table V.4: Capacity Cuts

\begin{tabular}{|c|c|c|c|c|c|c|c|c|c|c|c|c|c|}
\hline \multirow{2}{*}{ Ins } & \multirow{2}{*}{$\mathrm{OPT}$} & \multicolumn{5}{|c|}{ without Im-SRC } & \multicolumn{7}{|c|}{ with $1 \mathrm{~m}$-SRC } \\
\hline & & Value & Time & Routes & Heu & Exa & Value & Time & Routes & $\mathrm{Heu}$ & Exa & Sep & Act \\
\hline A-n32-k5 & 784 & 784 & 1.536 & 1185 & 87 & 3 & 784 & 1.428 & 1185 & 87 & 3 & 0 & 0 \\
\hline A-n33-k5 & 661 & 661 & 0.555 & 823 & 56 & 2 & 661 & 0.668 & 823 & 57 & 2 & 78 & 1 \\
\hline A-n33-k6 & 742 & 740.25 & 0.971 & 904 & 68 & 3 & 742 & 1.065 & 916 & 72 & 3 & 27 & 5 \\
\hline$A-n 34-k 5$ & 778 & 774.429 & 1.244 & 1111 & 80 & 2 & 778 & 2.396 & 1205 & 98 & 3 & 101 & 14 \\
\hline A-n36-k5 & 799 & 798.322 & 2.728 & 1515 & 109 & 3 & 799 & 3.159 & 1520 & 113 & 3 & 323 & 8 \\
\hline$A-n 37-k 5$ & 669 & 666.625 & 2.299 & 1659 & 107 & 2 & 669 & 5.185 & 1915 & 135 & 3 & 89 & 10 \\
\hline $\mathrm{A}-\mathrm{n} 37-\mathrm{k} 6$ & 949 & 937.027 & 1.03 & 942 & 65 & 3 & 945.577 & 9.546 & 1404 & 170 & 4 & 1077 & 58 \\
\hline A-n38-k5 & 730 & 723.4 & 2.078 & 1286 & 97 & 2 & 728.8 & 9.118 & 1544 & 153 & 6 & 665 & 54 \\
\hline A-n39-k5 & 822 & 817.524 & 4.207 & 1631 & 123 & 3 & 822 & 46.575 & 2432 & 230 & 5 & 1362 & 54 \\
\hline $\mathrm{A}-\mathrm{n} 39-\mathrm{k} 6$ & 831 & 824.38 & 1.988 & 1365 & 98 & 2 & 831 & 13.268 & 1824 & 152 & 5 & 542 & 46 \\
\hline $\mathrm{A}-\mathrm{n} 44-\mathrm{k} 6$ & 937 & 934.9 & 1.991 & 1258 & 92 & 2 & 937 & 2.331 & 1269 & 96 & 2 & 155 & 5 \\
\hline $\mathrm{A}-\mathrm{n} 45-\mathrm{k} 6$ & 944 & 941.226 & 2.972 & 1548 & 112 & 4 & 944 & 8.115 & 1722 & 128 & 6 & 676 & 41 \\
\hline $\mathrm{A}-\mathrm{n} 45-\mathrm{k} 7$ & 1146 & 1140.53 & 3.757 & 1515 & 122 & 2 & 1146 & 10.719 & 1769 & 156 & 5 & 660 & 56 \\
\hline $\mathrm{A}-\mathrm{n} 46-\mathrm{k} 7$ & 914 & 914 & 2.33 & 1733 & 112 & 3 & 914 & 2.494 & 1762 & 115 & 2 & 138 & 1 \\
\hline $\mathrm{A}-\mathrm{n} 48-\mathrm{k} 7$ & 1073 & 1071.54 & 2.981 & 1504 & 114 & 3 & 1073 & 10.765 & 1883 & 154 & 7 & 422 & 32 \\
\hline$A-n 53-k 7$ & 1010 & 1003.63 & 10.092 & 2615 & 206 & 2 & 1010 & 160.185 & 3196 & 301 & 8 & 2128 & 70 \\
\hline $\mathrm{A}-\mathrm{n} 54-\mathrm{k} 7$ & 1167 & 1155.15 & 7.267 & 1986 & 148 & 4 & 1166.36 & 130.96 & 3173 & 338 & 9 & 2801 & 153 \\
\hline A-n55-k9 & 1073 & 1068.47 & 3.592 & 1683 & 116 & 3 & 1071.8 & 10.344 & 1988 & 173 & 3 & 1224 & 32 \\
\hline $\mathrm{A}-\mathrm{n} 60-\mathrm{k} 9$ & 1354 & 1344.96 & 6.223 & 2167 & 144 & 2 & 1352.02 & 40.567 & 2865 & 237 & 5 & 2003 & 123 \\
\hline $\mathrm{A}-\mathrm{n} 61-\mathrm{k} 9$ & 1034 & 1023.58 & 5.091 & 1745 & 126 & 3 & 1032 & 31.269 & 2242 & 220 & 6 & 1475 & 78 \\
\hline $\mathrm{A}-\mathrm{n} 62-\mathrm{k} 8$ & 1288 & 1280.75 & 10.769 & 2622 & 179 & 4 & 1286.07 & 98.741 & 3433 & 346 & 10 & 4832 & 94 \\
\hline$A-n 63-k 10$ & 1314 & 1302.42 & 5.007 & 2073 & 133 & 5 & 1309.66 & 24.298 & 2665 & 216 & 5 & 1862 & 73 \\
\hline
\end{tabular}


PUC-Rio - Certificação Digital № 1321837/CA

Table V.4: Continued from previous page

\begin{tabular}{|c|c|c|c|c|c|c|c|c|c|c|c|c|c|}
\hline \multirow{2}{*}{ Ins } & \multirow{2}{*}{$\mathrm{OPT}$} & \multicolumn{5}{|c|}{ without $1 \mathrm{~m}$-SRC } & \multicolumn{7}{|c|}{ with $1 \mathrm{~m}$-SRC } \\
\hline & & Value & Time & Routes & Heu & Exa & Value & Time & Routes & Heu & Exa & Sep & Act \\
\hline A-n63-k9 & 1616 & 1608.54 & 9.112 & 2023 & 156 & 1 & 1616 & 44.395 & 2831 & 244 & 5 & 1482 & 65 \\
\hline A-n64-k9 & 1401 & 1387.16 & 5.764 & 2275 & 149 & 3 & 1395.86 & 124.498 & 3208 & 328 & 9 & 3491 & 125 \\
\hline $\mathrm{A}-\mathrm{n} 65-\mathrm{k} 9$ & 1174 & 1166.56 & 7.007 & 2090 & 151 & 1 & 1174 & 35.977 & 2775 & 219 & 8 & 854 & 67 \\
\hline A-n69-k9 & 1159 & 1143.18 & 9.42 & 2463 & 165 & 2 & 1157.18 & 62.64 & 3370 & 276 & 5 & 2654 & 115 \\
\hline $\mathrm{A}-\mathrm{n} 80-\mathrm{k} 10$ & 1763 & 1755.82 & 15.563 & 3434 & 215 & 4 & 1761.55 & 177.429 & 4614 & 396 & 9 & 3241 & 128 \\
\hline $\mathrm{B}-\mathrm{n} 45-\mathrm{k} 5$ & 751 & 750.6 & 6.196 & 2566 & 173 & 6 & 751 & 7.888 & 2658 & 186 & 5 & 281 & 8 \\
\hline $\mathrm{B}-\mathrm{n} 41-\mathrm{k} 6$ & 829 & 828.429 & 1.93 & 1246 & 98 & 3 & 829 & 2.46 & 1268 & 101 & 3 & 104 & 6 \\
\hline B-n39-k5 & 549 & 549 & 3.259 & 1862 & 133 & 4 & 549 & 3.249 & 1862 & 133 & 4 & 0 & 0 \\
\hline $\mathrm{B}-\mathrm{n} 38-\mathrm{k} 6$ & 805 & 804.143 & 1.82 & 1383 & 104 & 3 & 805 & 2.418 & 1401 & 111 & 3 & 150 & 10 \\
\hline B-n35-k5 & 955 & 955 & 1.675 & 1713 & 109 & 2 & 955 & 1.724 & 1713 & 109 & 2 & 0 & 0 \\
\hline B-n34-k5 & 788 & 784.926 & 3.658 & 1897 & 148 & 2 & 788 & 13.108 & 2255 & 184 & 5 & 539 & 41 \\
\hline $\mathrm{B}-\mathrm{n} 31-\mathrm{k} 5$ & 672 & 672 & 0.609 & 997 & 59 & 2 & 672 & 0.624 & 997 & 59 & 2 & 0 & 0 \\
\hline $\mathrm{B}-\mathrm{n} 57-\mathrm{k} 7$ & 1153 & 1153 & 5.504 & 2352 & 148 & 4 & 1153 & 5.72 & 2352 & 148 & 4 & 0 & 0 \\
\hline $\mathrm{B}-\mathrm{n} 56-\mathrm{k} 7$ & 707 & 705 & 6.278 & 2512 & 172 & 5 & 705 & 7.874 & 2548 & 181 & 5 & 483 & 4 \\
\hline B-n52-k7 & 747 & 746.333 & 6.075 & 2384 & 162 & 3 & 747 & 7.942 & 2447 & 169 & 3 & 738 & 10 \\
\hline $\mathrm{B}-\mathrm{n} 51-\mathrm{k} 7$ & 1032 & 1026.83 & 6.75 & 2253 & 158 & 2 & 1032 & 535.377 & 2886 & 237 & 10 & 2438 & 82 \\
\hline B-n50-k8 & 1312 & 1303.39 & 4.563 & 1602 & 118 & 2 & 1309.35 & 42.724 & 2123 & 294 & 7 & 3259 & 68 \\
\hline B-n50-k7 & 741 & 741 & 4.917 & 2328 & 158 & 4 & 741 & 6.047 & 2368 & 164 & 4 & 619 & 3 \\
\hline $\mathrm{B}-\mathrm{n} 45-\mathrm{k} 6$ & 678 & 677.973 & 2.684 & 1515 & 113 & 2 & 678 & 5.585 & 1619 & 127 & 3 & 500 & 22 \\
\hline $\mathrm{B}-\mathrm{n} 44-\mathrm{k} 7$ & 909 & 909 & 1.963 & 1420 & 94 & 3 & 909 & 1.95 & 1420 & 94 & 3 & 0 & 0 \\
\hline $\mathrm{B}-\mathrm{n} 43-\mathrm{k} 6$ & 742 & 736.825 & 2.601 & 1505 & 102 & 2 & 740.091 & 32.751 & 1978 & 219 & 5 & 2365 & 93 \\
\hline $\mathrm{B}-\mathrm{n} 78-\mathrm{k} 10$ & 1221 & 1216.39 & 12.419 & 3348 & 209 & 2 & 1221 & 41.201 & 3803 & 264 & 7 & 2021 & 56 \\
\hline B-n68-k9 & 1272 & 1263.7 & 12.939 & 3006 & 202 & 3 & 1267.79 & 1060.51 & 4070 & 424 & 11 & 4180 & 140 \\
\hline
\end{tabular}


PUC-Rio - Certificação Digital № 1321837/CA

Table V.4: Continued from previous page

\begin{tabular}{|c|c|c|c|c|c|c|c|c|c|c|c|c|c|}
\hline \multirow{2}{*}{ Ins } & \multirow{2}{*}{$\mathrm{OPT}$} & \multicolumn{5}{|c|}{ without $1 \mathrm{~m}-\mathrm{SRC}$} & \multicolumn{7}{|c|}{ with $1 \mathrm{~m}-\mathrm{SRC}$} \\
\hline & & Value & Time & Routes & $\mathrm{Heu}$ & Exa & Value & Time & Routes & Heu & Exa & Sep & Act \\
\hline $\mathrm{B}-\mathrm{n} 67-\mathrm{k} 10$ & 1032 & 1027.56 & 7.744 & 2634 & 179 & 4 & 1030.85 & 125.411 & 3416 & 333 & 10 & 3062 & 107 \\
\hline $\mathrm{B}-\mathrm{n} 66-\mathrm{k} 9$ & 1316 & 1307.84 & 9.36 & 2769 & 183 & 2 & 1315.24 & 237.342 & 3788 & 378 & 10 & 3548 & 149 \\
\hline $\mathrm{B}-\mathrm{n} 64-\mathrm{k} 9$ & 861 & 860.417 & 7.706 & 2779 & 176 & 3 & 861 & 9.044 & 2839 & 184 & 3 & 152 & 10 \\
\hline $\mathrm{B}-\mathrm{n} 57-\mathrm{k} 9$ & 1598 & 1596 & 5.47 & 2061 & 150 & 4 & 1598 & 25.824 & 2405 & 218 & 7 & 2508 & 67 \\
\hline $\mathrm{B}-\mathrm{n} 63-\mathrm{k} 10$ & 1496 & 1487.07 & 6.154 & 2166 & 150 & 3 & 1496 & 57.377 & 3241 & 262 & 8 & 1487 & 89 \\
\hline E-n76-k8 & 735 & 725.19 & 21.273 & 3307 & 233 & 2 & 734.091 & 469.267 & 5330 & 506 & 9 & 4543 & 187 \\
\hline $\mathrm{E}-\mathrm{n} 76-\mathrm{k} 7$ & 682 & 669.015 & 11.097 & 3317 & 193 & 2 & - & - & - & - & - & - & - \\
\hline E-n76-k14 & 1021 & 1006.94 & 1.812 & 1362 & 79 & 2 & 1014.75 & 8.906 & 1662 & 148 & 3 & 1357 & 109 \\
\hline E-n76-k10 & 830 & 816.627 & 5.125 & 2040 & 130 & 2 & 826.44 & 46.967 & 2844 & 232 & 5 & 2469 & 156 \\
\hline $\mathrm{E}-\mathrm{n} 51-\mathrm{k} 5$ & 521 & 518.357 & 4.529 & 1874 & 128 & 3 & 521 & 13.683 & 2202 & 160 & 4 & 500 & 37 \\
\hline E-n33-k4 & 835 & 835 & 4.343 & 1507 & 96 & 3 & 835 & 4.418 & 1507 & 96 & 3 & 0 & 0 \\
\hline$E-n 30-k 3$ & 534 & 518.1 & 3.572 & 1779 & 138 & 3 & - & - & - & - & - & - & - \\
\hline$E-n 23-k 3$ & 569 & 569 & 9.122 & 1023 & 91 & 3 & 569 & 9.195 & 1023 & 91 & 3 & 0 & 0 \\
\hline $\mathrm{E}-\mathrm{n} 22-\mathrm{k} 4$ & 375 & 375 & 0.112 & 363 & 27 & 1 & 375 & 0.112 & 363 & 27 & 1 & 0 & 0 \\
\hline $\mathrm{E}-\mathrm{n} 101-\mathrm{k} 8$ & 815 & 802.626 & 61.075 & 5594 & 364 & 4 & - & - & - & - & - & - & - \\
\hline E-n101-k14 & 1067 & 1053.52 & 8.969 & 3097 & 184 & 2 & 1063.29 & 87.762 & 4115 & 334 & 6 & 2739 & 193 \\
\hline $\mathrm{E}-\mathrm{n} 31-\mathrm{k} 7$ & 379 & 378.333 & 0.795 & 1030 & 62 & 1 & 379 & 0.675 & 1054 & 70 & 1 & 46 & 5 \\
\hline E-n13-k4 & 247 & 247 & 0.021 & 73 & 10 & 1 & 247 & 0.014 & 73 & 10 & 1 & 0 & 0 \\
\hline P-n55-k10 & 694 & 681.754 & 1.086 & 1051 & 67 & 1 & 689.202 & 7.701 & 1330 & 144 & 4 & 1003 & 86 \\
\hline $\mathrm{P}-\mathrm{n} 23-\mathrm{k} 8$ & 529 & 529 & 0.017 & 563 & 4 & 1 & 529 & 0.017 & 563 & 4 & 1 & 0 & 0 \\
\hline P-n50-k10 & 696 & 689.362 & 0.594 & 850 & 52 & 1 & 694.907 & 1.741 & 992 & 80 & 2 & 272 & 47 \\
\hline$P-n 45-k 5$ & 510 & 505.944 & 2.67 & 1628 & 110 & 1 & 510 & 16.43 & 2168 & 174 & 3 & 952 & 57 \\
\hline $\mathrm{P}-\mathrm{n} 40-\mathrm{k} 5$ & 458 & 456.875 & 1.699 & 1395 & 87 & 1 & 458 & 5.474 & 1697 & 117 & 3 & 201 & 17 \\
\hline
\end{tabular}


PUC-Rio - Certificação Digital № 1321837/CA

Table V.4: Continued from previous page

\begin{tabular}{|c|c|c|c|c|c|c|c|c|c|c|c|c|c|}
\hline \multirow{2}{*}{ Ins } & \multirow{2}{*}{$\mathrm{OPT}$} & \multicolumn{5}{|c|}{ without $1 \mathrm{~m}-\mathrm{SRC}$} & \multicolumn{7}{|c|}{ with $1 \mathrm{~m}$-SRC } \\
\hline & & Value & Time & Routes & Heu & Exa & Value & Time & Routes & Heu & Exa & Sep & Act \\
\hline $\mathrm{P}-\mathrm{n} 22-\mathrm{k} 8$ & 603 & 603 & 0.034 & 147 & 14 & 1 & 603 & 0.028 & 147 & 14 & 1 & 0 & 0 \\
\hline $\mathrm{P}-\mathrm{n} 22-\mathrm{k} 2$ & 216 & 215.5 & 0.77 & 884 & 68 & 2 & 216 & 1.157 & 971 & 80 & 1 & 60 & 3 \\
\hline $\mathrm{P}-\mathrm{n} 21-\mathrm{k} 2$ & 211 & 211 & 0.464 & 672 & 54 & 1 & 211 & 0.477 & 672 & 54 & 1 & 0 & 0 \\
\hline $\mathrm{P}-\mathrm{n} 20-\mathrm{k} 2$ & 216 & 213 & 0.526 & 650 & 60 & 2 & 216 & 1.264 & 719 & 83 & 2 & 198 & 9 \\
\hline P-n19-k2 & 212 & 212 & 0.369 & 443 & 44 & 2 & 212 & 0.36 & 443 & 44 & 2 & 0 & 0 \\
\hline P-n16-k8 & 450 & 448 & 0.033 & 64 & 12 & 1 & 450 & 0.024 & 64 & 14 & 1 & 1 & 1 \\
\hline $\mathrm{P}-\mathrm{n} 101-\mathrm{k} 4$ & 681 & 676.428 & 392.77 & 12593 & 854 & 17 & - & - & - & - & - & - & - \\
\hline $\mathrm{P}-\mathrm{n} 76-\mathrm{k} 5$ & 627 & 615.748 & 37.079 & 4666 & 308 & 4 & - & - & - & - & - & - & - \\
\hline $\mathrm{P}-\mathrm{n} 76-\mathrm{k} 4$ & 593 & 587.459 & 62.493 & 5560 & 409 & 4 & 593 & 1533.34 & 8953 & 771 & 13 & 3500 & 76 \\
\hline $\mathrm{P}-\mathrm{n} 70-\mathrm{k} 10$ & 827 & 813.335 & 2.631 & 1695 & 103 & 1 & 823.157 & 31.852 & 2353 & 222 & 4 & 2077 & 155 \\
\hline $\mathrm{P}-\mathrm{n} 65-\mathrm{k} 10$ & 792 & 786.858 & 2.14 & 1432 & 90 & 2 & 792 & 5.785 & 1685 & 111 & 3 & 696 & 54 \\
\hline $\mathrm{P}-\mathrm{n} 60-\mathrm{k} 15$ & 968 & 963.469 & 0.57 & 827 & 55 & 1 & 967.717 & 2.181 & 928 & 94 & 2 & 338 & 54 \\
\hline $\mathrm{P}-\mathrm{n} 60-\mathrm{k} 10$ & 744 & 738.864 & 1.039 & 1188 & 68 & 1 & 743.513 & 6.475 & 1521 & 125 & 3 & 1013 & 73 \\
\hline $\mathrm{P}-\mathrm{n} 55-\mathrm{k} 7$ & 568 & 558.912 & 2.467 & 1605 & 96 & 2 & 565.667 & 88.576 & 2597 & 216 & 6 & 1833 & 108 \\
\hline $\mathrm{P}-\mathrm{n} 55-\mathrm{k} 15$ & 989 & 972.543 & 29.417 & 162386 & 18 & 2 & 984.614 & 210.101 & 162464 & 82 & 3 & 379 & 55 \\
\hline $\mathrm{P}-\mathrm{n} 51-\mathrm{k} 10$ & 741 & 736.075 & 0.872 & 899 & 63 & 2 & 741 & 2.474 & 1042 & 86 & 3 & 357 & 43 \\
\hline P-n50-k8 & 631 & 616.66 & 0.723 & 851 & 52 & 1 & 625.753 & 10.61 & 1249 & 145 & 4 & 933 & 111 \\
\hline P-n50-k7 & 554 & 550.651 & 2.698 & 1431 & 96 & 2 & 554 & 6.103 & 1720 & 120 & 2 & 351 & 31 \\
\hline $\mathrm{M}-\mathrm{n} 151-\mathrm{k} 12$ & 1015 & 998.665 & 73.574 & 7685 & 436 & 4 & 1012.1 & 4563.55 & 11909 & 968 & 19 & 9849 & 324 \\
\hline $\mathrm{M}-\mathrm{n} 121-\mathrm{k} 7$ & 1034 & 1032.43 & 148.464 & 8962 & 543 & 11 & 1033.6 & 1544.63 & 10699 & 790 & 16 & 5993 & 42 \\
\hline $\mathrm{M}-\mathrm{n} 101-\mathrm{k} 10$ & 820 & 820 & 20.81 & 5340 & 349 & 9 & 820 & 29.92 & 5721 & 378 & 11 & 1470 & 3 \\
\hline $\mathrm{M}-\mathrm{n} 200-\mathrm{k} 16$ & 1274 & 1251.35 & 161.984 & 9784 & 528 & 5 & - & - & - & - & - & - & - \\
\hline
\end{tabular}


PUC-Rio - Certificação Digital № 1321837/CA

Table V.4: Continued from previous page

\begin{tabular}{|c|c|c|c|c|c|c|c|c|c|c|c|c|c|}
\hline \multirow{2}{*}{ Ins } & \multirow{2}{*}{$\mathrm{OPT}$} & \multicolumn{5}{|c|}{ without $1 \mathrm{~m}$-SRC } & \multicolumn{7}{|c|}{ with $1 \mathrm{~m}$-SRC } \\
\hline & & Value & Time & Routes & Heu & Exa & Value & Time & Routes & $\mathrm{Heu}$ & Exa & Sep & Act \\
\hline $\mathrm{M}-\mathrm{n} 200-\mathrm{k} 17$ & 1275 & 1254.15 & 170.64 & 9854 & 540 & 4 & - & - & - & - & - & - & - \\
\hline Average & 856.524 & 851.644 & 7.882 & 3801.631 & 126.405 & 2.607 & 855.595 & 143.019 & 4259.167 & 194.988 & 4.893 & 1261.024 & 53.679 \\
\hline
\end{tabular}


PUC-Rio - Certificação Digital № 1321837/CA

Table V.5: DSSR + CB + CC

\begin{tabular}{|c|c|c|c|c|c|c|c|c|c|c|c|c|c|}
\hline \multirow{2}{*}{ Ins } & \multirow{2}{*}{$\mathrm{OPT}$} & \multicolumn{5}{|c|}{ without $1 \mathrm{~m}-\mathrm{SRC}$} & \multicolumn{7}{|c|}{ with $1 \mathrm{~m}-\mathrm{SRC}$} \\
\hline & & Value & Time & Routes & $\mathrm{Heu}$ & Exa & Value & Time & Routes & Heu & Exa & Sep & Act \\
\hline$A-n 32-k 5$ & 784 & 784 & 1.234 & 1180 & 84 & 1 & 784 & 1.257 & 1180 & 84 & 1 & 0 & 0 \\
\hline$A-n 33-k 5$ & 661 & 661 & 0.524 & 822 & 55 & 1 & 661 & 0.614 & 822 & 56 & 1 & 78 & 0 \\
\hline$A-n 33-k 6$ & 742 & 740.25 & 0.964 & 903 & 68 & 3 & 742 & 1.08 & 916 & 72 & 3 & 27 & 5 \\
\hline$A-n 34-k 5$ & 778 & 774.429 & 1.309 & 1111 & 80 & 2 & 778 & 2.423 & 1205 & 98 & 3 & 101 & 14 \\
\hline$A-n 36-k 5$ & 799 & 798.322 & 2.637 & 1513 & 109 & 3 & 799 & 3.54 & 1520 & 114 & 4 & 323 & 5 \\
\hline $\mathrm{A}-\mathrm{n} 37-\mathrm{k} 5$ & 669 & 666.625 & 2.413 & 1659 & 107 & 2 & 669 & 5.327 & 1916 & 136 & 3 & 89 & 11 \\
\hline $\mathrm{A}-\mathrm{n} 37-\mathrm{k} 6$ & 949 & 937.027 & 0.891 & 941 & 65 & 3 & 945.582 & 10.332 & 1401 & 171 & 5 & 1077 & 57 \\
\hline $\mathrm{A}-\mathrm{n} 38-\mathrm{k} 5$ & 730 & 723.4 & 2.041 & 1284 & 97 & 2 & 728.8 & 9.654 & 1529 & 153 & 6 & 636 & 55 \\
\hline$A-n 39-k 5$ & 822 & 817.524 & 3.91 & 1631 & 123 & 3 & 822 & 76.514 & 2412 & 228 & 6 & 1362 & 61 \\
\hline$A-n 39-k 6$ & 831 & 824.395 & 2.082 & 1363 & 96 & 1 & 831 & 27.136 & 1820 & 154 & 7 & 542 & 47 \\
\hline $\mathrm{A}-\mathrm{n} 44-\mathrm{k} 6$ & 937 & 934.9 & 2.085 & 1258 & 92 & 2 & 937 & 2.446 & 1269 & 96 & 2 & 155 & 5 \\
\hline$A-n 45-k 6$ & 944 & 941.238 & 2.992 & 1551 & 110 & 3 & 944 & 7.243 & 1705 & 123 & 3 & 676 & 47 \\
\hline $\mathrm{A}-\mathrm{n} 45-\mathrm{k} 7$ & 1146 & 1140.53 & 4.692 & 1515 & 123 & 2 & 1146 & 10.894 & 1758 & 152 & 3 & 660 & 53 \\
\hline $\mathrm{A}-\mathrm{n} 46-\mathrm{k} 7$ & 914 & 914 & 2.782 & 1747 & 114 & 2 & 914 & 2.955 & 1762 & 115 & 2 & 138 & 1 \\
\hline $\mathrm{A}-\mathrm{n} 48-\mathrm{k} 7$ & 1073 & 1071.54 & 3.636 & 1504 & 114 & 3 & 1073 & 11.487 & 1874 & 148 & 5 & 422 & 37 \\
\hline $\mathrm{A}-\mathrm{n} 53-\mathrm{k} 7$ & 1010 & 1003.63 & 12.283 & 2613 & 206 & 2 & 1010 & 244.663 & 3178 & 294 & 8 & 1899 & 69 \\
\hline $\mathrm{A}-\mathrm{n} 54-\mathrm{k} 7$ & 1167 & 1155.17 & 7.223 & 1976 & 148 & 3 & 1166.38 & 196.794 & 3187 & 330 & 8 & 2867 & 150 \\
\hline$A-n 55-k 9$ & 1073 & 1068.47 & 3.322 & 1682 & 116 & 3 & 1071.8 & 10.571 & 1987 & 168 & 5 & 1168 & 43 \\
\hline $\mathrm{A}-\mathrm{n} 60-\mathrm{k} 9$ & 1354 & 1344.96 & 5.334 & 2164 & 142 & 1 & 1352.04 & 61.802 & 2879 & 252 & 7 & 2164 & 121 \\
\hline $\mathrm{A}-\mathrm{n} 61-\mathrm{k} 9$ & 1034 & 1023.58 & 4.642 & 1743 & 127 & 2 & 1032 & 41.279 & 2296 & 257 & 7 & 1706 & 79 \\
\hline$A-n 62-k 8$ & 1288 & 1280.75 & 9.813 & 2626 & 179 & 3 & 1286.07 & 123.024 & 3394 & 323 & 9 & 3846 & 93 \\
\hline$A-n 63-k 10$ & 1314 & 1302.43 & 4.058 & 2066 & 128 & 2 & 1309.67 & 25.685 & 2670 & 221 & 5 & 1953 & 74 \\
\hline
\end{tabular}


PUC-Rio - Certificação Digital № 1321837/CA

Table V.5: Continued from previous page

\begin{tabular}{|c|c|c|c|c|c|c|c|c|c|c|c|c|c|}
\hline \multirow{2}{*}{ Ins } & \multirow{2}{*}{$\mathrm{OPT}$} & \multicolumn{5}{|c|}{ without $1 \mathrm{~m}$-SRC } & \multicolumn{7}{|c|}{ with $1 \mathrm{~m}$-SRC } \\
\hline & & Value & Time & Routes & $\mathrm{Heu}$ & Exa & Value & Time & Routes & Heu & Exa & Sep & Act \\
\hline A-n63-k9 & 1616 & 1608.54 & 8.875 & 2023 & 156 & 1 & 1616 & 42.104 & 2833 & 248 & 5 & 1482 & 70 \\
\hline$A-n 64-k 9$ & 1401 & 1388.08 & 6.168 & 2274 & 153 & 3 & 1395.86 & 1098.3 & 3173 & 329 & 7 & 3356 & 134 \\
\hline$A-n 65-k 9$ & 1174 & 1166.56 & 6.657 & 2090 & 151 & 1 & 1174 & 30.899 & 2776 & 218 & 5 & 854 & 65 \\
\hline$A-n 69-k 9$ & 1159 & 1143.3 & 7.007 & 2459 & 165 & 2 & 1157.18 & 76.585 & 3353 & 278 & 4 & 2545 & 113 \\
\hline $\mathrm{A}-\mathrm{n} 80-\mathrm{k} 10$ & 1763 & 1755.83 & 15.552 & 3426 & 217 & 4 & 1761.58 & 862.729 & 4580 & 395 & 7 & 2970 & 124 \\
\hline $\mathrm{B}-\mathrm{n} 45-\mathrm{k} 5$ & 751 & 750.6 & 5.488 & 2562 & 168 & 4 & 751 & 7.335 & 2626 & 182 & 3 & 281 & 8 \\
\hline $\mathrm{B}-\mathrm{n} 41-\mathrm{k} 6$ & 829 & 828.429 & 2.046 & 1246 & 98 & 3 & 829 & 2.257 & 1267 & 101 & 2 & 104 & 7 \\
\hline B-n39-k5 & 549 & 549 & 3.501 & 1860 & 137 & 4 & 549 & 3.463 & 1860 & 137 & 4 & 0 & 0 \\
\hline$B-n 38-k 6$ & 805 & 804.143 & 1.941 & 1383 & 104 & 3 & 805 & 2.54 & 1401 & 111 & 3 & 150 & 10 \\
\hline $\mathrm{B}-\mathrm{n} 35-\mathrm{k} 5$ & 955 & 955 & 1.931 & 1713 & 109 & 2 & 955 & 1.942 & 1713 & 109 & 2 & 0 & 0 \\
\hline B-n34-k5 & 788 & 784.926 & 4.251 & 1897 & 148 & 2 & 788 & 15.622 & 2253 & 183 & 5 & 539 & 41 \\
\hline B-n31-k5 & 672 & 672 & 0.648 & 997 & 59 & 2 & 672 & 0.634 & 997 & 59 & 2 & 0 & 0 \\
\hline $\mathrm{B}-\mathrm{n} 57-\mathrm{k} 7$ & 1153 & 1153 & 4.954 & 2336 & 146 & 3 & 1153 & 5.128 & 2336 & 146 & 3 & 0 & 0 \\
\hline $\mathrm{B}-\mathrm{n} 56-\mathrm{k} 7$ & 707 & 705 & 5.711 & 2473 & 166 & 4 & 705 & 6.689 & 2484 & 169 & 3 & 483 & 3 \\
\hline $\mathrm{B}-\mathrm{n} 52-\mathrm{k} 7$ & 747 & 746.333 & 5.825 & 2380 & 164 & 3 & 747 & 9.066 & 2452 & 175 & 4 & 859 & 11 \\
\hline $\mathrm{B}-\mathrm{n} 51-\mathrm{k} 7$ & 1032 & 1026.83 & 6.218 & 2252 & 158 & 2 & 1032 & 3160.47 & 2880 & 234 & 9 & 2492 & 87 \\
\hline $\mathrm{B}-\mathrm{n} 50-\mathrm{k} 8$ & 1312 & 1303.48 & 3.984 & 1591 & 117 & 2 & 1309.35 & 45.249 & 2186 & 308 & 7 & 3899 & 67 \\
\hline $\mathrm{B}-\mathrm{n} 50-\mathrm{k} 7$ & 741 & 741 & 4.194 & 2319 & 158 & 4 & 741 & 4.806 & 2384 & 167 & 4 & 619 & 3 \\
\hline$B-n 45-k 6$ & 678 & 677.973 & 2.831 & 1515 & 113 & 2 & 678 & 5.035 & 1610 & 129 & 3 & 500 & 24 \\
\hline $\mathrm{B}-\mathrm{n} 44-\mathrm{k} 7$ & 909 & 909 & 1.795 & 1417 & 94 & 2 & 909 & 1.734 & 1417 & 94 & 2 & 0 & 0 \\
\hline$B-n 43-k 6$ & 742 & 736.825 & 2.588 & 1503 & 101 & 1 & 740.09 & 119.843 & 1977 & 226 & 5 & 2311 & 89 \\
\hline $\mathrm{B}-\mathrm{n} 78-\mathrm{k} 10$ & 1221 & 1216.39 & 12.983 & 3345 & 210 & 2 & 1221 & 37.655 & 3761 & 256 & 6 & 2000 & 50 \\
\hline $\mathrm{B}-\mathrm{n} 68-\mathrm{k} 9$ & 1272 & 1263.71 & 11.017 & 2998 & 201 & 2 & - & - & - & - & - & - & - \\
\hline
\end{tabular}


PUC-Rio - Certificação Digital № 1321837/CA

Table V.5: Continued from previous page

\begin{tabular}{|c|c|c|c|c|c|c|c|c|c|c|c|c|c|}
\hline \multirow{2}{*}{ Ins } & \multirow{2}{*}{$\mathrm{OPT}$} & \multicolumn{5}{|c|}{ without $1 \mathrm{~m}-\mathrm{SRC}$} & \multicolumn{7}{|c|}{ with $1 \mathrm{~m}-\mathrm{SRC}$} \\
\hline & & Value & Time & Routes & Heu & Exa & Value & Time & Routes & $\mathrm{Heu}$ & Exa & Sep & Act \\
\hline $\mathrm{B}-\mathrm{n} 67-\mathrm{k} 10$ & 1032 & 1027.59 & 6.717 & 2616 & 171 & 2 & 1030.86 & 655.782 & 3391 & 316 & 6 & 2581 & 120 \\
\hline $\mathrm{B}-\mathrm{n} 66-\mathrm{k} 9$ & 1316 & 1307.84 & 8.963 & 2769 & 184 & 3 & 1315.24 & 3879 & 3791 & 384 & 10 & 3847 & 152 \\
\hline $\mathrm{B}-\mathrm{n} 64-\mathrm{k} 9$ & 861 & 860.438 & 8.215 & 2777 & 176 & 3 & 861 & 9.305 & 2834 & 183 & 2 & 152 & 11 \\
\hline B-n57-k9 & 1598 & 1596 & 6.783 & 2065 & 152 & 4 & 1598 & 23.306 & 2389 & 216 & 4 & 2283 & 66 \\
\hline B-n63-k10 & 1496 & 1487.07 & 5.844 & 2162 & 150 & 3 & 1496 & 62.087 & 3207 & 257 & 5 & 1487 & 86 \\
\hline E-n76-k8 & 735 & 725.19 & 18.542 & 3254 & 227 & 2 & 734.092 & 1160.41 & 5323 & 525 & 9 & 4648 & 191 \\
\hline $\mathrm{E}-\mathrm{n} 76-\mathrm{k} 7$ & 682 & 669.015 & 9.838 & 3317 & 193 & 2 & - & - & - & - & - & - & - \\
\hline E-n76-k14 & 1021 & 1006.94 & 1.559 & 1362 & 79 & 2 & 1014.75 & 10.203 & 1661 & 155 & 3 & 1371 & 106 \\
\hline E-n76-k10 & 830 & 816.627 & 5.075 & 2040 & 130 & 2 & 826.438 & 49.762 & 2844 & 238 & 5 & 2464 & 149 \\
\hline E-n51-k5 & 521 & 518.357 & 4.163 & 1874 & 128 & 3 & 521 & 13.395 & 2188 & 164 & 5 & 500 & 41 \\
\hline $\mathrm{E}-\mathrm{n} 33-\mathrm{k} 4$ & 835 & 835 & 3.672 & 1514 & 99 & 3 & 835 & 3.687 & 1514 & 99 & 3 & 0 & 0 \\
\hline$E-n 30-k 3$ & 534 & 518.1 & 2.769 & 1779 & 138 & 3 & - & - & - & - & - & - & - \\
\hline$E-n 23-k 3$ & 569 & 569 & 7.326 & 1023 & 91 & 3 & 569 & 5.971 & 1023 & 91 & 3 & 0 & 0 \\
\hline $\mathrm{E}-\mathrm{n} 22-\mathrm{k} 4$ & 375 & 375 & 0.098 & 363 & 27 & 1 & 375 & 0.1 & 363 & 27 & 1 & 0 & 0 \\
\hline E-n101-k8 & 815 & 802.626 & 63.515 & 5608 & 366 & 4 & - & - & - & - & - & - & - \\
\hline E-n101-k14 & 1067 & 1053.52 & 8.041 & 3097 & 184 & 2 & 1063.3 & 89.425 & 4106 & 334 & 6 & 2713 & 196 \\
\hline $\mathrm{E}-\mathrm{n} 31-\mathrm{k} 7$ & 379 & 378.333 & 0.522 & 1030 & 62 & 1 & 379 & 0.646 & 1054 & 70 & 1 & 46 & 5 \\
\hline $\mathrm{E}-\mathrm{n} 13-\mathrm{k} 4$ & 247 & 247 & 0.014 & 73 & 10 & 1 & 247 & 0.014 & 73 & 10 & 1 & 0 & 0 \\
\hline $\mathrm{P}-\mathrm{n} 55-\mathrm{k} 10$ & 694 & 681.754 & 0.914 & 1051 & 67 & 1 & 689.203 & 7.707 & 1328 & 146 & 5 & 1013 & 86 \\
\hline $\mathrm{P}-\mathrm{n} 23-\mathrm{k} 8$ & 529 & 529 & 0.022 & 563 & 4 & 1 & 529 & 0.03 & 563 & 4 & 1 & 0 & 0 \\
\hline P-n50-k10 & 696 & 689.362 & 0.589 & 850 & 52 & 1 & 695.019 & 1.817 & 992 & 80 & 2 & 250 & 47 \\
\hline$P-n 45-k 5$ & 510 & 505.944 & 2.585 & 1628 & 110 & 1 & 510 & 15.187 & 2168 & 174 & 3 & 952 & 57 \\
\hline $\mathrm{P}-\mathrm{n} 40-\mathrm{k} 5$ & 458 & 456.875 & 1.631 & 1395 & 87 & 1 & 458 & 4.65 & 1694 & 116 & 3 & 201 & 17 \\
\hline
\end{tabular}


PUC-Rio - Certificação Digital № 1321837/CA

Table V.5: Continued from previous page

\begin{tabular}{|c|c|c|c|c|c|c|c|c|c|c|c|c|c|}
\hline \multirow{2}{*}{ Ins } & \multirow{2}{*}{$\mathrm{OPT}$} & \multicolumn{5}{|c|}{ without $1 \mathrm{~m}-\mathrm{SRC}$} & \multicolumn{7}{|c|}{ with $1 \mathrm{~m}-\mathrm{SRC}$} \\
\hline & & Value & Time & Routes & Heu & Exa & Value & Time & Routes & $\mathrm{Heu}$ & Exa & Sep & Act \\
\hline $\mathrm{P}-\mathrm{n} 22-\mathrm{k} 8$ & 603 & 603 & 0.041 & 147 & 14 & 1 & 603 & 0.087 & 147 & 14 & 1 & 0 & 0 \\
\hline $\mathrm{P}-\mathrm{n} 22-\mathrm{k} 2$ & 216 & 215.5 & 0.646 & 884 & 68 & 2 & 216 & 1.011 & 971 & 80 & 1 & 60 & 3 \\
\hline $\mathrm{P}-\mathrm{n} 21-\mathrm{k} 2$ & 211 & 211 & 0.465 & 672 & 54 & 1 & 211 & 0.461 & 672 & 54 & 1 & 0 & 0 \\
\hline $\mathrm{P}-\mathrm{n} 20-\mathrm{k} 2$ & 216 & 213 & 0.482 & 650 & 60 & 2 & 216 & 1.143 & 719 & 83 & 2 & 198 & 9 \\
\hline $\mathrm{P}-\mathrm{n} 19-\mathrm{k} 2$ & 212 & 212 & 0.297 & 443 & 44 & 2 & 212 & 0.348 & 443 & 44 & 2 & 0 & 0 \\
\hline $\mathrm{P}-\mathrm{n} 16-\mathrm{k} 8$ & 450 & 448 & 0.024 & 64 & 12 & 1 & 450 & 0.018 & 64 & 14 & 1 & 1 & 1 \\
\hline $\mathrm{P}-\mathrm{n} 101-\mathrm{k} 4$ & 681 & 676.428 & 430.519 & 12573 & 867 & 14 & - & - & - & - & - & - & - \\
\hline $\mathrm{P}-\mathrm{n} 76-\mathrm{k} 5$ & 627 & 615.748 & 38.204 & 4697 & 311 & 5 & - & - & - & - & - & - & 一 \\
\hline $\mathrm{P}-\mathrm{n} 76-\mathrm{k} 4$ & 593 & 587.459 & 62.629 & 5560 & 409 & 4 & 593 & 2238.44 & 9002 & 763 & 15 & 3000 & 68 \\
\hline $\mathrm{P}-\mathrm{n} 70-\mathrm{k} 10$ & 827 & 813.335 & 3.429 & 1695 & 103 & 1 & 823.172 & 45.677 & 2324 & 231 & 5 & 2082 & 157 \\
\hline $\mathrm{P}-\mathrm{n} 65-\mathrm{k} 10$ & 792 & 786.858 & 1.886 & 1432 & 90 & 2 & 792 & 6.538 & 1682 & 111 & 3 & 696 & 54 \\
\hline $\mathrm{P}-\mathrm{n} 60-\mathrm{k} 15$ & 968 & 963.469 & 0.578 & 827 & 55 & 1 & 967.717 & 2.004 & 928 & 94 & 2 & 338 & 54 \\
\hline $\mathrm{P}-\mathrm{n} 60-\mathrm{k} 10$ & 744 & 738.864 & 1.033 & 1188 & 68 & 1 & 743.516 & 5.914 & 1512 & 118 & 2 & 975 & 73 \\
\hline $\mathrm{P}-\mathrm{n} 55-\mathrm{k} 7$ & 568 & 558.922 & 1.879 & 1604 & 95 & 1 & 565.667 & 212.994 & 2603 & 218 & 5 & 1833 & 108 \\
\hline $\mathrm{P}-\mathrm{n} 55-\mathrm{k} 15$ & 989 & 972.572 & 24.743 & 162385 & 16 & 1 & 985.347 & 140.187 & 162452 & 58 & 1 & 267 & 55 \\
\hline $\mathrm{P}-\mathrm{n} 51-\mathrm{k} 10$ & 741 & 736.075 & 0.862 & 899 & 63 & 2 & 741 & 2.005 & 1038 & 85 & 2 & 357 & 44 \\
\hline $\mathrm{P}-\mathrm{n} 50-\mathrm{k} 8$ & 631 & 616.66 & 0.666 & 851 & 52 & 1 & 625.773 & 12.586 & 1236 & 143 & 4 & 884 & 107 \\
\hline $\mathrm{P}-\mathrm{n} 50-\mathrm{k} 7$ & 554 & 550.651 & 3.205 & 1430 & 95 & 1 & 554 & 6.153 & 1719 & 121 & 3 & 351 & 33 \\
\hline $\mathrm{M}-\mathrm{n} 151-\mathrm{k} 12$ & 1015 & 998.727 & 83.733 & 7658 & 435 & 3 & - & - & - & - & - & - & 一 \\
\hline $\mathrm{M}-\mathrm{n} 121-\mathrm{k} 7$ & 1034 & 1032.44 & 139.966 & 8777 & 532 & 10 & 1033.6 & 2476.88 & 10665 & 792 & 13 & 6820 & 49 \\
\hline $\mathrm{M}-\mathrm{n} 101-\mathrm{k} 10$ & 820 & 820 & 20.708 & 5330 & 344 & 14 & 820 & 29.576 & 5806 & 383 & 13 & 970 & 4 \\
\hline $\mathrm{M}-\mathrm{n} 200-\mathrm{k} 16$ & 1274 & 1251.35 & 206.593 & 9762 & 530 & 5 & - & - & - & - & - & - & - \\
\hline
\end{tabular}


PUC-Rio - Certificação Digital № 1321837/CA

Table V.5: Continued from previous page

\begin{tabular}{|c|c|c|c|c|c|c|c|c|c|c|c|c|c|}
\hline \multirow{2}{*}{ Ins } & \multirow{2}{*}{$\mathrm{OPT}$} & \multicolumn{5}{|c|}{ without $1 \mathrm{~m}$-SRC } & \multicolumn{7}{|c|}{ with $1 \mathrm{~m}$-SRC } \\
\hline & & Value & Time & Routes & Heu & Exa & Value & Time & Routes & $\mathrm{Heu}$ & Exa & Sep & Act \\
\hline $\mathrm{M}-\mathrm{n} 200-\mathrm{k} 17$ & 1275 & 1254.15 & 191.417 & 9812 & 534 & 3 & - & - & - & - & - & - & - \\
\hline Average & 849.524 & 844.842 & 6.717 & 3759.232 & 121.207 & 2.259 & 848.672 & 214.528 & 4164.488 & 182.854 & 4.293 & 1105.768 & 49.780 \\
\hline
\end{tabular}


Table V.6: Comparison with Pecin et al.

\begin{tabular}{|c|c|c|c|c|}
\hline Ins & $\mathrm{OPT}$ & PPPU & Our results & Difference \\
\hline A-n37-k5 & 669 & 669 & 669 & 0 \\
\hline$A-n 37-k 6$ & 949 & 946.02 & 945.582 & 0.438 \\
\hline$A-n 38-k 5$ & 730 & 730 & 728.8 & 1.2 \\
\hline$A-n 39-k 5$ & 822 & 822 & 822 & 0 \\
\hline$A-n 39-k 6$ & 831 & 831 & 831 & 0 \\
\hline$A-n 44-k 6$ & 937 & 937 & 937 & 0 \\
\hline$A-n 45-k 6$ & 944 & 944 & 944 & 0 \\
\hline$A-n 45-k 7$ & 1146 & 1146 & 1146 & 0 \\
\hline $\mathrm{A}-\mathrm{n} 46-\mathrm{k} 7$ & 914 & 914 & 914 & 0 \\
\hline $\mathrm{A}-\mathrm{n} 48-\mathrm{k} 7$ & 1073 & 1073 & 1073 & 0 \\
\hline$A-n 53-k 7$ & 1010 & 1010 & 1010 & 0 \\
\hline $\mathrm{A}-\mathrm{n} 54-\mathrm{k} 7$ & 1167 & 1167 & 1166.38 & 0.62 \\
\hline$A-n 55-k 9$ & 1073 & 1073 & 1071.8 & 1.2 \\
\hline $\mathrm{A}-\mathrm{n} 60-\mathrm{k} 9$ & 1354 & 1354 & 1352.04 & 1.96 \\
\hline$A-n 61-k 9$ & 1034 & 1034 & 1032 & 2 \\
\hline$A-n 62-k 8$ & 1288 & 1287.15 & 1286.07 & 1.08 \\
\hline$A-n 63-k 9$ & 1616 & 1616 & 1616 & 0 \\
\hline$A-n 63-k 10$ & 1314 & 1310.61 & 1309.67 & 0.94 \\
\hline$A-n 64-k 9$ & 1401 & 1394.55 & 1395.86 & -1.31 \\
\hline$A-n 65-k 9$ & 1174 & 1174 & 1174 & 0 \\
\hline$A-n 69-k 9$ & 1159 & 1159 & 1157.18 & 1.82 \\
\hline$A-n 80-k 10$ & 1763 & 1763 & 1761.58 & 1.42 \\
\hline$B-n 38-k 6$ & 805 & 805 & 805 & 0 \\
\hline B-n39-k5 & 549 & 549 & 549 & 0 \\
\hline $\mathrm{B}-\mathrm{n} 41-\mathrm{k} 6$ & 829 & 829 & 829 & 0 \\
\hline$B-n 43-k 6$ & 742 & 742 & 740.09 & 1.91 \\
\hline $\mathrm{B}-\mathrm{n} 44-\mathrm{k} 7$ & 909 & 909 & 909 & 0 \\
\hline $\mathrm{B}-\mathrm{n} 45-\mathrm{k} 5$ & 751 & 751 & 751 & 0 \\
\hline $\mathrm{B}-\mathrm{n} 45-\mathrm{k} 6$ & 678 & 678 & 678 & 0 \\
\hline $\mathrm{B}-\mathrm{n} 50-\mathrm{k} 7$ & 741 & 741 & 741 & 0 \\
\hline $\mathrm{B}-\mathrm{n} 50-\mathrm{k} 8$ & 1312 & 1309.68 & 1309.35 & 0.33 \\
\hline $\mathrm{B}-\mathrm{n} 51-\mathrm{k} 7$ & 1032 & 1032 & 1032 & 0 \\
\hline $\mathrm{B}-\mathrm{n} 52-\mathrm{k} 7$ & 747 & 747 & 747 & 0 \\
\hline $\mathrm{B}-\mathrm{n} 56-\mathrm{k} 7$ & 707 & 705 & 705 & 0 \\
\hline $\mathrm{B}-\mathrm{n} 57-\mathrm{k} 7$ & 1153 & 1153 & 1153 & 0 \\
\hline $\mathrm{B}-\mathrm{n} 57-\mathrm{k} 9$ & 1598 & 1598 & 1598 & 0 \\
\hline B-n63-k10 & 1496 & 1496 & 1496 & 0 \\
\hline B-n64-k9 & 861 & 861 & 861 & 0 \\
\hline
\end{tabular}

Continued on next page 
Table V.6: Continued from previous page

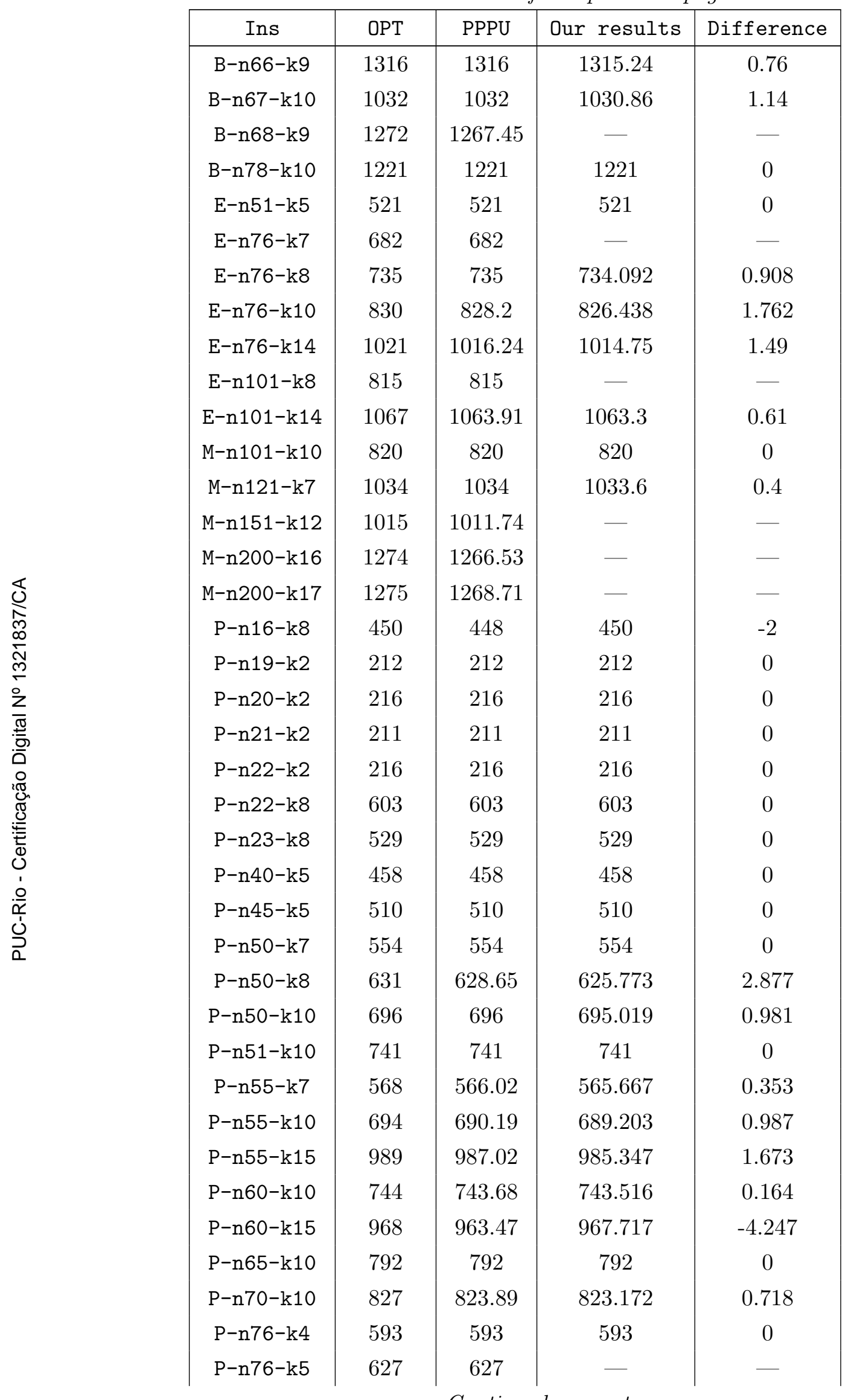

Continued on next page 
Table V.6: Continued from previous page

\begin{tabular}{|c|c|c|c|c|}
\hline Ins & OPT & PPPU & Our results & Difference \\
\hline P-n101-k4 & 681 & 681 & - & - \\
\hline Average & 885.174 & 884.482 & 884.161 & 0.322 \\
\hline
\end{tabular}




\section{VI \\ Conclusion}

This master thesis proposed to assess the leverage achieved with the combination of the lm-SRC with other techniques, like Decremental Space State Relaxation (DSSR), Completion Bounds, $n g$-routes and capacity cuts over a Set Partitioning Formulation for the problem.

Observing the results presented in Chapter $\mathrm{V}$ we can highlight some points:

- The addition of lm-SRC was responsible to improve the bounds for almost all instances with running time smaller than two hours however when combining them with capacity cuts, the bounds have a great improvement. The average difference between the optimum value and the bound found decreased from 5.0 to 0.9 in the last two configurations.

- The column generation lower bounds found were on majority equal to the ones found by Pecin et al. [19]. When they were better, the difference was quite small and for 3 instances our lower bounds were better. However, 9 instances found in their work did not finished within the time limit.

- The time required by the $\mathrm{lm}$-SRC did not improved with the consideration of DSSR and Completion Bounds when using these techniques with respect to the $n g$-routes. These techniques can be adapted to the lm-SRC, but it was not implemented in this work.

As future works and extensions we suggest: $(i)$ a route enumeration to verify which instances can be solved; and (ii) the improvement of the approach started in this work. Techniques that speed up the pricing as reduced cost variable fixing, ways to strengthen the completion bounds should be tested, as well as other strong cuts which can be separated in the SP formulation (other lm-SRCs and Strong Degree cuts, for example). 


\section{Bibliography}

[1] DANTZIG, G. B.; RAMSER, J. H.. The truck dispatching problem. Management science, 1959. I

[2] TOTH, P.; VIGO, D.. The Vehicle Routing Problem. Monographs on Discrete Mathematics and Applications. SIAM, Philadelphia, 2002. I

[3] FORD JR, L. R.; FULKERSON, D. R.. A suggested computation for maximal multi-commodity network flows. Management Science, 5(1):97101, 1958. I

[4] LAPORTE, G.; NOBERT, Y.. A branch and bound algorithm for the capacitated vehicle routing problem. OR Spectrum, 1983. I, II

[5] BALINSKI, M. L.; QUANDT, R. E.. On an integer program for a delivery problem. Operations Research, 1964. I, II

[6] DROR, M.. Note on the complexity of the shortest path models for column generation in vrptw. Operations Research, 42(5):977-978, 1994. I

[7] CHRISTOFIDES, N.; MINGOZZI, A.; TOTH, P.. Exact algorithms for the vehicle routing problem, based on spanning tree and shortest path relaxations. Mathematical programming, 1981. I, III.1

[8] IRNICH, S.; VILLENEUVE, D.. The Shortest-Path Problem with Resource Constraints and $\mathrm{k}$-Cycle Elimination for $\mathrm{k} \geq 3$. INFORMS Journal on Computing, 18(3):391-406, 2006. I, I.1

[9] BALDACCI, R.; MINGOZZI, A.; ROBERTI, R.. New route relaxation and pricing strategies for the vehicle routing problem. Operations Research, 59(5):1269-1283, 2011. I, I.1, III.2, IV.2

[10] FUKASAWA, R.; LONGO, H.; LYSGAARD, J.; POGGI DE ARAGÃO, M.; REIS, M.; UCHOA, E.; WERNECK, R. F.. Robust Branch-and-Cut-and-Price for the Capacitated Vehicle Routing Problem. Mathematical Programming, 106(3):491-511, 2006. I.1, III.1

[11] BALDACCI, R.; CHRISTOFIDES, N.; MINGOZZI, A.. An Exact Algorithm for the Vehicle Routing Problem Based on the Set Partitioning 
Formulation with Additional Cuts. Math. Program., 115(2):351-385, 2008. I.1

[12] PESSOA, A.; DE ARAGÃO, M. P.; UCHOA, E.. Robust branch-cut-andprice algorithms for vehicle routing problems. In: THE VEHICLE ROUTING PROBLEM: LATEST ADVANCES AND NEW CHALLENGES, $p$. 297-325. Springer, 2008. I.1

[13] MARTINELli, R.; PECIN, D.; POGGI, M.; LONGO, H.. A branch-cutand-price algorithm for the capacitated arc routing problem. In: Pardalos, P.; Rebennack, S., editors, EXPERIMENTAL ALGORITHMS, v. 6630 of Lecture Notes in Computer Science, p. 315-326. Springer Berlin / Heidelberg, 2011. I.1

[14] RIGHINI, G.; SALANI, M.. Symmetry helps: Bounded bi-directional dynamic programming for the elementary shortest path problem with resource constraints. Discrete Optimization, 3(3):255-273, Sept. 2006. I.1

[15] MARTINELLI, R.; PECIN, D.; POGGI, M.. Efficient elementary and restricted non-elementary route pricing. European Journal of Operational Research, 2014. I.1, III.2

[16] CONTARDO, C.. A new exact algorithm for the multi-depot vehicle routing problem under capacity and route length constraints. Technical report, Archipel-UQAM 5078, Université du Québec à Montréal, Canada, 2012. I.1

[17] RØPKE, S.. Branching decisions in branch-and-cut-and-price algorithms for vehicle routing problems. Presentation in Column Generation, 2012. I.1

[18] CONTARDO, C.; MARTINELLI, R.. A new exact algorithm for the multi-depot vehicle routing problem under capacity and route length constraints. Discrete Optimization, 12:129-146, 2014. I.1, IV.2

[19] PECIN, D.; PESSOA, A.; POGGI, M.; UCHOA, E.. Improved branch-cutand-price for capacitated vehicle routing. In: INTEGER PROGRAMMING AND COMBINATORIAL OPTIMIZATION, p. 393-403. Springer, 2014. I.1, IV.3, $\mathrm{V}, \mathrm{VI}$

[20] JEPSEN, M.; PETERSEN, B.; SPOORENDONK, S.; PISINGER, D.. Subsetrow inequalities applied to the vehicle-routing problem with time windows. Operations Research, 2008. I.1, IV, IV.2

[21] PECIN, D.; PESSOA, A.; POGGI, M.; UCHOA, E.. Improved branch-cutand-price for capacitated vehicle routing. In: INTEGER PROGRAMMING AND COMBINATORIAL OPTIMIZATION. Springer, 2014. I.2 
[22] GAREY, M. R.; JOHNSON, D. S.. Computers and Intractability; A Guide to the Theory of NP-Completeness. W. H. Freeman \& Co., New York, NY, USA, 1979. II.1, IV.1

[23] RIGHINI, G.; SALANI, M.. New Dynamic Programming Algorithms for the Resource Constrained Elementary Shortest Path Problem. Networks, 51(3):155-170, 2008. III.2

[24] LYSGAARD, J.; LETCHFORD, A. N.; EGLESE, R. W.. A new branch-andcut algorithm for the capacitated vehicle routing problem. Mathematical Programming, 100(2):423-445, June 2004. IV

[25] LYSGAARD, J.. CVRPSEP: A package of separation routines for the capacitated vehicle routing problem. Institut for Driftøkonomi og Logistik, Handelshøjskolen i Århus, 2003. IV.1

[26] GUROBI OPTIMIZATION, I.. Gurobi optimizer reference manual, 2015. $\mathrm{V}$ 